ESTUDIO DE LA ONTOGENIA DE LA CONDUCTA DEL LOBO

MEXICANO (Canis lupus

baileyi) EN CAUTIVERIO
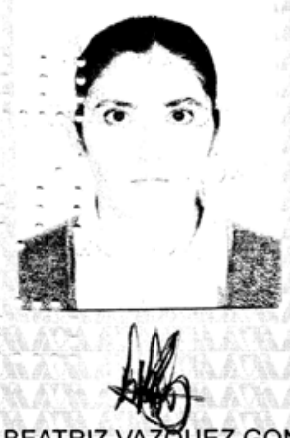

CA.RMEN BEATRIZ VAZQUEZ GONZALEZ ALUMNA

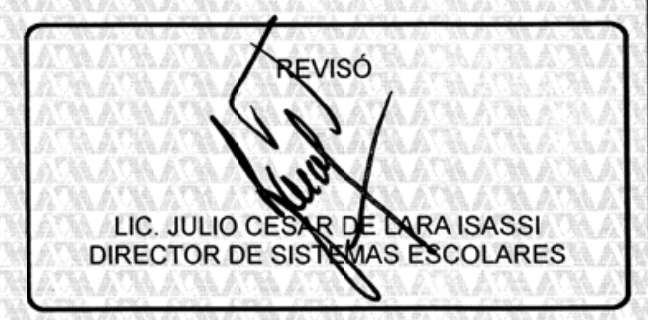

DIRECTORA DE LA DIVISIÓN DE CBS

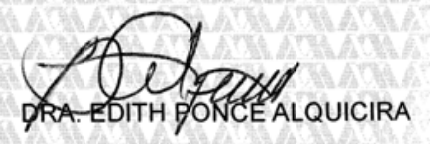

Acto continuo, el presidente del jurado comunicó a la interesada el resultado de la evaluación $y$, en caso aprobatorio, le fue tomada la protesta. Autónoma Metropolitana, los miembros del jurado
En la Ciudad de México, se presentaron a las 12:00 horas del día 14 del mes de diciembre del año 2016 en la Unidad Iztapalapa de la Universidad Autónoma Metropolitana, los suscritos miembros del jurado:

DR. ALBERTO CASTILLO MORALES

DR. JUAN CARLOS LOPEZ VIDAL

DRA. CYNTHIA ELIZALDE ARELLANO

M. EN C. MARIA DE LA ASUNCION SOTO ALVAREZ

Bajo la presidencia del primero y con carácter de Secretario el último, se reunieron para proceder al Examen de Grado cuya denominación aparece al margen, para la obtención del grado de:

MAESTRA EN BIOLOGIA

DE: CARMEN BEATRIZ VAZQUEZ GONZALEZ

$y$ de acuerdo con el artículo 78 fracción III del Reglamento de Estudios Superiores de la Universidad resolvieron:

$$
\text { Dprobar }
$$




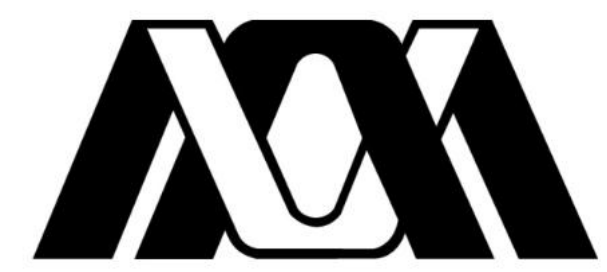

Casa abierta al tiempo

UNIVERSIDAD AUTONOMA METROPOLITANA

UNIDAD IZTAPALAPA

\title{
Estudio de la Ontogenia de la conducta del Lobo Mexicano (Canis lupus baileyi) en cautiverio
}

TES IS

Que para obtener el grado de Maestra en Biología

\author{
PRESENTA
}

Carmen Beatriz Vázquez González 
La Maestría en Biología de la Universidad Autónoma Metropolitana pertenece al Padrón de Postgrados de Excelencia del CONACyT 
El jurado designado por la División de Ciencias Biológicas y de la Salud de la Unidad Iztapalapa aprobó la tesis que presentó

\section{CARMEN BEATRIZ VÁZQUEZ GONZÁLEZ}

El día 14 de diciembre de 2016

Comité Tutoral y Jurado

Director: Dr. Miguel Ángel Armella Villalpando

Asesor: Dr. Jorge Ignacio Servín Martínez

Asesor: M. en C. María de la Asunción Soto Álvarez

Presidente: Dr. Alberto Castillo Morales

Secretaria: M. en C. María de la Asunción Soto Álvarez

Sinodal: Dr. Juan Carlos López Vidal

Sinodal: Dra. Cynthia Elizalde Arellano 


\section{RESUMEN}

La ontogenia de la conducta es el proceso por el cual aparecen los cambios progresivos en el comportamiento del individuo durante su desarrollo. A pesar de que el lobo gris ha sido ampliamente estudiado existe muy poca información al respecto, y menos aún del lobo mexicano, que es una subespecie en peligro de extinción. El objetivo de este estudio fue analizar el desarrollo del comportamiento del lobo mexicano desde su nacimiento hasta los 2 años de edad, basándose en las etapas propuestas por Mech (1970), que no habían sido previamente estudiadas a profundidad. Para ello, se consideraron las observaciones conductuales de 44 individuos pertenecientes a 11 camadas diferentes, nacidos en el Zoológico San Juan de Aragón, en la Ciudad de México entre 1989 y 1997, así como las observaciones de las interacciones entre éstos y los otros miembros de sus respectivas manadas. Se construyó una base de datos con 28050 registros para los cachorros y juveniles, y una de 8290 para los adultos, a partir de las cuales se hizo un análisis cualitativo de los cambios conductuales y uno cuantitativo de los cambios en las frecuencias de exhibición de los comportamientos durante el periodo de estudio. Los resultados soportan la validez de las etapas de desarrollo. La etapa neonatal se caracteriza por la presencia de muy pocas conductas debido al limitado desarrollo físico, especialmente del sistema nervioso. En la etapa de transición comienzan a aparecer los patrones típicos de la especie. Durante la etapa de socialización es cuando se presentan por primera vez la mayor parte de los comportamientos y el sistema nervioso alcanza un nivel de desarrollo muy similar al del adulto. La etapa juvenil se caracteriza por la aparición de pocas conductas nuevas, pero los cambios más notables son con respecto a la frecuencia relativa de las mismas, de tal manera que se han podido identificar 4 sub etapas: en la primera se aprecia el carácter infantil de los individuos, en la segunda se lleva a cabo la independencia alimenticia y el inicio de la integración a la estructura jerárquica de la manada, la tercera se relaciona principalmente con el cuidado parental que brindan a los cachorros de la siguiente camada y en la cuarta es cuando se presentan las conductas sexuales y la completa integración al orden social del grupo. Los comportamientos de juego y alimentación tienen una mayor importancia en las primeras etapas, mientras que los agonistas y sumisos en las últimas. Las conductas parentales y tolerancia hacia las crías son mayores al inicio del desarrollo y van disminuyendo gradualmente, también se encontró que pueden asociarse directamente a algunas conductas de los cachorros. En este estudio se ha demostrado que el comportamiento del lobo mexicano sufre cambios cualitativos y cuantitativos durante su desarrollo. 


\begin{abstract}
The ontogeny of behavior is the process by which progressive changes appear in the behavior of the individual during its development. Although the gray wolf has been extensively studied there is very little information about it, even less the Mexican wolf, which is an endangered subspecies. The objective of this study was to analyze the development of Mexican wolf behavior from birth to 2 years old, based on the periods proposed by Mech (1970), which had not previously been studied in depth. For this, the behavioral observations of 44 individuals belonging to 11 different litters, born at San Juan de Aragón Zoo, in Mexico City between 1989 and 1997, as well as the observations of the interactions between these and the other members of their respective packs. A database was constructed with 28050 records for puppies and juveniles, and one for 8290 for adults, from which a qualitative analysis of the behavioral changes and a quantitative analysis of the changes in the display frequencies of the behaviors were done during the study period. The results support the validity of the periods of development. The neonatal period is characterized by the presence of very few behaviors due to limited physical development, especially of the nervous system. In the transition period the typical patterns of the species begin to appear. During the period of socialization most of the behaviors appear for the first time and the nervous system reaches a level of development very similar to that of the adult. The juvenile stage is characterized by the appearance of few new behaviors, but the most notable changes are with respect to the relative frequency of the same ones, in such a way that it has been possible to identify 4 sub periods: in the first one it the infantile character is appreciated. In the second, the food independence and the beginning of the integration to the hierarchical structure of the pack are carried out. The third one is related mainly to the parental care provided to the puppies of the next year and in the fourth it is when the sexual behaviors are presented and the complete integration to the social order of the group. Behaviors of play and feeding are of greater importance in the early periods, while agonists and submissive in the latter. Parental behaviors and tolerance towards offspring are higher at the onset of development and are gradually declining, they were also found to be directly associated with some puppy behaviors. In this study it has been demonstrated that the behavior of the Mexican wolf undergoes qualitative and quantitative changes during its development.
\end{abstract}




\section{INDICE}

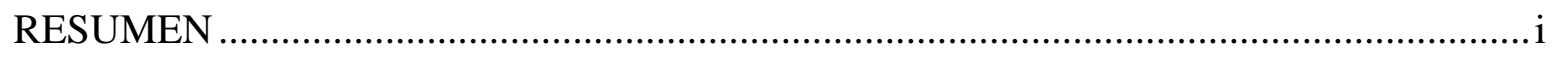

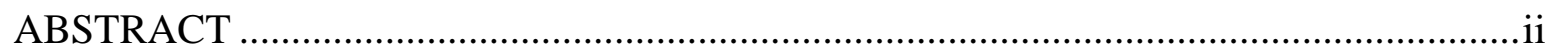

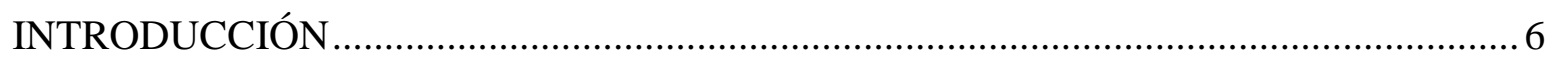

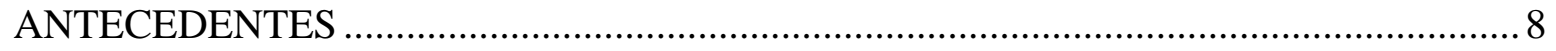

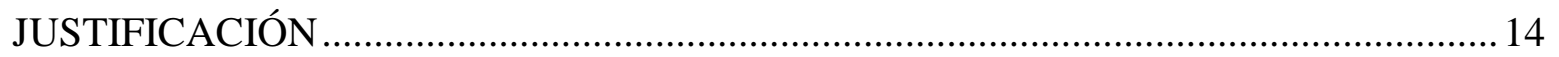

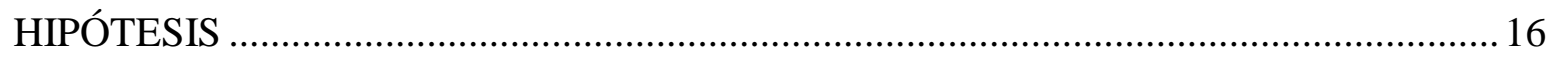

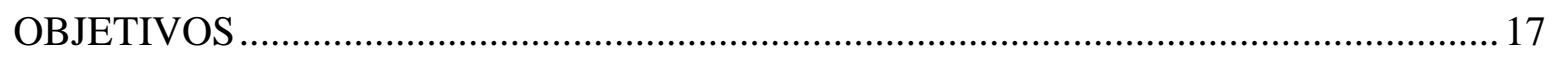

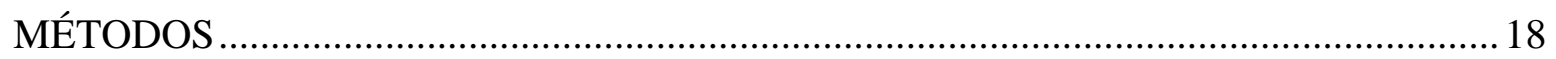

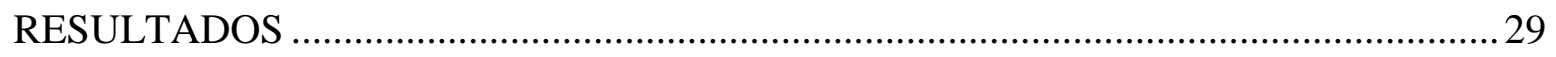

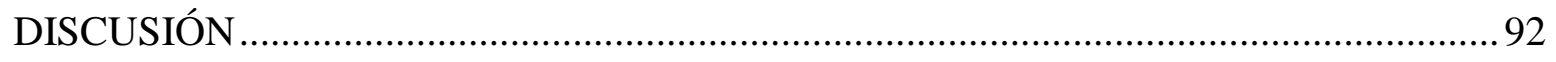

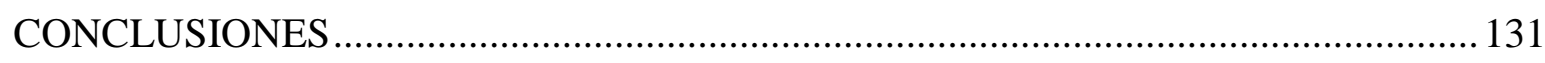

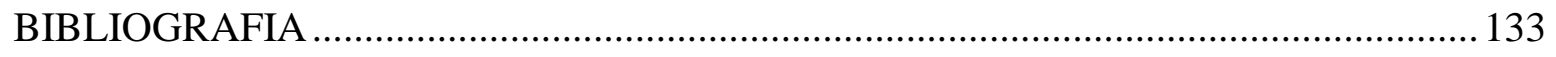

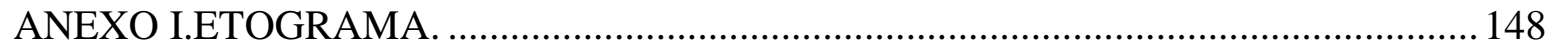

ANEXO II ANTECEDENTES ETAPAS DE DESARROLLO Y SISTEMA NERVIOSO 166

ANEXO III.ANTECEDENTES HUDDLING. ..................................................... 176

ANEXO IVANTECEDENTES CONDUCTAS DE JUEGO. .................................. 178

ANEXO V.ANTECEDENTES CONDUCTAS AGONISTAS ................................... 182 
Lista de Cuadros

Cuadro No. 1. Relación de individuos estudiados........................................... 23

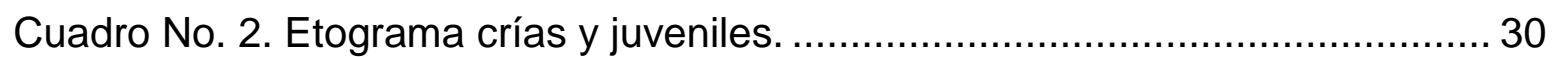

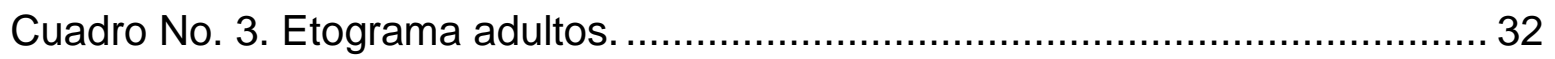

Cuadro No. 4. Edad de aparición de conductas ................................................ 35

Cuadro No. 5. Edades propuestas para las etapas de desarrollo. ........................ 62

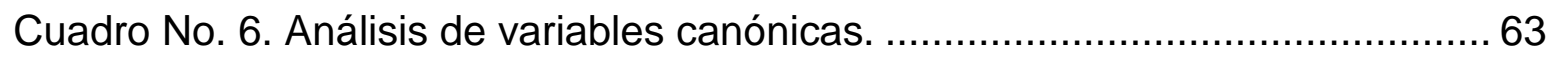

Cuadro No. 7. Coeficientes estandarizados de las variables canónicas. .............. 63

Cuadro No. 8. Análisis discriminante. Etapas neonatal a socialización.................. 65

Cuadro No. 9. Análisis de variables canónicas. Etapa juvenil............................... 66

Cuadro No. 10. Coeficientes estandarizados de las variables canónicas. Etapa

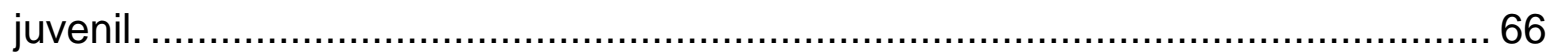

Cuadro No. 11. Análisis discriminante. Etapa juvenil. ....................................... 68 
Figura No. 1.Cronograma de aparición de conductas de alimentación, tempranas,

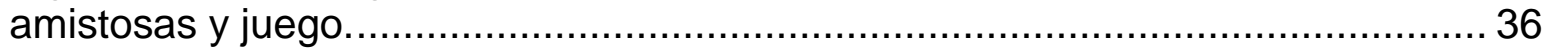
Figura No. 2. Cronograma de aparición de conductas de agresión, defensa y sumisión.

Figura No. 3. Cronograma de aparición de conductas sexuales, pseudosexuales y

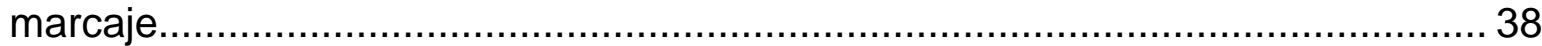

Figura No. 4. Frecuencias totales por mes............................................... 40

Figura No. 5. Frecuencias relativas de las conductas. Etapa neonatal. ................ 41

Figura No. 6. Frecuencia relativa de las conductas. Etapa de transición. ............. 42

Figura No. 7. Frecuencia relativa de las conductas. Etapa de socialización. ........ 44

Figura No. 8. Frecuencia relativa de las conductas. Etapa juvenil. ...................... 46

Figura No. 9. Frecuencia relativa de las conductas. Mes 1 a 4 . ......................... 48

Figura No. 10. Frecuencia relativa de las conductas. Mes 5 a $8 \ldots \ldots \ldots \ldots \ldots \ldots \ldots \ldots \ldots . .50$

Figura No. 11. Frecuencia relativa de las conductas. Mes 9 a $15 \ldots \ldots \ldots \ldots \ldots \ldots \ldots . . .55$

Figura No. 12. Frecuencia relativa de las conductas. Mes 16 a 20. ...................58

Figura No. 13. Frecuencia relativa de las conductas. Mes 21 a 24. ....................61 61

Figura No. 14. Análisis discriminante canónico. Etapas neonatal a socialización. 64

Figura No. 15. Análisis discriminante canónico. Etapa juvenil.............................67

Figura No. 16. Frecuencias totales mensuales de las conductas por categorías.. 70

Figura No. 17. Frecuencias mensuales totales. Conductas tempranas ............... 73

Figura No. 18.Frecuencias totales mensuales. Conductas de alimentación. ........ 75

Figura No. 19. Frecuencias mensuales promedio por camada y error estandar.

Solicitud de alimentación general ........................................................... 75

Figura No. 20. Frecuencias totales mensuales. Conductas amistosas. ……........ 77

Figura No. 21. Frecuencias totales mensuales. Conductas de juego................... 78

Figura No. 22. Frecuencias mensuales promedio por camada y error estandar.

Juego con contacto corporal. ..................................................................... 79

Figura No. 23. Frecuencias totales mensuales. Conductas de sumisión .............. 81

Figura No. 24. Frecuencias mensuales promedio por camada y error estandar.

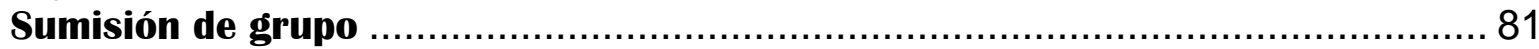

Figura No. 25. Frecuencias totales mensuales. Conductas de agresión................ 84

Figura No. 26. Frecuencias totales mensuales. Conductas de agresión por

intensidad.....

Figura No. 27. Frecuencias promedio mensuales por camada. Amenaza ofensiva85

Figura No. 28. Frecuencias totales mensuales. Conductas defensivas ............... 86

Figura No. 29. Frecuencias totales mensuales. Conductas sexuales y

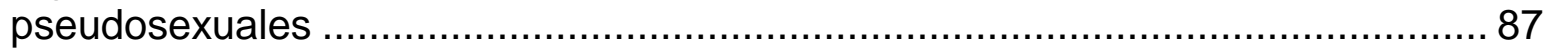

Figura No. 30. Frecuencias totales mensuales. Conductas de marcaje............... 88

Figura No. 31. Frecuencias totales mensuales. Conductas parentales por

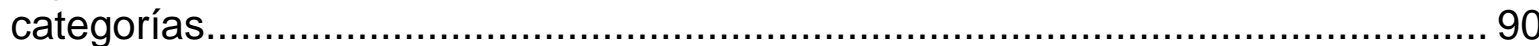

Figura No. 32. Frecuencias mensuales promedio por camada y error estandar. Dar

carne

Figura No. 33. Frecuencias mensuales promedio por camada y error estandar. 


\section{Estudio de la Ontogenia de la conducta del Lobo Mexicano \\ (Canis lupus baileyi) en cautiverio}

\section{INTRODUCCIÓN}

Lobo Mexicano

El lobo mexicano (Canis lupus baileyi Nelson y Goldman, 1929) es la subespecie más pequeña de lobo gris en Norteamérica (Bogan y Melhop, 1983; Hall y Kelson, 1959; Nowak 1995; Young y Goldman, 1944), y genéticamente la más distinta de los lobos de Norteamérica (Chambers et al., 2012, Wayne y Vilá, 2003).

El lobo es una especie social que vive en grupos familiares muy bien estructurados; (López, 1978, Mech, 1999), con un complejo repertorio conductual. Sus crías, nacen en una condición de desarrollo muy incipiente, lo que los hace altamente dependientes de la madre (altriciales). Durante su crecimiento pasan por varios períodos de desarrollo bien definidos: neonatal, de transición, socialización, juvenil y adulto, aunque algunos consideran también el período senil (Mech, 1970).

Originalmente, se le encontraba en las zonas boscosas del suroeste de los Estados Unidos, norte y centro de México (Baker y Villa, 1959, Brown, 1983; Goodwin, 1969, Leopold, 1959, Nelson y Goldman, 1929, Young y Goldman 
1944). Desafortunadamente, actualmente se encuentra en grave peligro de extinción (Parsons, 1996, SEMARNAT, 2009, Villa, 1960).

En 1982 se concretó, entre México y Estados Unidos, el Plan de Recuperación del Lobo Mexicano, el cual contempla la implementación de un programa de cría en cautiverio para posteriormente poder reintroducir lobos en zonas de distribución original y lograr finalmente una población genéticamente sana y autosustentable (USFWS, 1982). Dicho programa inició con la captura de los últimos ejemplares silvestres hallados en México, posteriormente se incorporaron algunos ejemplares que se encontraban cautivos pero su identidad como lobo mexicano no había podido ser establecida sino hasta 1995 (Ames, 1980; García-Moreno et al., 1996; Hedrick et al., 1997; López Islas y Vázquez González, 1993; McBride, 1980, USFWS, 1982).

En 1998 se inicia la reintroducción de los ejemplares en los Estados Unidos (Boitani, 2003; Holaday 2003, Parsons, 1998), que continúa hasta el día de hoy (Siminski, 2016a, USFWS, 2015).

Posteriormente, México ha seguido este mismo proceso, estableciendo el marco legal correspondiente, haciendo prospecciones para determinar las áreas potenciales de liberación, y finalmente en 2011 ha iniciado la reintroducción de ejemplares en áreas de distribución original (Carreón, 2014, Lara et al., 2015, Martínez, 2007; Martínez-Meyer et al., 2006; SEMARNAP, 1997, 2000; SEMARNAT, 2009, Servín et al., 2003, Zamora, 2011). 


\section{ANTECEDENTES}

La ontogenia es el desarrollo de un organismo, desde el huevo fertilizado hasta el adulto maduro, aunque algunos consideran que continúa hasta la senectud y muerte (Immelmann y Beer, 1989). La ontogenia del comportamiento, comprende el desarrollo y maduración de las conductas a lo largo del desarrollo postembrionario y juvenil (Heymer, 1982).

La ontogenia de la conducta o desarrollo del comportamiento es el proceso por el cual se desarrollan los cambios progresivos en la conducta durante la maduración del individuo (Martin y Bateson, 1991). Es indispensable su estudio para poder llegar a comprender cualquier comportamiento (Tinbergen, 1963).

Durante algún tiempo prevaleció una controversia en el campo de la conducta animal, acerca de cuáles eran los factores que moldeaban y determinaban un comportamiento durante el desarrollo. Algunos investigadores pensaban que la conducta era controlada por factores genéticas, mientras que otros afirmaban que era resultado del aprendizaje acontecido durante el desarrollo así como de las influencias del medio ambiente. Sin embargo, actualmente la mayoría acepta el concepto de epigénesis, que es el proceso integrado del desarrollo conductual que involucra la interacción del genoma con el medio ambiente (Drickamer y Vessey, 1992; Logan y Johnston, 2007; Snowdown et al., 1996). 
El primer paso en este tipo de estudios, y en general, para cualquier estudio de comportamiento es la construcción del etograma (Bekoff, 1989), Quera-Jordana (1997) señala que para poder estudiar la conducta es preciso dividirla en unidades de conducta, que son aquellos elementos del comportamiento observado que para el investigador son los más pequeños posibles de acuerdo con los objetivos de la investigación.

La manera en que éstas sean definidas afectará las explicaciones sobre cómo se desarrolla el comportamiento (Fentress, 1983). Bekoff (1972) menciona que para un estudio que implique interacciones sociales, se deberán utilizar patrones motores discretos, relativamente simples, observables y medibles.

De acuerdo con Huntingford (1984), una vez que se han identificado unidades reconocibles de conducta en el repertorio de un animal, la siguiente fase en la descripción de la ontogenia del comportamiento involucra determinar los tiempos en los cuales aparecen, y en algunos otros, desaparecen. Sin embargo, esto no es suficiente para tener una descripción completa, ya que es posible que una conducta cambie durante el periodo en el que se presenta, tanto en forma, función, facilidad de evocación y frecuencia, además de que algunos otros pueden combinarse o separarse.

Por su estado de desarrollo físico y conductual al nacimiento (o eclosión en el caso de ovíparos) los animales en general se dividen en dos grupos: Algunos son altriciales al nacimiento o eclosión, ésto es que están muy poco desarrollados, 
son indefensos, no pueden valerse por sí mismos y requieren mayor cuidado y atención antes de dejar el sitio de nacimiento o eclosión, tales como un nido o madriguera. Otras especies pueden ser precociales, es decir, que pueden moverse, alimentarse y tener al menos una capacidad limitada de tratar con los desafíos de sobrevivir por sí mismos, cabe señalar que estos términos sólo definen los extremos de un continuo (Grier, 1984).

De acuerdo con McFarland (1987) el cuidado parental incluye todas las actividades de los animales que están dirigidas hacia el mantenimiento y sustento de su propia progenie o la de parientes cercanos, mientras que Clutton-Brock (1991) lo define como cualquier conducta parental que incremente el fitness (o adecuación darwiniana), de la descendencia de los padres. Considera que en un sentido amplio comprende la preparación de nidos y territorios, la producción de huevos de mayor tamaño con grandes cantidades de reservas, la producción, cuidado de huevos y crías, el aprovisionamiento de las crías antes y después de la eclosión o nacimiento, así como el apoyo después de la independencia alimenticia.

La dimensión y procedencia del tipo de cuidado que reciben las crías dependen del grado de parentesco entre éstas y el individuo que proporciona los cuidados, así como de la relación entre el costo que representa para éste último y el beneficio que reciben las crías (Baker, et. al., 1996), dado que el dar cuidados es costoso, debe haber un beneficio, que finalmente es la preservación del genotipo y el aumento de su frecuencia relativa. Sin embargo, no parece haber una mejor 
opción en cuanto al patrón de cuidado parental utilizada, sino que son diferentes estrategias que han sido adoptadas en diferentes situaciones por especies diferentes (Klopfer, 1981).

A muchos animales se les proporciona alimento después de la eclosión o parto, y esto puede ocurrir de cuatro maneras (Clutton-Brock, 1991):

- Con la dieta del adulto

- Con una dieta especializada que cubra los requerimientos de las crías

- Con alimento previamente preparado o parcialmente digerido

- Con productos especializados o secreciones, como la leche materna.

Los patrones generales de cuidado parental pueden ser:

- Cuidado materno, es aquel exhibido por las madres hacia sus crías, el cual se presume las ayuda a su supervivencia, crecimiento y desarrollo, tanto física como conductualmente (McFarland, 1987).

- Cuidado paterno, se refiere a los cuidados dados por los padres a sus crías (Barrows, 2000).

- Cuidado biparental, se refiere a cuando ambos padres participan de los cuidados a sus crías (Bolhuis y Giraldeau, 2005, Krebs y Davis, 1997). 
- Cuidado aloparental, es cuando un individuo que no es ninguno de los padres asiste a éstos en el cuidado de las crías, puede ser mostrado por las hembras (cuidado alomaterno) y/o los machos (cuidado alopaterno) (Barrows, 2000).

- Adopción es cualquier situación en la cual un individuo proporciona cuidados a una cría que no le pertenece, y actúa como padre/madre sustituto de tiempo completo, incluye el hacerse cargo de crías por parientes cercanos con mayor frecuencia que con relación distante o no relacionados (Immelmann y Beer, 1989).

El desarrollo de la conducta es un continuo, sin embargo para su estudio, se tiende a dividirla en estados discretos, (Dewsbury, 1978), que en ocasiones pueden coincidir con estados definidos del desarrollo físico.

En el caso de los lobos, se han reconocido diferentes etapas de desarrollo, tomadas del estudio de Scott y Fuller (1965) llevado a cabo con perros, dada la similitud observada en el patrón de desarrollo físico y conductual entre ambas subespecies, particularmente durante las primeras semanas de vida; las diferencias en el comportamiento entre perros y lobos son notables a partir del periodo de socialización, por lo que esta propuesta ha sido ampliamente aceptada para los estudios con cachorros de lobos (Bekoff, 1974a, Fox, 1969, FeddersenPetersen, 1991, Kreeger, 2003, Markwell y Thorne, 1987, Mech, 1970, Packard, 2003, Sott, 1967, Seal et al., 1979, Zimen, 1987): 
* La etapa neonatal corresponde a las primeras dos o tres semanas después de su nacimiento, los cachorros son ciegos y sordos, su capacidad de movimiento es muy limitada y son incapaces de regular su temperatura.

* A continuación, sigue la etapa de transición, que se caracteriza por la apertura de los ojos, percepción auditiva, así como el inicio de su locomoción cuadrúpeda, ésta dura aproximadamente una semana.

* La etapa de socialización se identifica por su salida de la madriguera y el inicio de la interacción social con todos los miembros de la manada, entre los comportamientos que exhiben se encuentran los filiativos, de juego y sumisos, permanece hasta la semana doce.

* Posteriormente entran en la etapa juvenil, en donde inician sus actividades de cacería, afianzando su orden social dentro de la estructura jerárquica de la manada, esta etapa dura hasta alrededor de los dos años de edad, que es cuando los lobos llegan a la etapa adulta, en la cual adquieren su madurez reproductiva (Kreeger, 2003; Seal et al., 1979).

Los lobos grises viven en manadas, con una estructura social definida, que se ocupan del cuidado de sus crías, entre otras cosas, se reproducen a finales del invierno, y en la primavera nacen los lobeznos - que son altriciales -, dentro de madrigueras construidas por los padres (Long, 1996; López, 1978; Mech, 1970; Packard, 2003; Zimen, 1981). Al principio, se alimentan de la leche materna, sin 
embargo, más adelante, al ser destetados, reciben alimento semidigerido proveniente de todos los miembros de la manada (Fentress y Ryon, 1982).

La información que se tiene sobre la conducta de los cachorros es escasa, particularmente aquélla sobre el comportamiento durante su desarrollo. Por tanto, es importante obtener un mayor conocimiento, sobre la ontogenia de su conducta.

En el presente trabajo se aborda el estudio del comportamiento de los lobos mexicanos en cautiverio, desde su nacimiento hasta alcanzar la edad adulta, con el fin de poder hacer una aportación al entendimiento y recuperación de la subespecie.

\section{JUSTIFICACIÓN}

El conocimiento de las diferentes etapas y procesos por los que atraviesan los lobos durante su desarrollo y en general durante toda su vida es muy importante para la implementación de programas de conservación y recuperación. Sin embargo, a pesar de que hace ya más de diez años que, acorde al Plan de recuperación de la subespecie, se ha iniciado ya la etapa de reintroducción de lobos mexicanos al medio silvestre, la mayoría de los estudios realizados recientemente continúan siendo con ejemplares cautivos, principalmente adultos, 
ya que la mayor parte de la población se encuentra aún en cautiverio (Siminski, 2016b).

Para este trabajo se tomó como caso de estudio la ontogenia del comportamiento al lobo mexicano, esta subespecie es un buen modelo para este tipo de estudios debido a que generalmente tienen varias crías por parto, su tamaño es apreciable a simple vista, su crecimiento es relativamente rápido; y existe, además, información comparable en otras subespecies de lobo gris

A pesar de que la Biología del lobo en general (Carbyn et al., 1995, Mech y Boitani, 2003, Musiani et al., 2010) y del lobo mexicano en particular (Bernal y Packard, 1997, Servín, 1984, 1991, Soto et al., 2004, Vázquez González, 2008) ha sido ampliamente estudiada, actualmente no es posible encontrar en la literatura un trabajo que examine el desarrollo completo del proceso ontogenético de la conducta de los lobos. El único trabajo que puede considerarse que cubre este aspecto es el publicado por Zimen $(1981,1982)$ que describe el desarrollo de los animales con un enfoque social (Lobos Alfa, Beta, Subordinados, juveniles y cachorros). Este autor enfoca su estudio en entender la conformación de la estructura jerárquica de la manada y no en el desarrollo conductual individual.

De otra forma la información se encuentra muy fragmentada y solamente como parte de estudios generales del comportamiento o bien de una fracción del mismo, como la agresión y el juego (Feddersen-Petersen, 1991), la alimentación ( Mech y Packard, 1999, Packard et al., 1992, o bien está limitada en tiempo o al 
comportamiento general de la manada (Fentress, y Ryon, 1982, Fox, 1969, 1970a, 1972a, McLeod, 1996). Fentress (1967) describe el desarrollo de un solo cachorro de lobo criado por humanos hasta la edad de 3 años, pero lo hace de manera cualitativa y no permite observar la conducta paterna de los adultos. De cualquier manera existe una carencia de información concerniente a la ontogenia del comportamiento de los lobos que cubra todo el periodo de desarrollo (considerado hasta los 24 meses).

En particular para la subespecie de lobo mexicano se carece de información al respecto, por lo que el presente trabajo pretende ser una importante contribución para llenar este vacío de conocimiento.

\section{HIPÓTESIS}

Si la ontogenia de la conducta de los lobos mexicanos (Canis lupus baileyi) es un proceso que implica la aparición y desaparición heterogénea de pautas conductuales entonces se podrán determinar cambios cualitativos y cuantitativos en los diferentes comportamientos durante su desarrollo, desde su nacimiento hasta alcanzar la edad adulta. 


\section{OBJETIVOS}

Objetivo general

Determinar las etapas discretas, si existen, en el desarrollo del comportamiento del lobo mexicano (Canis lupus baileyi) durante su crecimiento

Objetivos particulares

1. Conocer los cambios en las frecuencias de exhibición de las conductas sociales de los lobos mexicanos (Canis lupus baileyi) durante su desarrollo de cachorros a adultos.

2. Determinación de las conductas de cuidado parental durante el período de estudio. 


\section{MÉTODOS}

Se utilizaron registros de observaciones conductuales de los lobos mexicanos del Zoológico San Juan de Aragón hechas entre 1990 y 1999 con un muestreo ad libtum (Altmann, 1974, Martin y Bateson, 1991).

Este zoológico se encuentra al oriente de la Ciudad de México, en la Delegación Gustavo A. Madero, a una altitud de 2237 msnm, con un clima semiseco templado, clasificado como BS1 K, con lluvias escasas, principalmente en verano (INEGI, 2015). Los encierros se localizan a $19^{\circ} 27^{\prime} 43.9^{\prime \prime}$ de latitud norte, y $99^{\circ} 5^{\prime}$ 3.7" de longitud oeste.

Se tomaron en cuenta un total de 44 ejemplares, 18 machos, 11 hembras y 15 de sexo indeterminado (18.11.15), distribuidos en 11 camadas, que nacieron entre 1989 y 1997. La numeración reportada con la que se identifican los individuos estudiados corresponde a la asignada por el Studbook de lobo Mexicano, que es el documento en el cual se registran todos los nacimientos, defunciones y traslados de los animales que participan en el programa de cría en cautiverio de esta subespecie y que se actualiza anualmente (Siminski, 2016b).

Se utilizaron registros conductuales desde el nacimiento a los 24 meses de edad; se consideraron también los registros de las conductas de los padres y otros adultos de las manadas con los cachorros y juveniles. 
Se generó el etograma específico para este trabajo, uno para los cachorros y juveniles, y otro para los adultos, considerando algunos de los trabajos previos, como el de Servín (1991), Vázquez González (2008) y Zimen (1982), además de las observaciones propias. Se adicionaron 3 categorías conductuales que no habían sido consideradas en los estudios anteriores.

Se integraron dos bases de datos, una para las crías y juveniles y otra para los adultos, estableciendo un registro como la aparición de una conducta por individuo por día; sólo se registraron eventos (Martin y Bateson, 1991).

A partir de la información contenida en estas bases de datos se elaboraron todas las gráficas, cuadros y análisis que se presentan en las páginas subsiguientes.

Posteriormente, se hizo un registro de la edad de aparición de cada una de las conductas para poder apreciar el patrón de aparición de los comportamientos en el tiempo.

Se cuantificaron las conductas de los cachorros y adultos por medio de las frecuencias de exhibición, que consisten en la suma de los registros de cada comportamiento emitido por parte de los cachorros o adultos en cada día del periodo de estudio, a partir de estas frecuencias se hizo un análisis de los cambios de las diferentes conductas, por categoría y por etapa de desarrollo. 
Se cuantificó el total de conductas emitidas por las crías y juveniles agrupadas por meses de 30 días para cada uno de los primeros 24 meses de vida, así como el número de nuevas conductas que se observaron también para cada mes, y el número total de conductas nuevas que se iban acumulando a lo largo de cada uno de los meses que duró el estudio. Con esta información se realizó una regresión lineal simple para el mes 1 a 4 , y otra para los meses restantes para poder determinar el patrón de la aparición de nuevos comportamientos durante el desarrollo de las crías.

Se representaron en gráficas de pastel las frecuencias totales mensuales de las diferentes conductas, para poder apreciar la proporción de los diferentes comportamientos en diversos momentos del desarrollo.

En una primera aproximación se generaron las gráficas de las frecuencias relativas de los comportamientos correspondientes a las diferentes etapas de desarrollo.

Para poder realizar un análisis detallado de los cambios que ocurren en las diferentes etapas se graficaron las frecuencias relativas de las conductas por cada uno de los meses del periodo de estudio. 
Dado que la etapa juvenil comprende más de 12 meses, se realizó un análisis particular de los comportamientos durante esta etapa, con la finalidad de investigar si las características del comportamiento eran homogéneas o si presentaban algunas variaciones que mostraran alguna tendencia específica. Para lo cual se realizó un análisis discriminante canónico, que es una técnica estadística multivariada, que permite estudiar las diferencias entre dos ó más grupos de objetos con respecto a varias variables simultáneamente. Es una técnica de clasificación y asignación de individuos a grupos, conocidas sus características.

El problema que resuelve el análisis discriminante es el reducir el número de variables que discriminan entre los grupos a una, dos, o varias nuevas variables (llamadas factores o variables canónicas) que son una combinación de las anteriores y que vienen expresadas por una función discriminante, de tal manera que ellas solas (generalmente las 2 ó 3 primeras) son capaces de identificar 0 discriminar los grupos previamente construidos tan bien como las variables originales (Abdelmonem et al., 2004, Gil et al., 2001, Johnson, 1998).

Tiene 2 objetivos. Determinar si las variables nuevas discriminan los grupos lo suficientemente. Y ver qué variables los caracterizan.

El otro es atribuir o asignar un individuo a alguno de los grupos con cierto margen de error. 


\section{Individuos estudiados}

En total, se estudiaron 44 ejemplares resultantes de 11 camadas producidas durante los años 1989 a 1997, cabe mencionar que los primeros 3 individuos de sexo indeterminado enlistados, 2 de 1989 y 1 de 1990 no forman parte del estudio, ya que el registro conductual inició en diciembre de 1990, y para entonces ya habían muerto, sin embargo se colocan en el cuadro para mostrar la composición original de cada una de las camadas. En el cuadro No. 1 se muestra la relación de las crías que fueron consideradas en el estudio.

Los lobeznos estudiados fueron 18 machos, 11 hembras y 15 de sexo indeterminado. El tamaño de las camadas va desde 2 hasta 7 individuos. En la columna de baja sólo se indica la fecha de defunción de los lobeznos ocurrida durante el periodo de estudio, del resto sólo se señala como adulto(a) puesto que a esta edad ya no es de relevancia para este estudio dar una fecha específica.

En la última columna se indican aquéllos casos en que los cachorros fueron devorados por la madre, sin haberse podido determinar si ya estaban muertos, la causa del deceso ni el sexo. 
Cuadro No. 1. Relación de individuos estudiados.

\begin{tabular}{|c|c|c|c|c|c|c|c|}
\hline $\begin{array}{c}\text { No. } \\
\text { camada }\end{array}$ & ID madre & Fecha parto & $\begin{array}{l}\text { Sexo } \\
\text { crias }\end{array}$ & $\begin{array}{c}\text { No. } \\
\text { Studbook }\end{array}$ & Baja & Causa baja & \multirow{6}{*}{$\begin{array}{l}\text { La relación de los } \\
\text { sexos se expresa } \\
\text { como sigue: }\end{array}$} \\
\hline \multirow[t]{5}{*}{1} & $(1)$ & 17 abr 89 & 0.1 .2 & - & - & - & \\
\hline & & & I & $\mathrm{s} / \mathrm{n}$ & Abr 89 & $\mathrm{D} \times \mathrm{M}$ & \\
\hline & & & I & $s / n$ & Abr 89 & $\mathrm{D} \times \mathrm{M}$ & \\
\hline & & & 오 & 116 & Adulta & & \\
\hline & & & & & & & \\
\hline \multirow[t]{5}{*}{2} & $45 \quad(1)$ & 17 abr 90 & 2.1 .1 & - & - & - & \multirow{7}{*}{$\begin{array}{l}\text { El primer número } \\
\text { corresponde a los } \\
\text { machos, el segundo } \\
\text { a las hembras y el } \\
\text { tercero a los de sexo }\end{array}$} \\
\hline & & & $I$ & 85 & 21 abr 90 & $\mathrm{D} \times \mathrm{M}$ & \\
\hline & & & $\hat{0}$ & 86 & Adulto & & \\
\hline & & & $0^{2}$ & 87 & 9 dic 91 & & \\
\hline & & & क & 88 & Adulta & & \\
\hline \multirow[t]{7}{*}{3} & $\begin{array}{ll}45 & (1) \\
\end{array}$ & 17 abr 91 & 2.1 .3 & - & - & - & \\
\hline & & & I & $s / n$ & Abr 91 & $\mathrm{D} \times \mathrm{M}$ & \\
\hline & & & $I$ & $\mathrm{~s} / \mathrm{n}$ & Abr 91 & $\mathrm{D} \times \mathrm{M}$ & \multirow{12}{*}{$\begin{array}{l}\text { indeterminado, es } \\
\text { decir que el cadáver } \\
\text { no pudo ser } \\
\text { recuperado para su } \\
\text { sexado por haber } \\
\text { sido devorado por la } \\
\text { madre. }\end{array}$} \\
\hline & & & I & $s / n$ & Abr 91 & $\mathrm{D} \times \mathrm{M}$ & \\
\hline & & & $\hat{\sigma}^{2}$ & 96 & 17 ago 91 & & \\
\hline & & & $\pi$ & 97 & Adulto & & \\
\hline & & & 오 & 98 & Adulta & & \\
\hline \multirow{6}{*}{4} & & & 032 & & - & & \\
\hline & (1) & II IIIa ge & $\frac{0.0 .2}{9}$ & 111 & 24 mar 92 & $D \times M$ & \\
\hline & & & $I$ & 112 & 21 abr 92 & $D \times M$ & \\
\hline & & & 오 & 113 & 22 abr 92 & & \\
\hline & & & $I$ & 114 & 25 abr 92 & $D \times M$ & \\
\hline & & & 우 & 115 & Adulta & & \\
\hline \multirow{9}{*}{5} & & & & & & & \\
\hline & 265 & 5 abr 92 & 3.1 .3 & $\frac{-}{274}$ & $\frac{-}{5 \text { in } 92}$ & - & \multirow{12}{*}{$\begin{array}{l}\text { (1) Se refiere a que } \\
\text { durante algún } \\
\text { periodo de tiempo } \\
\text { los integrantes de } \\
\text { las manadas } \\
\text { señaladas } \\
\text { coexistieron en el } \\
\text { mismo encierro. }\end{array}$} \\
\hline & & & $\frac{7}{1}$ & $\begin{array}{l}2 / 4 \\
275\end{array}$ & $\begin{array}{l}9 \text { jul } 92 \\
9 \text { jul } 92\end{array}$ & & \\
\hline & & & 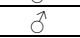 & 276 & 8 jul 92 & & \\
\hline & & & $\pi$ & 277 & $6 \operatorname{sep} 92$ & & \\
\hline & & & I & 278 & 8 abr 92 & $D \times M$ & \\
\hline & & & I & 279 & 8 abr 92 & $D \times M$ & \\
\hline & & & $I$ & 280 & 8 abr 92 & $D \times M$ & \\
\hline & & & & & & & \\
\hline \multirow[t]{6}{*}{6} & $\begin{array}{ll}116 & (1)\end{array}$ & 12 abr 92 & 3.0 .1 & - & - & - & \\
\hline & & & I & 117 & 13 abr 92 & $D \times M$ & \\
\hline & & & $0^{n}$ & 118 & Adulto & & \\
\hline & & & $0^{\pi}$ & 119 & Adulto & & \\
\hline & & & $0^{2}$ & 120 & Adulto & & \multirow{11}{*}{$\begin{array}{l}\text { (2) Las camadas } \\
\text { señaladas con este } \\
\text { número coexistieron } \\
\text { en algún momento } \\
\text { durante el desarrollo } \\
\text { del estudio. }\end{array}$} \\
\hline & & & & & & & \\
\hline \multirow[t]{6}{*}{7} & $265 \quad(2)$ & 26 mar 93 & 2.2 .1 & - & - & - & \\
\hline & & & 오 & 281 & Adulta & & \\
\hline & & & 우 & 282 & Adulta & & \\
\hline & & & $0^{2}$ & 283 & 22 sept. 93 & & \\
\hline & & & $0^{\pi}$ & 284 & Adulto & & \\
\hline & & & $I$ & 285 & 29 marzo 93 & $D \times M$ & \\
\hline \multirow[t]{4}{*}{8} & 45 & 17 abr 93 & 1.0 .2 & - & - & - & \\
\hline & & & I & 151 & 19 abril 93 & $\mathrm{D} \times \mathrm{M}$ & \\
\hline & & & I & 152 & 24 abril 93 & $\mathrm{D} \times \mathrm{M}$ & \\
\hline & & & $0^{1}$ & 153 & 5 mayo 93 & & \multirow{4}{*}{$\begin{array}{l}\text { D X M.= Cría } \\
\text { devorada por la } \\
\text { madre. }\end{array}$} \\
\hline 9 & 45 & 17 abr 94 & 0.0 .2 & - & - & - & \\
\hline & & & $I$ & 154 & 19 abril 94 & $\mathrm{D} \times \mathrm{M}$ & \\
\hline & & & $I$ & 155 & 19 abril 94 & $\mathrm{D} \times \mathrm{M}$ & \\
\hline 10 & $265 \quad$ (2) & 31 mar 94 & 211 & - & - & - & \\
\hline & & & I & 286 & 2 abril 94 & $\mathrm{D} \times \mathrm{M}$ & $\delta=$ macho \\
\hline & & & $\hat{0}^{2}$ & 287 & 2 abril 94 & $\mathrm{D} \times \mathrm{M}$ & \\
\hline & & & q & 288 & Adulta & & \\
\hline & & & $\hat{0}^{2}$ & 289 & Adulto & & q =hembra \\
\hline & & & & & & & \\
\hline 11 & 281 & 14 abr 97 & 3.1 .0 & - & - & - & \\
\hline & & & $0^{\pi}$ & 535 & Adulto & & $I=$ sexo \\
\hline & & & $\hat{0}$ & 536 & Adulto & & \\
\hline & & & $0^{2}$ & 537 & Adulto & & indeterminado. \\
\hline & & & o & 538 & Adulta & & \\
\hline
\end{tabular}




\section{Manadas estudiadas}

Todas las crías y juveniles consideradas en este estudio se encontraban formando parte de alguno de los siguientes grupos, las manadas son identificadas por el nombre de los progenitores (hembra-macho):

\section{Manada Sonora-Cujo}

Este grupo fue iniciado por una pareja de lobos (Macho No. 33, Hembra No. 45), en Octubre de 1987, de entonces 3 y 2 años de edad, respectivamente. Produjeron su primera camada en 1989 (camada 1), continuaron reproduciéndose en 1990, 1991, 1992, 1993 y 1994 (camadas 2, 3, 4, 8 y 9), siendo las últimas crías viables las de 1992.

En el verano-otoño de 1991 la hembra tuvo que permanecer encerrada y separada del resto del grupo durante varios meses por problemas conductuales, lo que trajo como consecuencia que la hija mayor que ya era adulta (No. 116), tomara su lugar, apoyada por una hembra juvenil (No. 88), durante algunos meses, además de que se produjo la camada No. 6 como resultado de la cruza de la loba No. 116 con el macho No. 86, nacido en 1990, por lo que en ese año se engendraron 2 camadas de dos parejas diferentes, las 3 crías de la camada 6 fueron retiradas de su madre y presentadas a la otra hembra (No. 45) que tenía sólo un cachorro, y se hizo cargo de los 4 lobeznos. 
Aunque ésta última recuperó su posición, los conflictos sociales en el grupo persistieron, por lo que en diversas ocasiones se encerraron temporalmente algunos individuos, mientras que otros fueron removidos del grupo en diferentes momentos; el padre (No. 33) murió en 1995 y la madre (No. 45) en 1996.

\section{Manada Claudicante-Cara Blanca}

Este grupo se inició en Octubre d e1991, cuando se juntaron dos hembras de por lo menos 10 años (No. 264 y No. 265), posiblemente hermanas de diferentes camadas, con dos machos hermanos de camada de 3 años de edad (No. 258 y 259). El macho No. 258 y la hembra No. 265 se acoplaron enseguida y formaron la pareja reproductora, mientras que el macho No. 259 murió en ese mismo año, y la hembra No. 264 permaneció como adulto acompañante hasta el otoño de 1993, ocupando la posición omega de la manada.

La pareja produjo camada en 1992, 1993 y 1994 (No.5, No. 7, No. 10 de este estudio), se mantuvo como tal hasta noviembre de 1994 en que la hembra murió y el grupo se disolvió, manteniendo al padre con los 2 animales más jóvenes (No. 288 y 289), se juntaron con la hembra No. 264 para formar una nueva pareja pero

no resultó y se tuvo que mantener separada, aunque podían seguir interactuando, hasta 1995 en que murió. En 1997 el padre y sus dos hijos fueron separados para formar nuevas parejas en otros lugares. 


\section{Manada Andra-Prieto}

Este grupo se formó a partir de la reunión en diciembre de 1994 del macho No. 86 de 4 años y la hembra No. 281 de casi dos años; en 1996 produjeron su primera camada pero fue devorada poco después del nacimiento, en 1997, la segunda en 1997 (No. 11); a finales de ese año los adultos fueron separados de los ya juveniles pero en un exhibidor contiguo, por lo que siguieron de algún modo en contacto; en febrero de 1998 muere el macho y en ese mismo mes fue remplazado por otro (No. 119) pero ya no tuvieron crías, las interacciones de los juveniles con éste persistieron hasta el otoño en que enfermó y murió en abril del año siguiente. La camada siguió en contacto con la madre hasta finales de 1999 en que fueron enviados a diferentes instituciones.

Concentración, análisis y presentación de los resultados

Los datos fueron obtenidos de los diarios de campo de la autora, basados en las observaciones diarias de cada una de las manadas consideradas. Para sistematizar los datos se transformaron en variables discretas, así se consideró un registro como: la emisión de una determinada conducta, por un individuo en un día determinado. Con esto se conformó la base de datos tanto para los cachorros como para los adultos acompañantes (padres, madres, tíos o hermanos mayores a dos años). 
Con la finalidad de presentar de manera clara toda la información recabada en la base de datos se analizó con base en la frecuencia de aparición, considerando que, debido al gran tamaño de la muestra la frecuencia puede considerarse proporcional a la relevancia en la vida del organismo.

Así los datos se analizaron primero en conjunto de todos los comportamientos encontrados y después estos datos se agruparon de acuerdo a las etapas propuestas, para cumplir con el objetivo de determinar si en realidad éstas eran diferenciables con base en los comportamientos exhibidos y en la frecuencia de los mismos.

Posteriormente, se agruparon por "categoría" de comportamiento, éstas fueron pautas afines como alimenticias, de juego etc. A fin de comprobar que las tendencias expresadas en frecuencias totales fueran reales, en algunas de las categorías se realizó el análisis obteniendo la media por camada y su error estándar. Los datos fueron procesados por medio del paquete Number Cruncher Statistical System (NCSS) (Kintze, J. 2007).

Para cumplir el objetivo sobre la definición específica de las etapas del proceso ontogenético de la conducta, los datos de frecuencia relativa de conducta se sometieron a un análisis de discriminante canónico. En primer término se estableció si las conductas emitidas podían discriminar entre las tres primeras etapas del desarrollo (Socialización, neonatal y transición.) y en un segundo análisis se incluyeron las subetapas propuestas (juvenil 1, 2, 3 y 4) usando las 
frecuencias relativas de las conductas como variables discriminatorias. Los análisis fueron realizados con el programa NCSS (Kintze, J. 2007). Cabe señalar que Bekoff (1989) considera que las técnicas estadísticas multivariadas son de gran utilidad para los estudios del desarrollo, ya que pueden considerar numerosas variables simultáneamente.

Los grupos de repetición se designaron conforme a las etapas descritas en estudios anteriores; las frecuencias relativas de las etapas neonatal, transición y socialización fueron analizadas por días mientras que en el caso de la etapa juvenil, se subdividió de acuerdo a los cambios observados en las gráficas de frecuencias relativas mensuales:

Posteriormente se realizó un segundo análisis discriminante canónico en el que los registros de conductas fueron ubicados en las diferentes categorías y subcategorías propuestas para llevar a cabo un análisis de errores de clasificación discriminante.

Se contabilizaron las frecuencias de exhibición totales de cada conducta del etograma para cada uno de los 24 meses que duró este estudio, con esta información se construyeron gráficas de líneas por categorías conductuales. Se analizaron por separado las conductas de las crías y juveniles y las de los adultos. Se graficaron la frecuencia promedio mensual por camada y el correspondiente error estándar para algunas conductas seleccionadas para comprobar las tendencias obtenidas con las frecuencias totales mensuales por conducta. 


\section{RESULTADOS}

\section{Etograma}

El etograma de las crías y juveniles está integrado por 64 conductas que fueron agrupadas en diferentes categorías:

\section{Tempranas}

2. Alimenticias

\section{Filiativas o Amistosas}

4. De juego

5. Sumisión

6. Antagónicas, Agonísticas o de Agresión

\section{Pseudosexuales}

\section{Sexuales \\ 9. Marcaje}

La relación de las 64 conductas, así como las abreviaturas utilizadas para cada una de ellas se presentan en el cuadro No. 2. La reseña detallada de todas las conductas se presenta en el Anexo I. 
Cuadro No. 2. Etograma crías y juveniles.

\begin{tabular}{|c|c|}
\hline Abreviatura conducta & Nombre completo conducta \\
\hline \multicolumn{2}{|c|}{ Tempranas y alimenticias } \\
\hline Huddling & Huddling \\
\hline 2. Mam & Mamar \\
\hline Mds pzs & Mordisquear pezones \\
\hline 4. $\quad$ sol ali gral & Solicitud de alimentación en general \\
\hline Sol carne & Solicitud de carne \\
\hline Sol reg & Solicitud de regurgitación \\
\hline Dar carne & Dar carne \\
\hline Reg & Regurgitar \\
\hline Disp. Ali & Disputa por alimento \\
\hline \multicolumn{2}{|l|}{ Amistosas } \\
\hline 10. Hoc piel & Olfateo/contacto hocico piel \\
\hline 11. Toque hoc & Toque de hocicos \\
\hline Lamer & Lamer piel \\
\hline 13. $\quad$ Parado/comp & Parado sobre compañero \\
\hline 14. Cab cab & Contacto cabeza-cabeza \\
\hline 15. Ol periné & Olfateo de periné \\
\hline 16. Ol genit & Olfateo de genitales \\
\hline 17. Lam genit & Lamer genitales \\
\hline \multicolumn{2}{|l|}{ Juego } \\
\hline 18. J c/objetos & Juego con objetos \\
\hline 19. J solitario & Juego solitario \\
\hline 20. $\quad$ Sol juego & Solicitud de juego \\
\hline 21. J persecut & Juego persecutorio \\
\hline 22. J J/corp & Juego con contacto corporal \\
\hline \multicolumn{2}{|l|}{ Sumisión } \\
\hline 23. Sum act & Sumisión activa \\
\hline Sum pas & Sumisión pasiva \\
\hline 25. Sum gpo & Sumisión de grupo \\
\hline 26. Reunión & Reunión \\
\hline \multicolumn{2}{|l|}{ Agonísticas } \\
\hline \multicolumn{2}{|c|}{ Sin contacto corporal } \\
\hline 27. $\mathrm{Am}$ of & Amenaza ofensiva \\
\hline 28. Am subord & Amenaza subordinada \\
\hline 29. Acecho & Acecho \\
\hline 30. Seguir & Seguir \\
\hline 31. Ataq & Ataque \\
\hline 32. $\quad$ Perseguir & Perseguir \\
\hline 33. Rodear & Rodear \\
\hline 34. Acoso & Acoso \\
\hline 35. $\mathrm{G} \times \mathrm{lam}$ & Golpear lámina \\
\hline 36. B tr $r \times$ lam & Buscar, trotar, correr por lámina \\
\hline 37. Saltar $\times$ lam & Saltar por lámina \\
\hline \multicolumn{2}{|c|}{ Con contacto corporal } \\
\hline 38. Imp parado & Imposición parado \\
\hline 39. $\quad I \mathrm{mp} \mathrm{p} /$ contr & Imposición parado sobre contrario \\
\hline 40. $\mathrm{m} /$ /lomocomp & Manos/lomo sobre contrario \\
\hline 41. Imp emp & Imposición por empujones \\
\hline 42. Derr opon & Derribar opononente \\
\hline 43. M/suelo/cpo & Mantener en suelo con cuerpo \\
\hline \multicolumn{2}{|c|}{ Con intento de mordida } \\
\hline 44. Cog hoc & Coger hocico \\
\hline 45. Lanz mord & Lanzar y morder \\
\hline 46. Lev mord & Levantarse y morder \\
\hline Con mordic & \\
\hline 47. Mord & Morder \\
\hline Defensivas & \\
\hline 48. $\quad$ Am def & Amenaza defensiva \\
\hline 49. $\quad$ Chasq & Chasquido \\
\hline 50. Mant dist & Mantener distancia \\
\hline 51. Huir & Huir \\
\hline 52. Def circulo & Defensa en círculo \\
\hline 53. Lanzmorddef & Lanzar y morder defensivo \\
\hline 54. $\quad$ Mord def & Mordida defensiva \\
\hline Sexuales & \\
\hline 55. Seguir $x$ cort & Seguir previo a cortejo \\
\hline 56. Sol amistosa & Solicitud amistosa \\
\hline 57. $\quad$ Cortejo & Cortejo \\
\hline 58. Pres gen & Presentar genitales \\
\hline 59. Mont & Monta \\
\hline 60. Mov pelv & Movimientos pélvicos \\
\hline 61. Cópula & Cópula \\
\hline Pseudosexu & \\
\hline 62. $\quad$ Mont pre & Monta no sexual \\
\hline 63. Movpelvpre & Movimientos pélvicos no sexual \\
\hline Marcaje & \\
\hline 64. Marc & Marcar \\
\hline
\end{tabular}


Para el etograma de los adultos (padres, tía, y hermanos de más de 2 años de edad) se describieron un total de 50 conductas, agrupadas en categorías similares a las de las crías y juveniles:

1) Conductas exhibidas exclusivamente durante las primeras semanas de vida de los cachorros, relacionadas con las conductas Tempranas de éstos

\section{2) Alimenticias}

3) Filiativas o Amistosas

4) Juego

5) Sumisión

6) Antagónicas, Agonísticas, o de Agresión

\section{7) Sexuales}

En el cuadro No. 3 se presenta la relación de las conductas emitidas por los adultos dirigidas hacia las crías y juveniles, así como las abreviaturas correspondientes utilizadas. La descripción de cada una de ellas se encuentra también en el Anexo I. 
Cuadro No. 3. Etograma adultos.

\begin{tabular}{|c|c|}
\hline Abreviatura conducta & \multirow{2}{*}{$\begin{array}{l}\text { Nombre completo conducta } \\
\text { semanas de vida de los cachorros }\end{array}$} \\
\hline Conductas exhibidas únicamente en las primeras & \\
\hline \multirow{2}{*}{\multicolumn{2}{|c|}{$\begin{array}{l}\text { Ech c/crías } \\
\text { Alimenticias }\end{array}$}} \\
\hline & \\
\hline Dar carne & Dar carne \\
\hline Reg & Regurgitar \\
\hline Disp. Ali & Disputa por alimento \\
\hline \multicolumn{2}{|l|}{ Amistosas } \\
\hline Hoc piel & Olfateo/contacto hocico piel \\
\hline Toque hoc & Toque de hocicos \\
\hline 7. Lamer & Lamer piel \\
\hline 8. $\quad$ Cab cab & Contacto cabeza-cabeza \\
\hline 9. Ol periné & Olfateo de periné \\
\hline 10. Ol genit & Olfateo de genitales \\
\hline 11. Lam periné & Lamer periné \\
\hline 12. Lam genit & Lamer genitales \\
\hline \multicolumn{2}{|l|}{ Juego } \\
\hline 13. J solitario & Juego solitario \\
\hline 14. Sol juego & Solicitud de juego \\
\hline 15. J persecut & Juego persecutorio \\
\hline 16. J $\mathrm{J} /$ corp & Juego con contacto corporal \\
\hline \multicolumn{2}{|l|}{ Sumisión } \\
\hline 17. Sum act & Sumisión activa \\
\hline 18. Sum pas & Sumisión pasiva \\
\hline \multicolumn{2}{|l|}{ Agonísticas } \\
\hline \multicolumn{2}{|l|}{ Sin contacto corporal } \\
\hline 19. Am of & Amenaza ofensiva \\
\hline 20. Am subord & Amenaza subordinada \\
\hline 21. Acecho & Acecho \\
\hline 22. Seguir & Seguir \\
\hline 23. Ataq & Ataque \\
\hline 24. Perseguir & Perseguir \\
\hline 25. Rodear & Rodear \\
\hline 26. Acoso & Acoso \\
\hline 27. $\mathrm{G} \times \mathrm{lam}$ & Golpear lámina \\
\hline 28. B tr $r \times$ lam & Buscar, trotar, correr por lámina \\
\hline \multicolumn{2}{|l|}{ Con contacto corporal } \\
\hline 29. Imp parado & Imposición parado \\
\hline 30. $\operatorname{Imp~p/contr~}$ & Imposición parado sobre contrario \\
\hline 31. $\mathrm{m} /$ lomocomp & Manos/lomo sobre contrario \\
\hline 32. Imp emp & Imposición por empujones \\
\hline 33. Derr opon & Derribar opononente \\
\hline 34. $\mathrm{m} / \mathrm{suelo} / \mathrm{hoc}$ & Mantener en suelo con hocico \\
\hline \multicolumn{2}{|l|}{ Con intento de mordida } \\
\hline 35. Cog hoc & Coger hocico \\
\hline 36. Lanz mord & Lanzar y morder \\
\hline 37. Lev mord & Levantarse y morder \\
\hline \multicolumn{2}{|l|}{ Con mordida } \\
\hline 38. Mord & Morder \\
\hline \multicolumn{2}{|l|}{ Defensivas } \\
\hline 39. Am def & Amenaza defensiva \\
\hline 40. Chasq & Chasquido \\
\hline 41. Mant dist & Mantener distancia \\
\hline 42. Huir & Huir \\
\hline 43. Def circulo & Defensa en círculo \\
\hline 44. Lanzmorddef & Lanzar y morder defensivo \\
\hline \multicolumn{2}{|l|}{ Sexuales } \\
\hline 45. Sol amistosa & Solicitud amistosa \\
\hline 46. Cortejo & Cortejo \\
\hline 47. Pres gen & Presentar genitales \\
\hline 48. Mont & Monta \\
\hline 49. Mov pelv & Movimientos pélvicos \\
\hline 50. Cópula & Cópula \\
\hline
\end{tabular}




\section{Base de datos}

A partir de las conductas observadas se obtuvo una base de datos con 28045 registros para las crías y juveniles y otra para los adultos con 8290 registros.

\section{Cronograma de aparición de conductas}

Las primeras conductas registradas en los cachorros fueron mamar desde el primer día y huddling, a los 7 días de nacidos, esta última conducta se refiere al agrupamiento estrecho que tienen los lobeznos cuando la madre los deja solos (Anexo I). Los últimos comportamientos en presentarse fueron presentación de genitales y cópula, a los 653 y 667 días de edad (Cuadro No.4).

Las conductas se agruparon por categorías de acuerdo a sus características: tempranas, alimenticias, amistosas, de juego, sumisión, agresión, defensivas, sexuales, pseudosexuales y marcaje

Las conductas tempranas se registraron desde el día 1 hasta el día 75. Cabe señalar que tanto mamar como mordisquear pezones son también conductas de alimenticias, pero se colocaron en otra categoría para poder apreciar mejor la cronología de los comportamientos en las primeras semanas posteriores al nacimiento. 
Los comportamientos alimenticios como categoría se registraron durante todo el periodo de estudio, sin embargo, mordisquear pezones y mamar se presentaron hasta el día 69 y 75, respectivamente; la solicitud de alimento, tanto los trozos de carne como la regurgitación se registran a partir del día 32 hasta los 676 días. Esto permite apreciar el inicio de alimentación a base de leche materna y la transición al alimento sólido, así como la independencia alimenticia. Dar carne y regurgitar se presentan solamente entre los 395 y 672 días de edad, que corresponden al periodo en que los juveniles contribuyen a la alimentación de los cachorros del siguiente año (Figura No. 1).

Las conductas amistosas se registraron desde el día 25 hasta el final del periodo de estudio, siendo la primera el contacto hocico-piel y la última lamer genitales (Figura No. 1).

Los comportamientos de juego se registraron a partir de los 20 días de edad, siendo el primero juego con contacto corporal, pocos días después, aparecieron solicitud de juego y juego persecutorio a los 27 y 29 días, respectivamente, y el último en presentarse fue juego solitario a los 70 días de edad (Figura No. 1). Se puede apreciar que estos comportamientos aparecieron en su mayoría dentro de un corto lapso de tiempo. 


\section{Cuadro No. 4. Edad de aparición de conductas}

\begin{tabular}{|c|c|c|}
\hline Conducta & & Edad aparición (días) \\
\hline 1. & Huddling & 7 \\
\hline 2. & Mamar & 1 \\
\hline 3. & Mordisquear pezones & 38 \\
\hline 4. & Solicitud alimentación general & 32 \\
\hline 5. & Solicitud de carne & 33 \\
\hline 6. & Dar carne & 395 \\
\hline 7. & Solicitud de regurgitación & 32 \\
\hline 8. & Regurgitar & 429 \\
\hline 9. & Disputa por alimento & 32 \\
\hline 10. & Contacto hocico-piel & 25 \\
\hline 11. & Toque de hocicos & 60 \\
\hline 12. & Lamer & 32 \\
\hline 13. & Parado sobre compañero & 109 \\
\hline 14. & Contacto cabeza-cabeza & 51 \\
\hline 15. & Olfateo periné & 50 \\
\hline 16. & Olfateo genitales & 50 \\
\hline 17. & Lamer genitales & 205 \\
\hline 18. & Juego con objetos & 34 \\
\hline 19. & Juego solitario & 70 \\
\hline 20. & Solicitud de juego & 27 \\
\hline 21. & Juego persecutorio & 29 \\
\hline 22. & Juego con contacto corporal & 20 \\
\hline 23. & Sumisión activa & 33 \\
\hline 24. & Sumisión pasiva & 50 \\
\hline 25. & Sumisión de grupo & 49 \\
\hline 26. & Reunión & 250 \\
\hline 27. & Amenaza ofensiva & 20 \\
\hline 28. & Amenaza subordinada & 123 \\
\hline 29. & Acecho & 283 \\
\hline 30. & Seguir & 203 \\
\hline 31. & Ataque & 54 \\
\hline 32. & Perseguir & 108 \\
\hline 33. & Rodear & 108 \\
\hline 34. & Acoso & 246 \\
\hline 35. & Golpear lámina & 235 \\
\hline 36. & Buscar por lámina & 225 \\
\hline 37. & Saltar por lámina & 314 \\
\hline 38. & Imposición parado & 127 \\
\hline 39. & Imposición parado sobre el contrario & 40 \\
\hline 40. & Manos/lomo sobre contrario & 59 \\
\hline 41. & Imposición por empujones & 113 \\
\hline 42. & Derribar oponente & 274 \\
\hline 43. & Mantener en suelo con cuerpo & 291 \\
\hline 44. & Coger hocico & 112 \\
\hline 45. & Lanzar y morder & 110 \\
\hline 46. & Levantarse y morder & 101 \\
\hline 47. & Mordida & 468 \\
\hline 48. & Amenaza defensiva & 40 \\
\hline 49. & Chasquido & 58 \\
\hline 50. & Mantener distancia & 66 \\
\hline 51. & Huir & 132 \\
\hline 52. & Defensa en círculo & 47 \\
\hline 53. & Lanzar y morder defensivo & 296 \\
\hline 54. & Mordida defensiva & 97 \\
\hline 55. & Solicitud amistosa & 377 \\
\hline 56. & Seguir por cortejo & 304 \\
\hline 57. & Cortejo & 299 \\
\hline 58. & Presentación de genitales & 653 \\
\hline 59. & Monta & 291 \\
\hline 60. & Movimientos pélvicos & 302 \\
\hline 61. & Cópula & 667 \\
\hline 62. & Monta no sexual & 87 \\
\hline 63. & Movimientos pélvicos no sexual & 87 \\
\hline 64. & Marcar & 273 \\
\hline
\end{tabular}




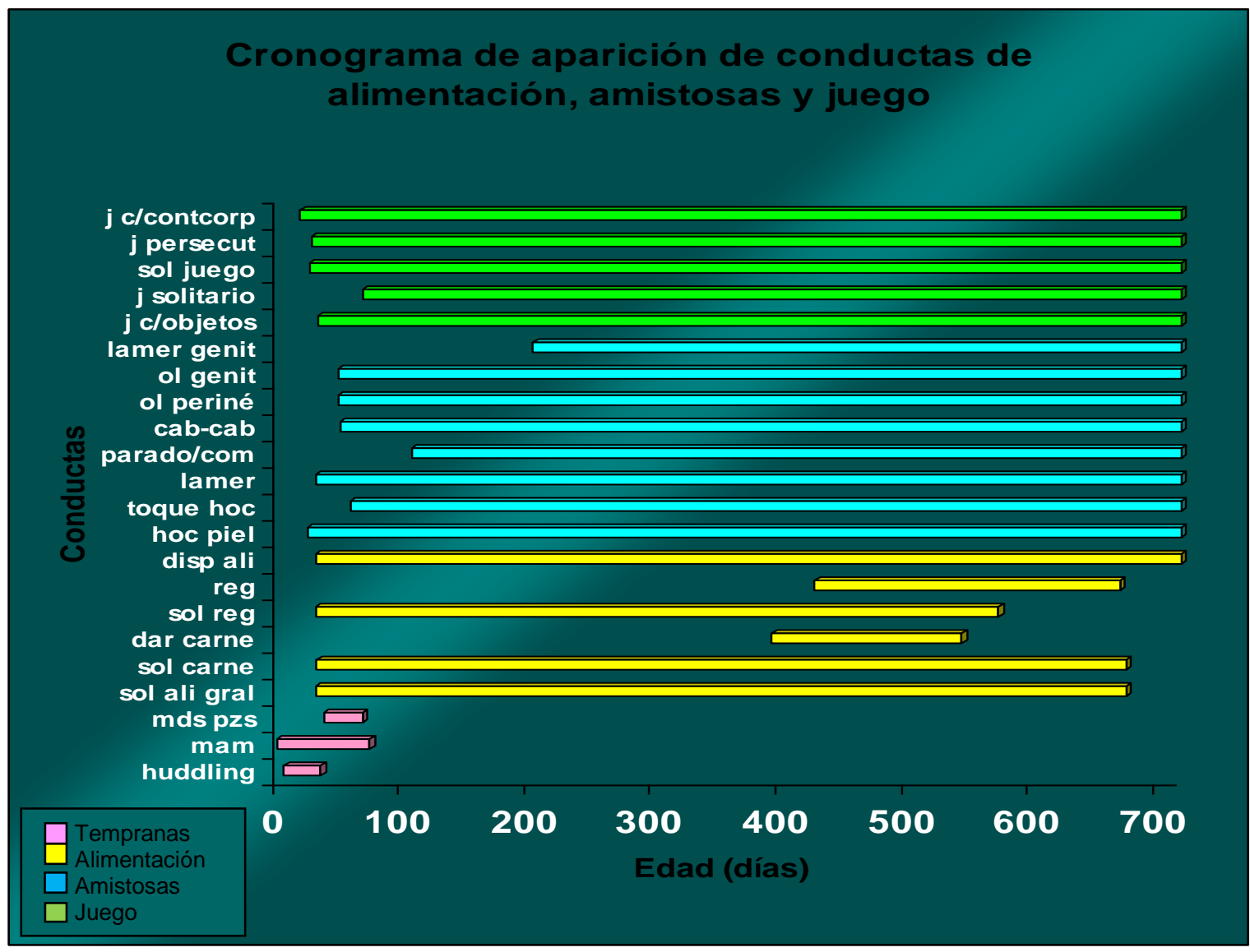

Figura No. 1.Cronograma de aparición de conductas de alimentación, tempranas, amistosas y juego.

Las conductas de agresión se registraron a partir de los 20 días, siendo la primera amenaza ofensiva y la última morder, a los 468 días, que además, es la de mayor intensidad de agresión; del resto de las conductas se aprecia que algunas aparecen durante los primeros meses de vida mientras que la mayor parte de ellas aparece después de los 6 meses (Figura No. 2). Estos comportamientos se observaron durante todo el periodo de estudio, pero además son parte del repertorio normal en la vida de los adultos. 
De los comportamientos defensivos, el primero en presentarse fue amenaza defensiva a los 40 días, y el último lanzar y morder defensivo a los 296 días, de tal modo que todas las conductas de esta categoría se registran antes de que los cachorros alcancen el primer año de vida (Figura No. 2).

Las conductas se sumisión se observaron a partir de los 33 días de edad, con sumisión activa, y la última en aparecer fue reunión a los 250 días. Los 3 comportamientos principales se registran antes de que alcancen los 2 meses de vida (Figura No. 2).

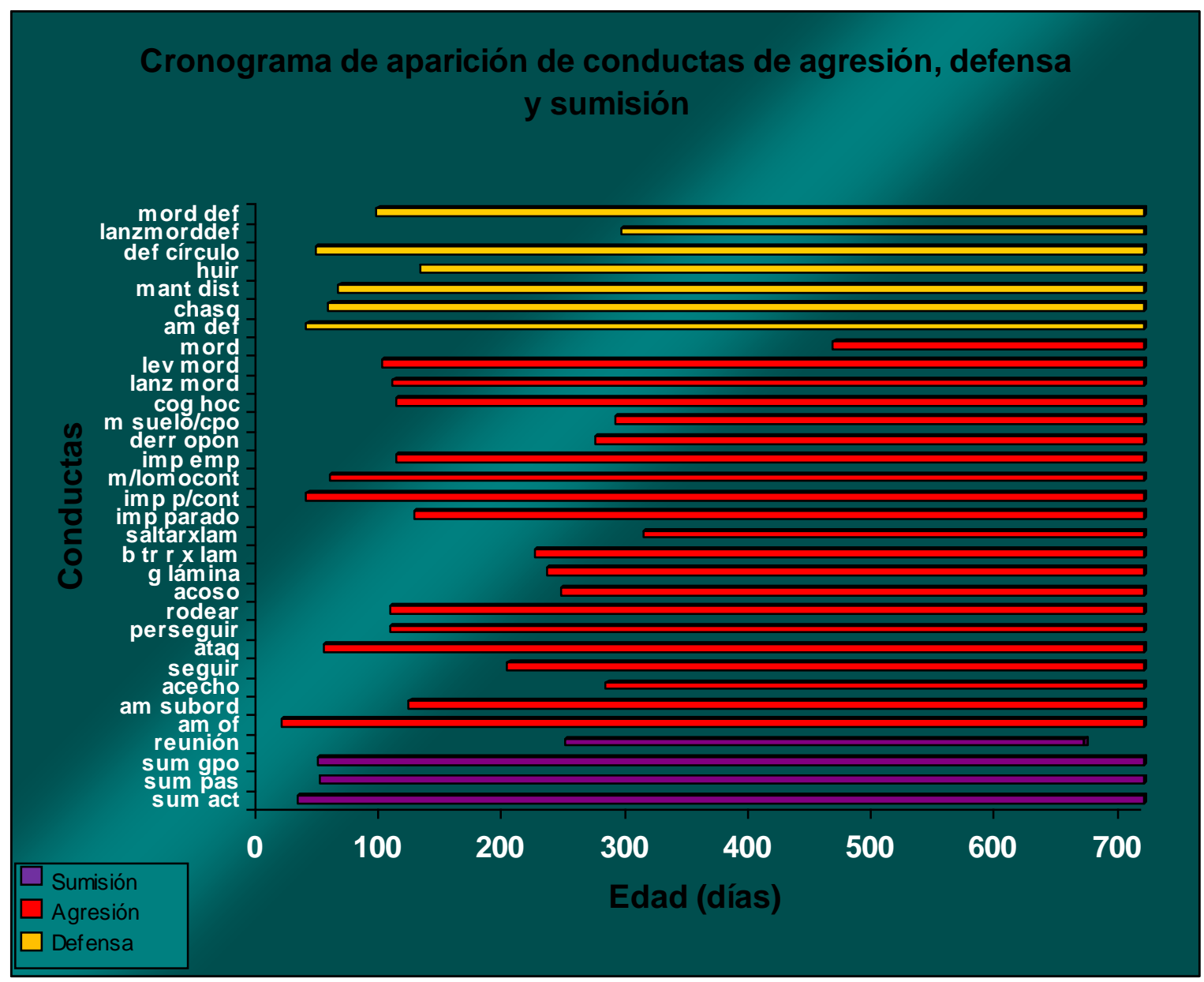

Figura No. 2. Cronograma de aparición de conductas de agresión, defensa y sumisión. 
Las conductas de marcaje se registraron por primera vez el día 273 , y prevalecieron hasta el final del periodo de estudio, aunque también tienen un papel importante en la vida adulta (Figura No. 3).

Los comportamientos pseudosexuales se presentaron entre los 87 y 330 días, sin embargo, fue durante 3 periodos separados, muy breves (Figura No. 3).

La primera conducta sexual en presentarse fue monta a los 291 días y la última cópula a los 667 días de edad. Cabe señalar que estos comportamientos solo se observan durante dos breves periodos durante el transcurso de este estudio, que corresponden a las épocas de celo de las hembras adultas (Figura No. 3).

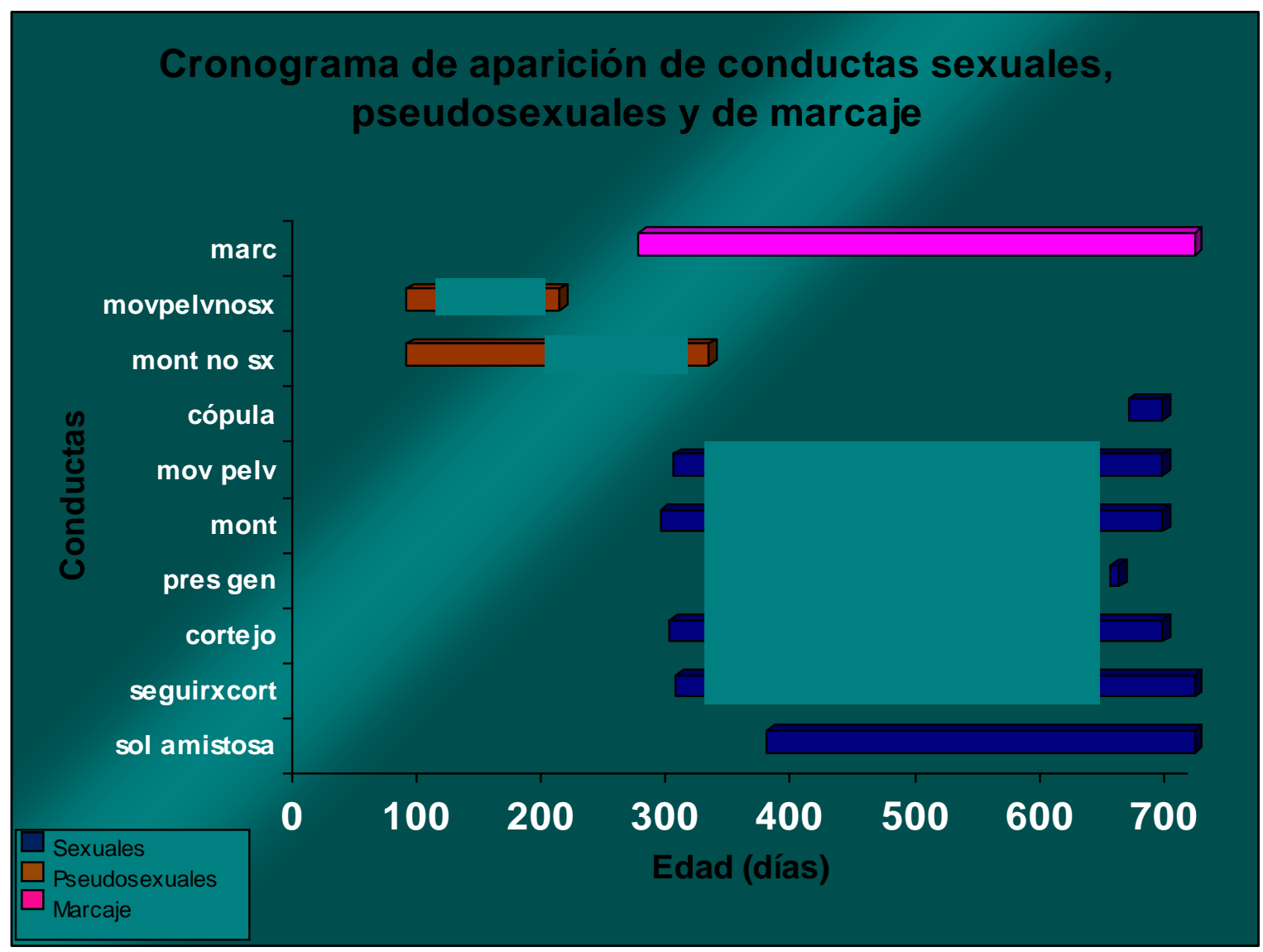

Figura No. 3. Cronograma de aparición de conductas sexuales, pseudosexuales y marcaje. 
Se puede observar que la totalidad de las conductas registradas en este estudio se presentaron por primera vez entre el primer día de nacidos y los 667 días de edad, es decir, cerca de los 2 años de edad; además, de manera general, se aprecia que los comportamientos que aparecieron primero son aquéllos relacionados con la obtención de alimento, mientras que los últimos son de tipo sexual.

Se aprecia también que antes de los 120 días de edad la mayoría de los comportamientos ya han aparecido, y se puede considerar que el repertorio conductual básico está completo.

\section{CUANTIFICACIÓN DE LAS CONDUCTAS DE LAS CRÍAS Y JUVENILES}

\section{Conductas totales por mes}

De las 64 conductas registradas para los cachorros y juveniles, 39 de ellas, es decir, el 60.94\%, apareció durante los primeros 4 meses, mientras que las 25 restantes (39.06\%) se presentaron por primera vez en el transcurso de 20 meses. El mayor número de comportamientos nuevos se registró en el segundo mes, con 20. El mayor número de comportamientos diferentes exhibidos por los lobeznos fue a los 11 y a los 16 meses, con 45 cada uno.

La diferencia entre las 2 pendientes es notable, por lo que se considera que durante los primeros cuatro meses de vida los cachorros van adquiriendo un gran 
número de conductas, y que más adelante, pasada la etapa de socialización, la incorporación de conductas nuevas al repertorio es más lenta, lo cual permite una primera división respecto a la adquisición de conductas (Figura No. 4).

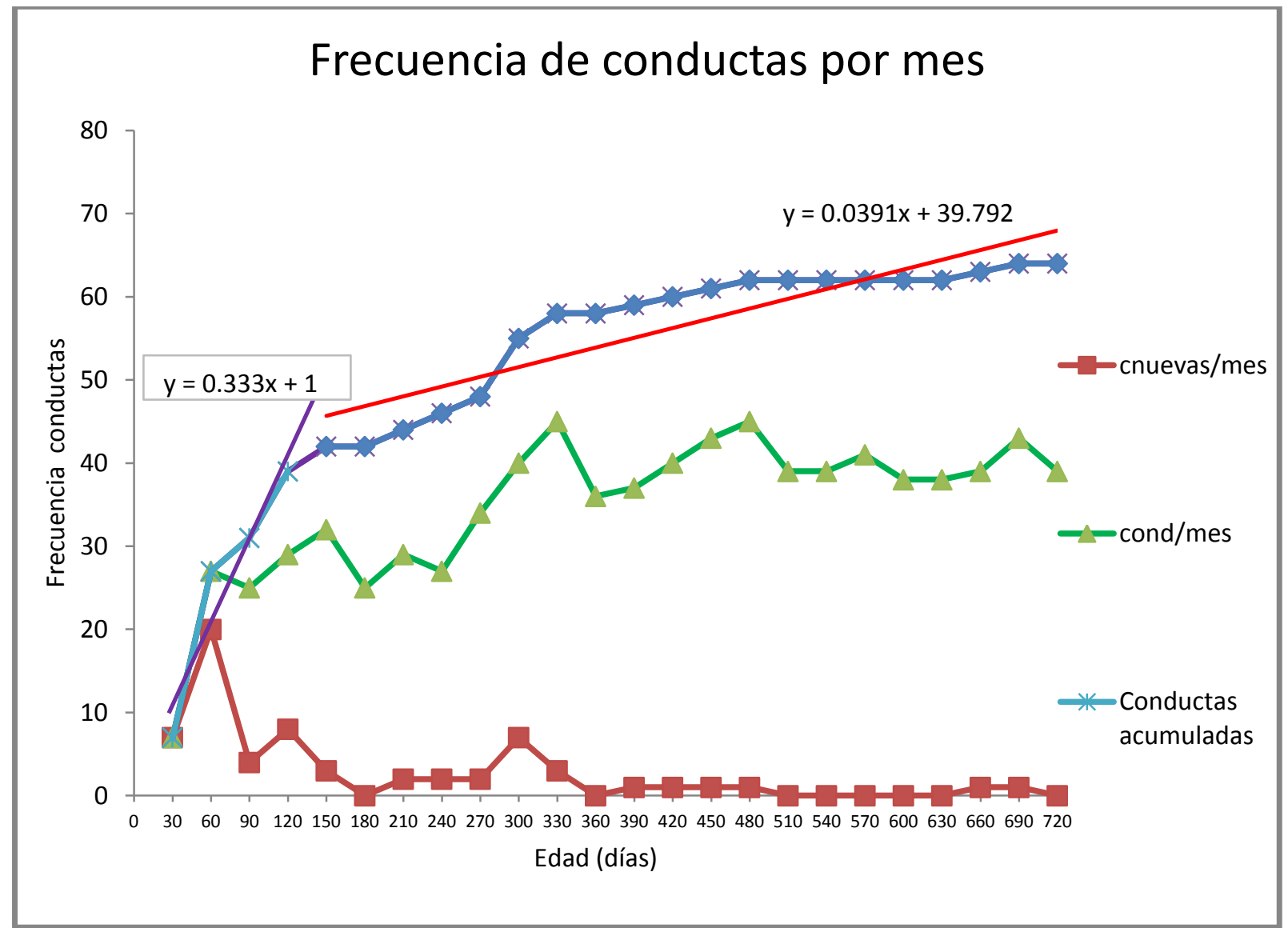

Figura No. 4. Frecuencias totales por mes. 


\section{$\underline{\text { Frecuencia relativa de las conductas }}$}

Las conductas con las mayores frecuencias relativas de los totales de todos los comportamientos fueron sumisión activa (11\%), sumisión de grupo (11\%) y juego con contacto corporal $(9 \%)$.

$\underline{\text { Frecuencias relativas por etapas de desarrollo }}$

Durante la etapa neonatal, que comprende los primeros 14 días de vida de los cachorros (Anexo II) sólo se registraron 2 conductas, huddling (se refiere al agrupamiento estrecho y dinámico de las crías para conservar su temperatura. Ver Anexo III) y mamar, la primera con una frecuencia relativa de $57 \%$, y la segunda con $43 \%$. Estos son los 2 elementos básicos para la supervivencia de las crías, la alimentación y la termorregulación (Figura No. 5).

\section{Conductas etapa neonatal}

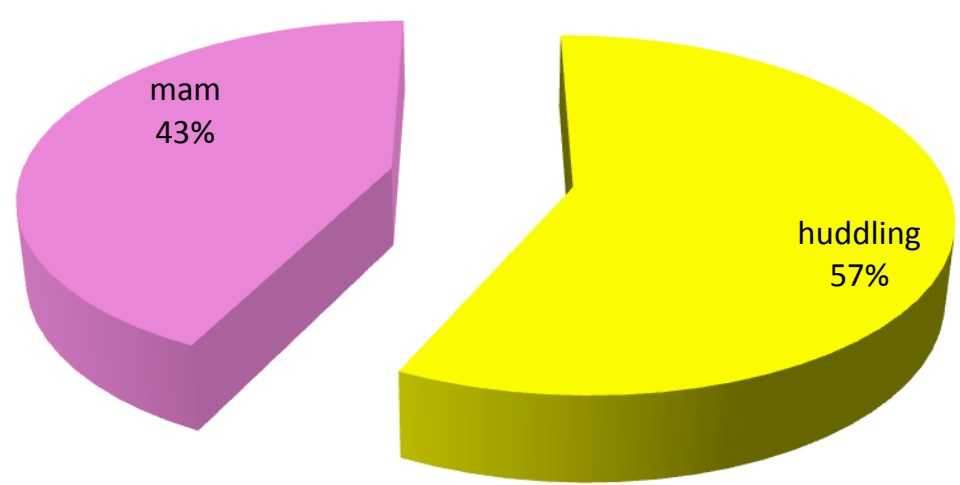

Figura No. 5. Frecuencias relativas de las conductas. Etapa neonatal. 
Durante la etapa de transición, que comprende del día 15 al 21 se registraron 4 comportamientos: huddling, mamar, juego con contacto corporal y amenaza ofensiva. De los cuales huddling ocupa la mayor proporción, con un $66 \%$, seguido por juego con contacto corporal con un $18 \%$, después mamar con un $15 \%$, y en menor proporción amenaza ofensiva con un 1\% (Figura No. 6).

Para esta etapa los cachorros han abierto los ojos y empieza a ser evidente su desarrollo psicomotriz, de ahí que juego y amenaza empiezan a tener cierta frecuencia, a pesar de que las actividades termorreguladoras siguen siendo las más dominantes. Las conductas de juego y amenaza aparecen en los últimos días del periodo.

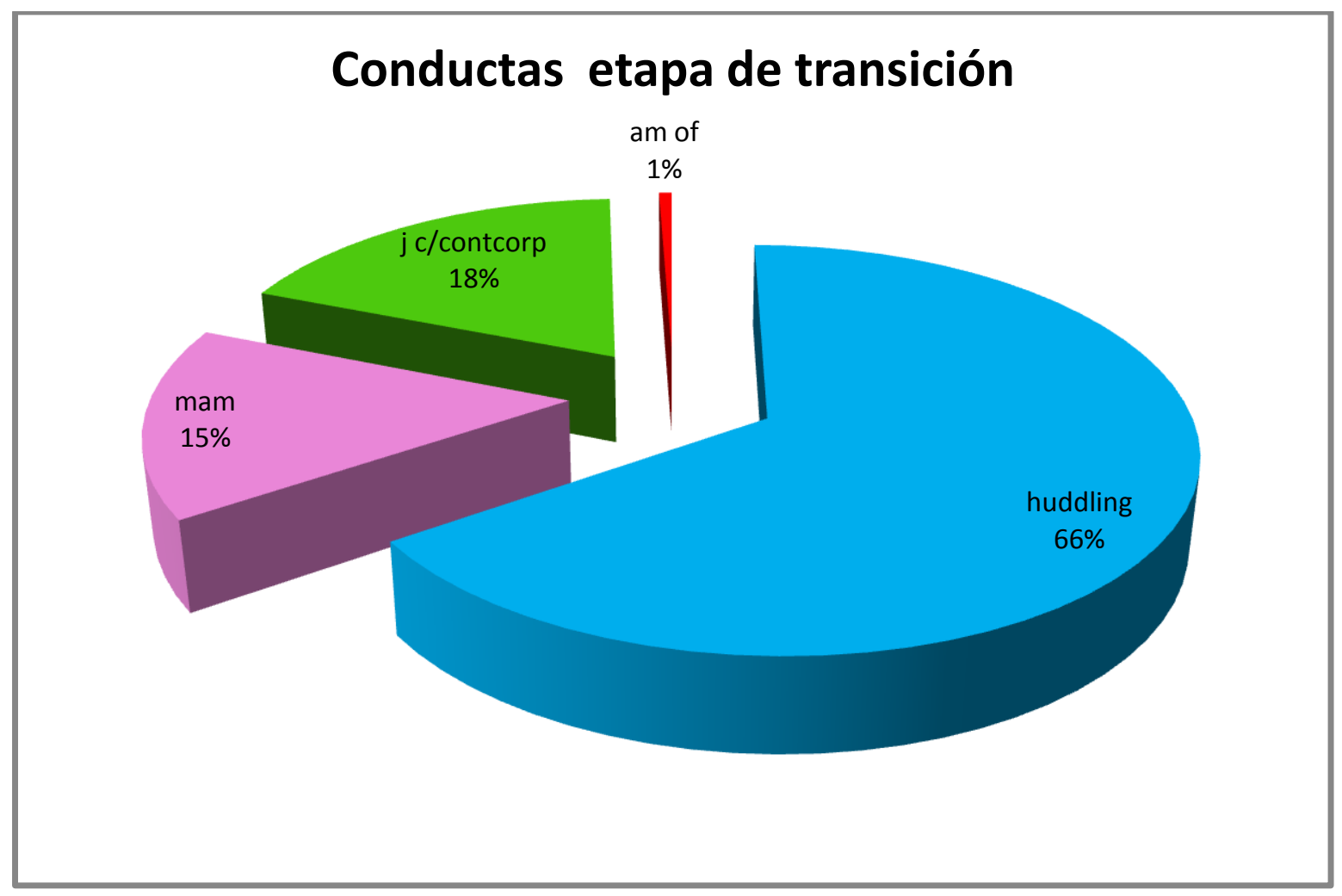

Figura No. 6. Frecuencia relativa de las conductas. Etapa de transición. 
En la etapa de socialización (21 a 120 días) se registraron un total de 38 comportamientos, de los cuales, los que ocupan la mayor proporción son: juego con contacto corporal con 24. 493\%, solicitud de carne con $11.076 \%$ y sumisión de grupo con $9.218 \%$. Si se consideran las categorías conductuales, se puede apreciar que, en diferentes tonos de verde, las conductas de juego ocupan una mayor proporción de la actividad de las crías, con un $40.516 \%$, seguidas por las de alimentación (en tonos de amarillo), con un 22.321\%, y las de sumisión (en tonos morados) con un $20.439 \%$ (Figura No. 7 ).

El desarrollo psicomotriz de los cachorros queda de manifiesto en la forma que van apareciendo las conductas, durante esta etapa, conforme van encontrando nuevos estímulos los cachorros desarrollan nuevas conductas. 


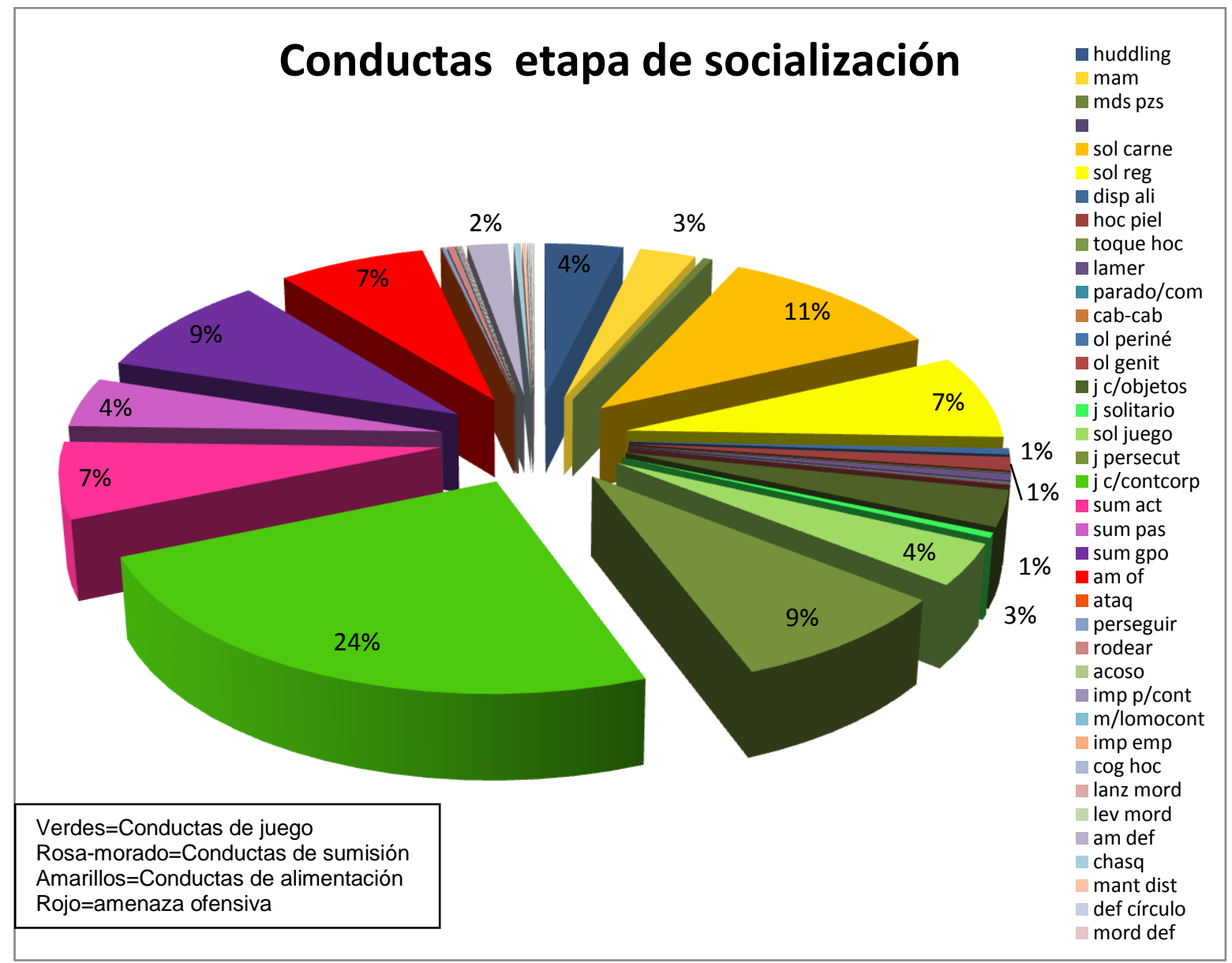

Figura No. 7. Frecuencia relativa de las conductas. Etapa de socialización.

Durante el período juvenil (mes 5 a 24) se registraron un total de 57 comportamientos diferentes, las que se muestran en mayor proporción son: sumisión activa con $13.003 \%$, sumisión de grupo con $11.552 \%$, juego con contacto corporal con $8.095 \%$ y juego con objetos con $7.649 \%$. Si se consideran por categorías, la que tiene una mayor proporción en esta etapa es la de agresión con $29.046 \%$, seguida de sumisión con $27.406 \%$, y las de juego con $21.416 \%$. Después siguen las de alimentación con $9.641 \%$, las defensivas con $5.425 \%$ y las amistosas con $3.490 \%$. Las que tienen una menor proporción son las sexuales con $1.513 \%$ y pseudosexuales con $0.028 \%$ (Figura No. 8). 
Durante esta etapa se completa el repertorio básico conductual de la especie, al inicio de la etapa los organismos casi han alcanzado la madurez del sistema nervioso central y su desarrollo psicomotriz, por lo que terminan de adquirir los elementos básicos, dejando para después aspectos finos que dependerán de la experiencia y la interacción con los adultos para su refinación. 


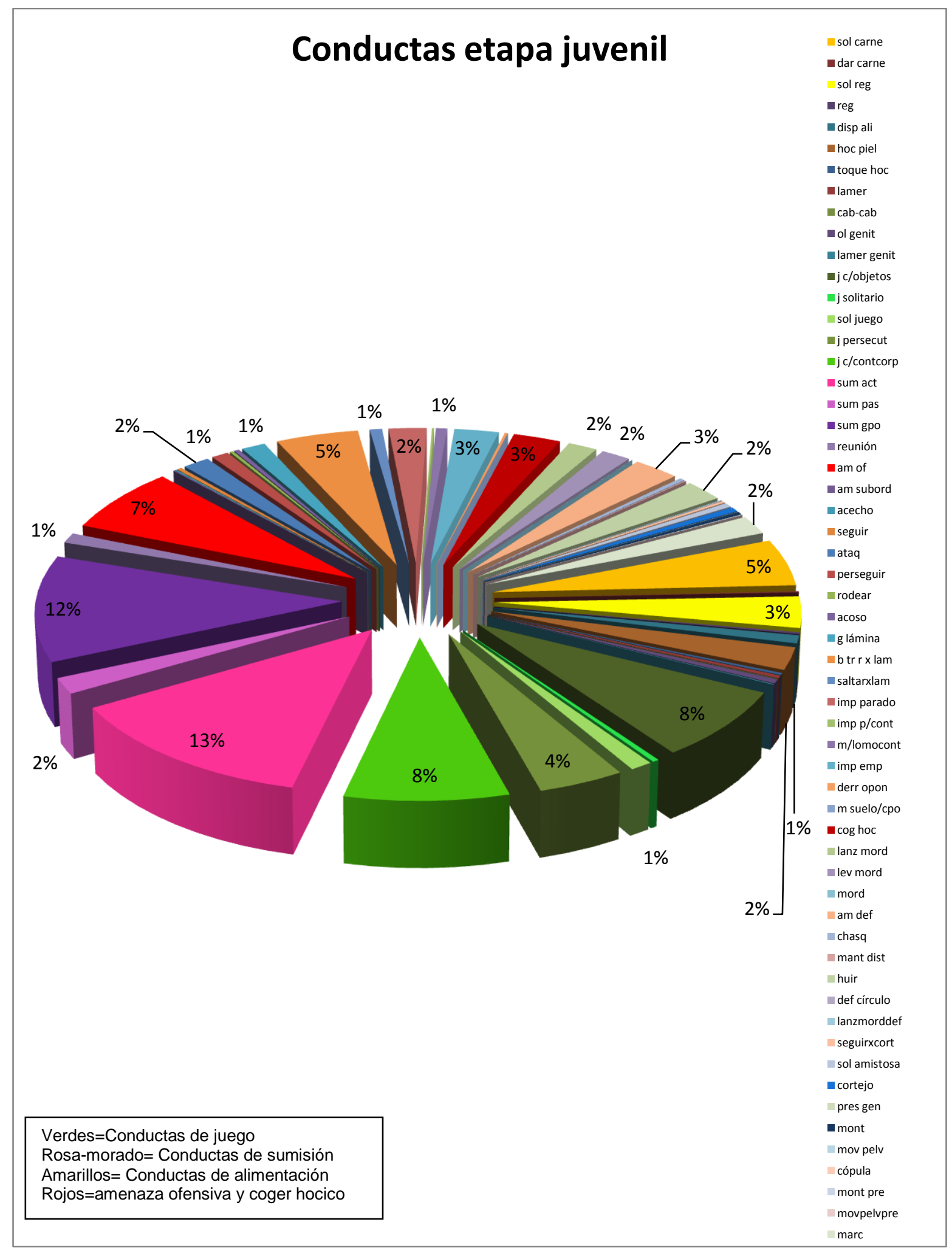

Figura No. 8. Frecuencia relativa de las conductas. Etapa juvenil. 


\section{$\underline{\text { Frecuencia relativa de las conductas por meses }}$}

Durante los primeros 4 meses de vida las conductas de mamar y huddling son muy importantes especialmente en el primer mes, pero para el segundo disminuyen notablemente, y más aún en el tercero, para desaparecer en el cuarto. Las conductas de solicitud de alimentación aparecieron en el segundo mes, solicitud de carne (23\%) en mayor proporción que solicitud de regurgitación (3\%), en el tercer $y$ cuarto mes las proporciones son similares $(7 \%$ y $9 \%$, respectivamente), pero en conjunto disminuyen un poco (Figura No. 9).

Juego con contacto corporal fue la conducta que se presentó en una mayor proporción durante los 4 meses $(34 \%, 26 \%, 18 \%, 22 \%)$, y en conjunto, las conductas de juego (en tonos verdes) fueron las más frecuentes y se incrementaron con el paso de los meses. Las conductas de sumisión, en tonos morados, aparecieron a partir del segundo mes con una frecuencia relativa de $4 \%$, se incrementaron notablemente para el tercero (23\%), y aumentaron otro poco en el cuarto, alcanzando un 30\% (Figura No. 9).

De las conductas de agresión destaca en color rojo amenaza ofensiva, que se presentó desde el primer mes con una frecuencia relativa de 22\%, se incrementó notablemente en el segundo (14\%), y disminuyó en el cuarto (1\%) (Figura No. 9). 
Esta etapa inicial establece las bases conductuales de los cachorros a través de la aparición sucesiva de las conductas (y desaparición de algunas) que los capacitan para la relación social que se da posteriormente.

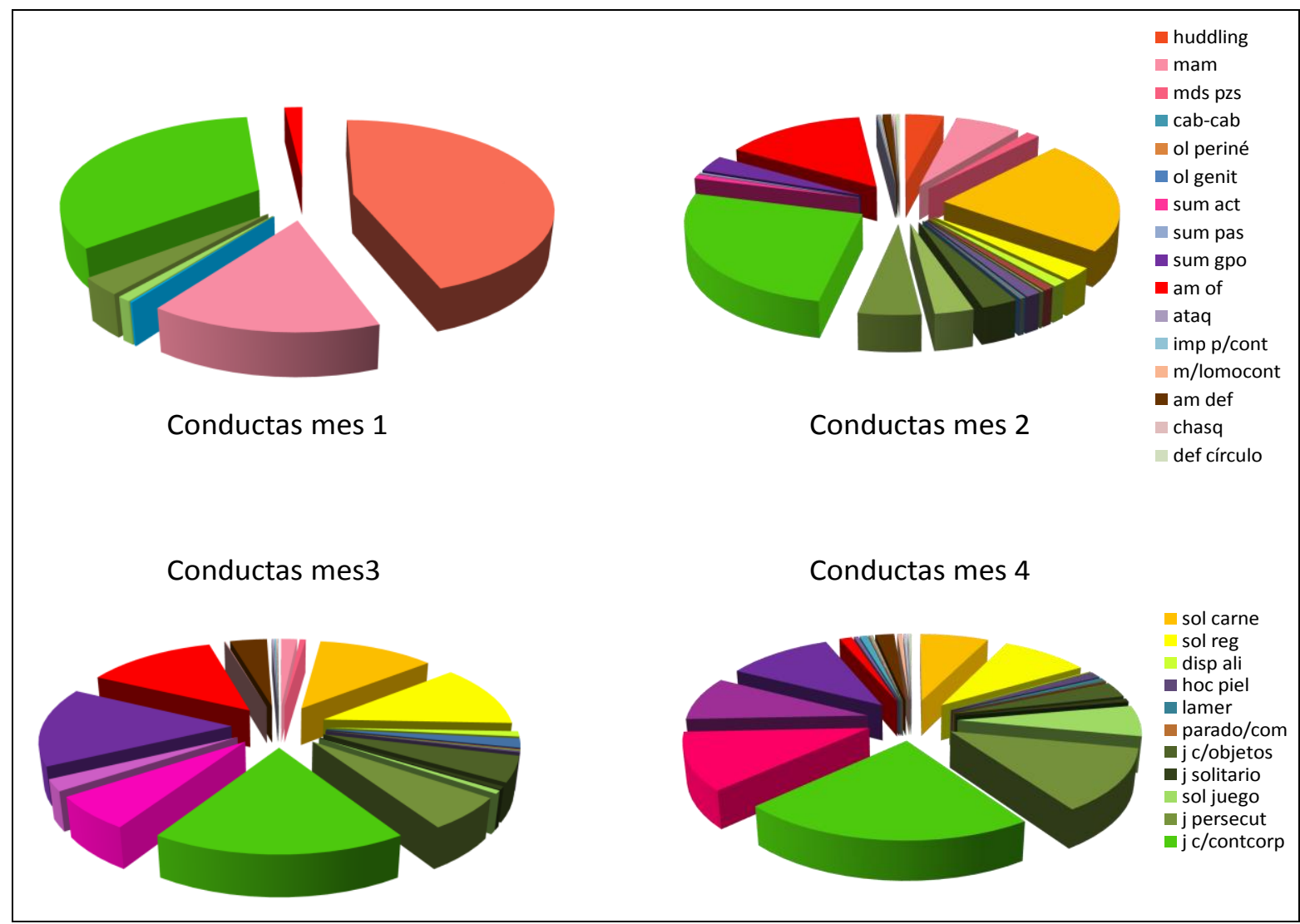

Figura No. 9. Frecuencia relativa de las conductas. Mes 1 a 4. Nótese la incorporación de nuevas conductas.

En los meses 5 a 8 las conductas más importantes fueron las de solicitud de alimentación (en amarillos), juego (en verdes) y sumisas (en morados).

En el mes 5 las más frecuentes fueron las de juego (38\%), seguidas por las de solicitud de alimentación (25\%) y las de sumisión (22\%), en el mes 6 se 
mantuvieron las proporciones del mes anterior, en el mes 7 las más frecuentes fueron las de solicitud de alimentación (30\%), seguidas por las de sumisión (29\%) y las de juego (27\%). En el mes 8 las más frecuentes fueron las de sumisión (41\%), seguidas por las de juego (27\%) y las de solicitud de alimentación (19\%) (Figura No. 10).

Se puede observar que las conductas de solicitud de alimentación se incrementaron del mes 5 al 7(25 a 30\%), pero en el 8 disminuyeron (19\%). Las conductas de juego tuvieron una ligera disminución entre el mes 5 y 8 (34 a 27\%). Por el contrario, las conductas de sumisión mostraron una tendencia a incrementarse (22 a 41\%) (Figura No. 10).

La frecuencia relativa de Solicitud de carne se incrementó del mes 5 al 7 (15\% a $20 \%)$, pero disminuye en el 8 (15\%); mientras que la de solicitud de regurgitación aumentó del mes 5 al $6(10 \%$ a 15\%), pero después disminuyó notablemente para el mes 8 (4\%). Juego con contacto corporal fue disminuyendo del mes 5 al 8 (18\% a 10\%), juego persecutorio también mostró una tendencia a disminuir (11\% a 5\%), solicitud de juego tuvo pocos cambios, juego con objetos presentó un pequeño incremento hasta el mes 8 (6\% a 10\%), y juego solitario se mantuvo en una baja proporción, con un valor de 1\% (Figura No. 10).

Sumisión activa disminuyó del mes 5 al $6(11 \%$ a $9 \%)$, pero después volvió a incrementarse (13\%), sumisión pasiva se mantuvo en baja proporción, con una ligera variación (entre 1\% y 4\%), y sumisión de grupo presentó una clara 
tendencia a incrementarse ( $7 \%$ a $25 \%)$. Amenaza ofensiva y amenaza defensiva se mantuvieron más o menos constantes y en baja proporción, con un valor de 3\% (Figura No. 10).

La diferencia cuantitativa de la proporción de las conductas permitió proponer la subdivisión de la etapa juvenil en subetapas (que se llamaron juvenil 1, 2, 3 y 4). La disminución en el porcentaje representado por la solicitud de alimento (carne o regurgitación) establece el fin de la sub etapa juvenil 1, ya que es el punto en el cual los cachorros dejan de depender de los adultos para alimentarse y se incluyen en la alimentación global de la manada. En la naturaleza corresponde al momento en que la manada abandona el sitio de crianza de los lobeznos.

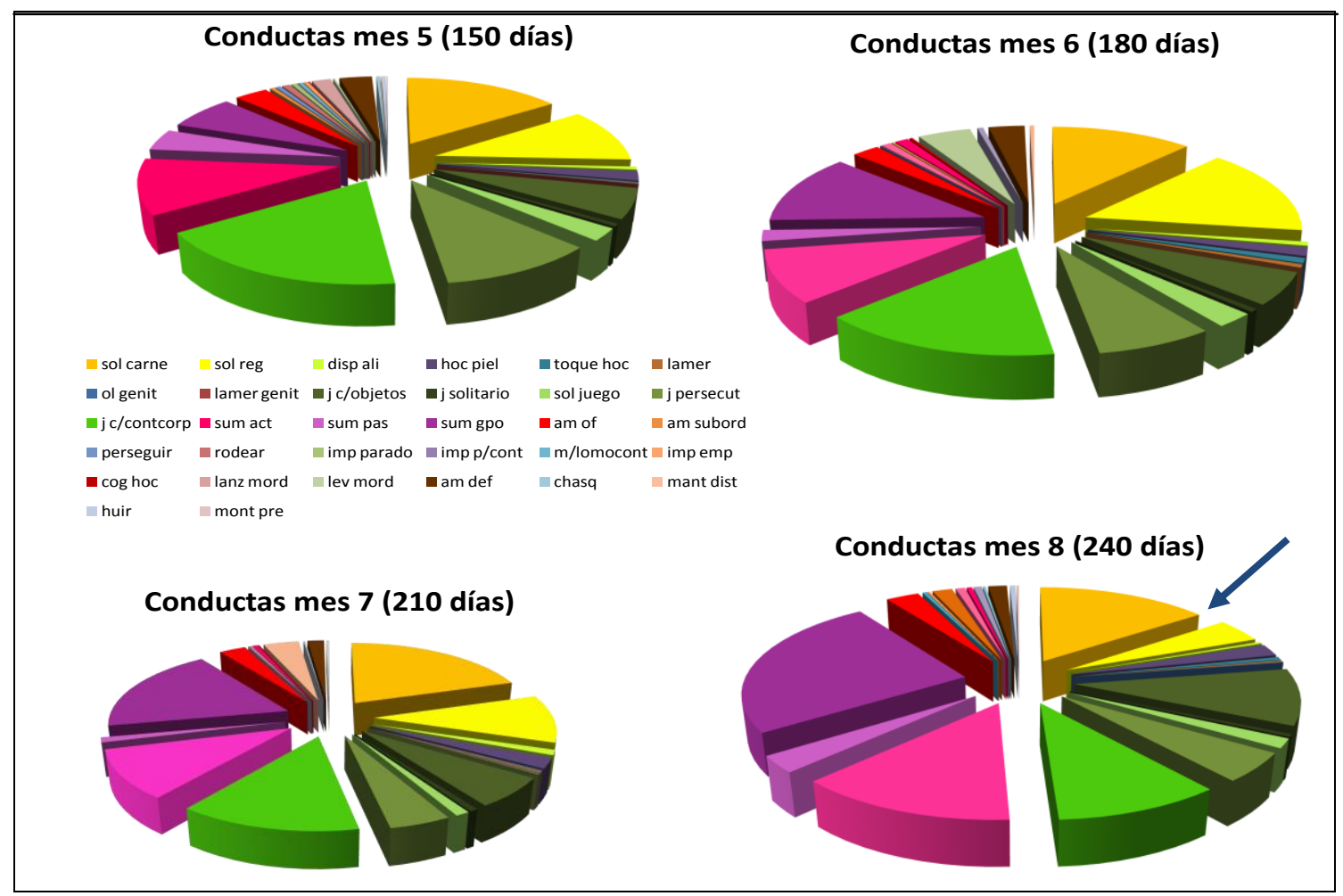

Figura No. 10. Frecuencia relativa de las conductas. Mes 5 a 8. La flecha indica la disminución en las conductas alimenticias (en tonos amarillos), que marcan el final de la sub etapa juvenil 1. 
Las conductas más frecuentes durante el mes 9 fueron: sumisión -en morados(33\%), juego -en verdes- (23\%) agresión (10.7\%) y solicitud de alimentación - en amarillos- (9\%) (Figura No. 11).

La frecuencia relativa de Juego con objetos fue mayor que en el mes anterior (10\% a $14 \%$, mientras que solicitud de juego, juego persecutorio y juego con contacto corporal disminuyeron con respecto al mes 8 (Figura No. 11).

Las conductas de sumisión tuvieron un ligero incremento con respecto al mes anterior, sumisión activa aumentó un poco (16\%), en tanto que sumisión pasiva (2\%) y sumisión de grupo (11\%) disminuyeron, particularmente ésta última. Las conductas de agresión aumentaron con respecto al mes anterior. Amenaza ofensiva (5\%) fue la más frecuente presentó un ligero incremento. De las conductas amistosas hocico-piel tuvo también un pequeño incremento en relación con el mes 8 (2\% a 4\%) (Figura No. 11).

En el mes 10 las proporciones de las conductas más frecuentes por categorías fueron: juego 32\%, sumisión 31\%, agresión (9.88\%) y solicitud de alimentación 7\%. De éstas últimas, solicitud de carne disminuyó, solicitud de regurgitación se mantuvo igual (Figura No. 11).

De las conductas amistosas, hocico-piel (6\%) se incrementó un poco con respecto al mes anterior. De las de juego, todas menos juego persecutorio tuvieron un pequeño decremento. De las de sumisión, sumisión activa (18\%) tuvo un ligero 
incremento, en tanto que sumisión de grupo (10\%) y reunión (1\%) disminuyeron, y sumisión pasiva (2\%) se mantuvo igual. De las de agresión, amenaza ofensiva (4\%) disminuyó un poco (Figura No. 11).

De los comportamientos defensivos, amenaza defensiva (4\%) tuvo un pequeño incremento, mientras que huir $(5 \%)$ presentó uno mayor. Es importante mencionar, que aunque es difícil de apreciar en la gráfica debido a su baja proporción, en este mes aparecieron las primeras conductas sexuales (Figura No. 11).

En el mes 11 las conductas de sumisión ocuparon el $31 \%$, las de juego el $29 \%$ y las de agresión el $17.5 \%$. Las de solicitud de alimentación tuvieron un notable decremento, pasando de 7 a 1\% (Figura No. 11).

En el mes 12 las conductas de sumisión se mantuvieron en $31 \%$, al igual que las de juego, con un 30\%; las de agresión se incrementaron hasta un $27.28 \%$ (Figura No. 11).

En el mes 13 los comportamientos de sumisión y juego disminuyeron hasta un $27 \%$, mientras que los de agresión se incrementaron hasta alcanzar un $34.14 \%$ (Figura No. 11). 
En el mes 14 las de agresión disminuyeron a un 30\%, las de juego descendieron hasta $21 \%$, mientras que las de sumisión tuvieron un modesto incremento a $31 \%$. (Figura No. 11)

En el mes 15 las conductas de agresión tuvieron un notable incremento, hasta alcanzar el $50.64 \%$, en tanto que las de sumisión descendieron a un $25 \%$, y las de juego tuvieron un importante decremento, llegando al 12\% (Figura No. 11).

De manera general, se puede apreciar que durante este período (mes 9 a 15) las conductas de solicitud de alimentación disminuyeron considerablemente, al igual que las de juego, particularmente juego persecutorio y juego con contacto corporal. Las de sumisión se mantuvieron en alrededor de $30 \%$ hasta el mes 15 que disminuyeron a un $25 \%$, mientras que los comportamientos agresivos tuvieron un muy importante incremento, pasando de 10.7 a $50.64 \%$, amenaza ofensiva se incrementó notablemente del mes 12 al 15 (2\% a 11\%), coger hocico (4\%) aumentó en el mes 15, y buscar, trotar, correr por lámina se incrementó del mes 11 al 13, disminuyó en el 14 y volvió a aumentar en el 15.

Las conductas de solicitud de alimentación se mantuvieron en muy bajas frecuencias hasta el mes 15, cuando tuvieron un pequeño incremento, además aparecieron por primera vez y en baja proporción, las conductas de dar carne $\mathbf{y}$ regurgitar (Figura No. 11). 
En el transcurso de los meses 9 a 15 se aprecia claramente la disminución en la proporción de las conductas de juego, que si bien fue gradual, permite, a los 15 meses la separación entre las sub etapas juvenil 2 y 3; ésto significa que, ontogenéticamente, la conducta de juego reduce su participación en el despliegue conductual de los lobos. Es aquí donde los organismos empiezan a incorporarse a la vida adulta. En la naturaleza, esta edad tiende a coincidir con una época de mayor probabilidad dispersión, para eventualmente buscar una pareja y formar su propia manada. 


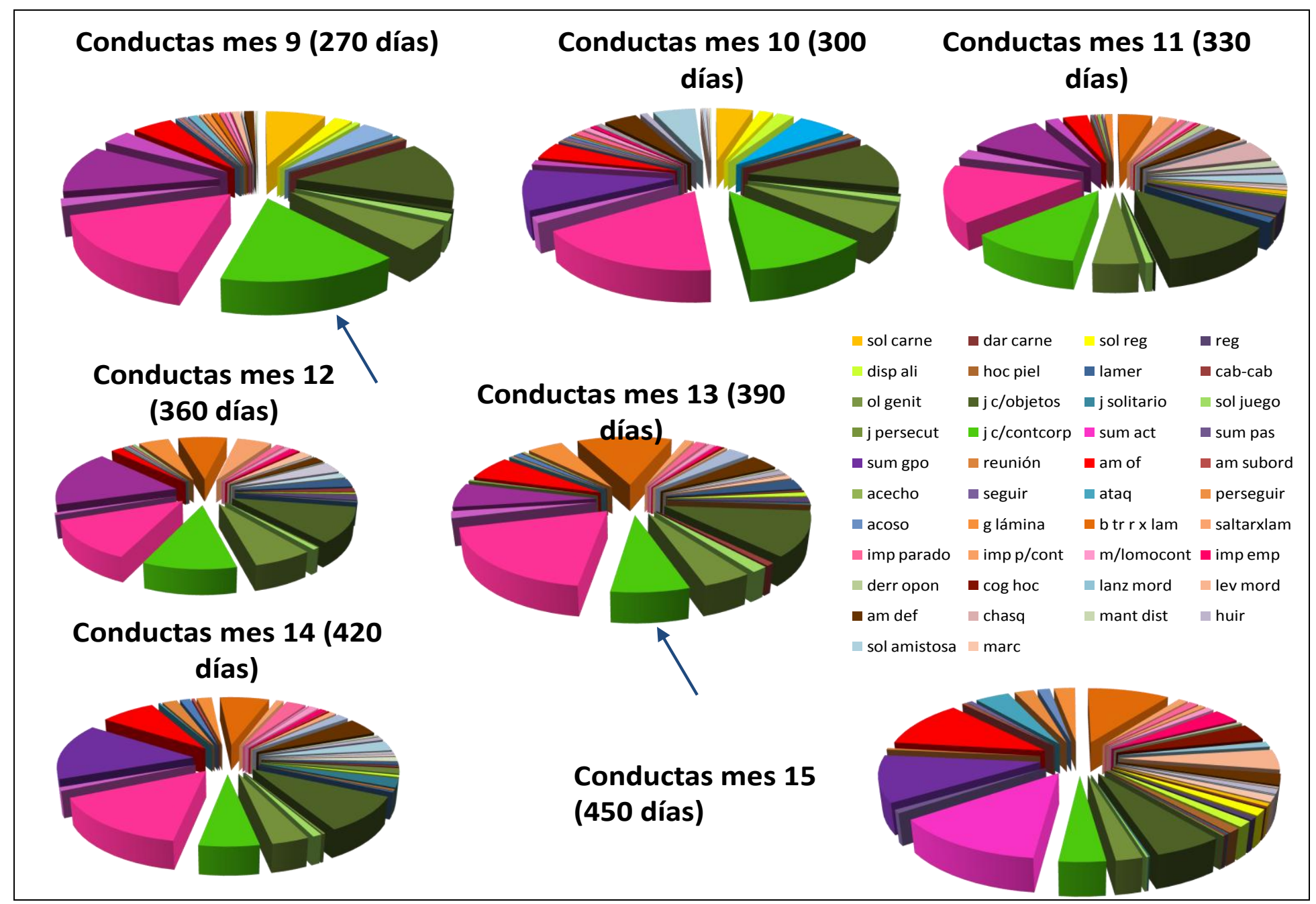

Figura No. 11. Frecuencia relativa de las conductas. Mes 9 a 15. Las flechas señalan la disminución en las conductas de juego (en tonos verdes), que son parte importante del final de la sub etapa juvenil 2 
En el mes 16 las conductas de agresión ocuparon el $46.93 \%$, seguidas por las de sumisión con $25 \%$ y las de juego con $14 \%$. En el mes 17 las de agresión representaron el 50.1\%, las de sumisión el 22\% y las de juego el 13\% (Figura No. 12).

En el mes 18 las de agresión se incrementaron al 53.69\%, las de sumisión disminuyeron al $20 \%$ y las de juego a $7 \%$. Para el mes 19 las agresivas disminuyeron al $49.3 \%$, las de sumisión se incrementaron al $29 \%$ y las de juego alcanzan el 8\%. En el mes 20 las de agresión descendieron a 43. 23\%, las de sumisión aumentaron al 37\% y las de juego disminuyeron a 6\% (Figura No. 12).

De manera general se observó que la frecuencia relativa de las conductas de juego continuó bajando, las de sumisión disminuyeron del mes 16 al 18 y se incrementaron en el 19 y 20 (Figura No. 12); en tanto que las agresivas primero descendieron un poco, después se incrementaron y disminuyeron en los meses 19 y 20, pero mantuvieron las mayores proporciones, alrededor del 50\% (Figura No. 12).

Con respecto a las conductas de solicitud de alimentación, la de solicitud de regurgitación tuvo un incremento en el mes 18 y después volvió a disminuir; ésto se presentó en aquéllos juveniles que convivieron con sus hermanos del año siguiente, lo que se podría entender como un intento de recuperar la alimentación por parte de los padres cuando éstos alimentan a los nuevos cachorros, pero también se observó cuando se perdía la nueva camada. Los comportamientos de 
dar carne y regurgitar desaparecieron para el mes 20; se observaron en aquellos juveniles que coexistieron con los lobeznos del siguiente año (Figura No. 12).

De las conductas de agresión, la más frecuente fue amenaza ofensiva, tuvo un pequeño incremento en el mes 17 (14\%), se mantuvo así y disminuyó en el mes $20(8 \%)$. Coger hocico se incrementó en el mes 16 (10\%), y después se mantuvo en un valor alrededor de 5\%. Buscar, trotar, correr por lámina se mantuvo en un $7 \%$ y disminuyó hasta el mes 20 . Las conductas de imposición se incrementaron a partir del mes 17, particularmente imposición parado e imposición por empujones (Figura No. 12). 


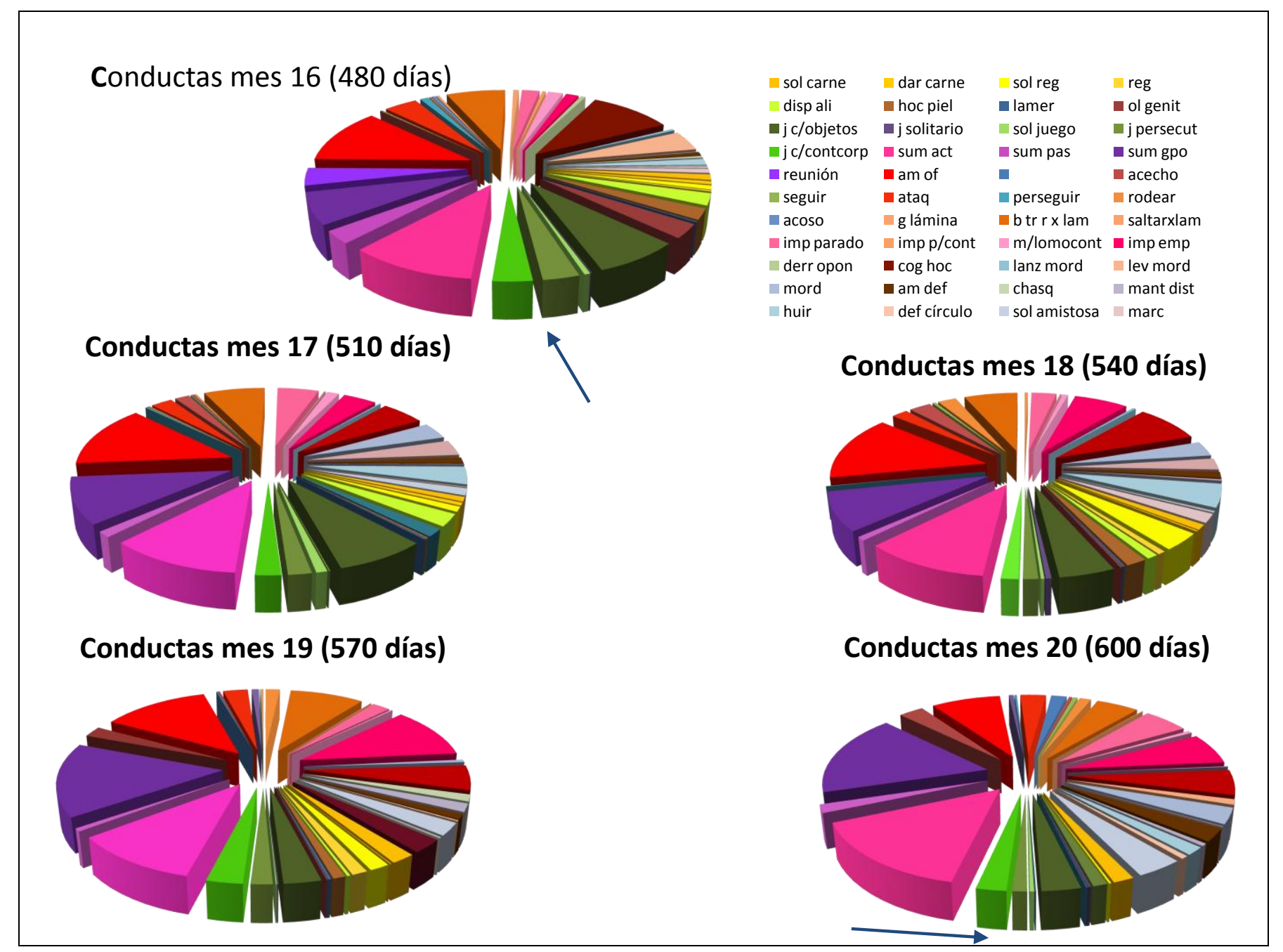

Figura No. 12. Frecuencia relativa de las conductas. Mes 16 a 20. Las flechas señalan la disminución en las conductas de juego (en tonos verdes), que junto al incremento en la proporción de conductas agonistas indican el final de la sub etapa juvenil 3. 
En el mes 21 las conductas de agresión ocuparon el 51.17\%, las de sumisión el $22 \%$ y las de juego el 11\%; en el mes 22 las agresivas representaron el 34.18\%, las de sumisión el $26 \%$ y las de juego el 13\%. Para el mes 23 las agresivas representaron el $28.21 \%$, las sumisas el $22 \%$ y las de juego el $8 \%$, y finalmente en el mes 24 las de agresión representaron el $30.54 \%$, las de sumisión el $22 \%$ y las de juego el 16\% (Figura No. 13).

Es importante señalar la aparición de las conductas sexuales del mes 22 al 24, a pesar de que no se aprecian bien en la gráfica (en tonos azul claro y azul obscuro), dado se que registraron con baja frecuencia (Figura No. 13).

Las conductas agresivas se incrementaron en el mes 21, disminuyeron en el 22 y 23, y tuvieron un pequeño incremento en el 24. Amenaza ofensiva descendió de $11 \%$ a $8 \%$, las conductas de imposición empezaron a disminuir a partir del mes 22, coger hocico se mantuvo en $4 \%$ en los meses 21 y 22, aumentó a $8 \%$ en el mes 23 y disminuyó a 3\% para el mes 24 . Buscar, trotar, correr por lámina descendió del mes 21 a $23(10 \%$ a 1\%) y se incrementó un poco en el mes 24 (3\%) (Figura No. 13).

Los comportamientos de sumisión disminuyeron en el mes 21, aumentaron un poco en el mes 22, y volvieron a bajar en el 23 , en el 24 se mantuvieron igual. Sumisión activa disminuyó en el mes 21 , se incrementó en el 22 y 23, volvió a disminuir en el 24; mientras que sumisión de grupo tuvo una tendencia a disminuir. La conducta de reunión disminuyó hasta desaparecer en el mes 24. Las 
conductas de juego disminuyen del mes 21 a 23 y en el 24 se incrementan un poco, se mantienen en baja proporción (Figura No. 13).

La presencia de las conductas sexuales y el repertorio conductual completo caracterizan a la sub etapa juvenil 4. Los individuos se integran completamente a la vida social en manada, pueden reproducirse o pueden dispersarse para formar su propia familia. 


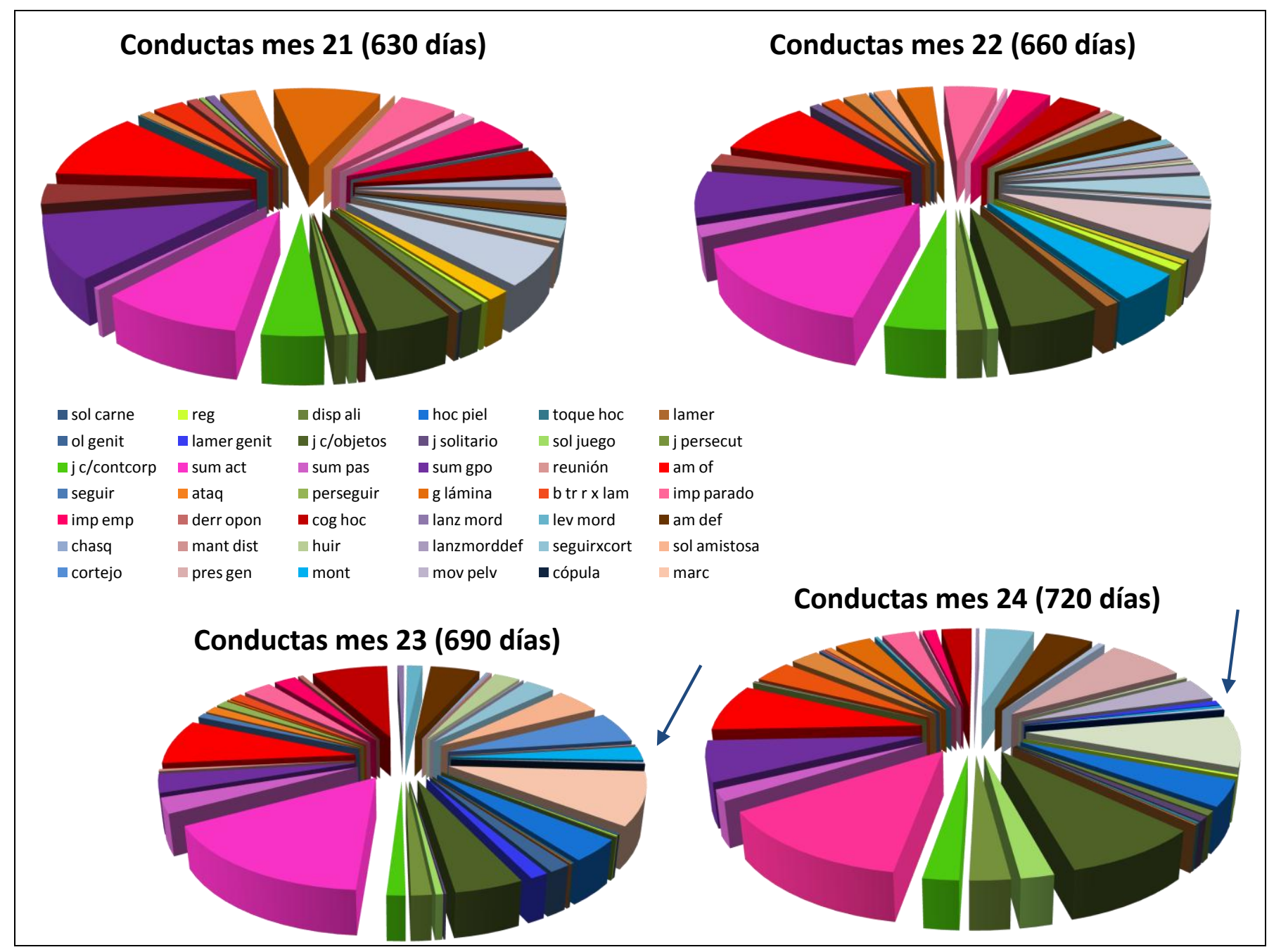

Figura No. 13. Frecuencia relativa de las conductas. Mes 21 a 24. Las flechas señalan la aparición de las conductas sexuales, que son las que caracterizan la subetapa juvenil 4. 


\title{
Discriminación de las etapas usando análisis multivariado
}

\author{
$\underline{\text { Primeras etapas }}$
}

Análisis discriminante canónico

La descripción de los grupos de repetición se muestra en el Cuadro No. 5:

Cuadro No. 5. Edades propuestas para las etapas de desarrollo.

\begin{tabular}{|l|l|}
\hline Etapa & Edad \\
\hline Neonatal. & Día 1 a 14 \\
\hline Transición. & Día 15 a 21 \\
\hline Socialización. & Día 22 a 120 \\
\hline Juvenil 1. & Mes 5 a 8 \\
\hline Juvenil 2. & Mes 9 a 15 \\
\hline Juvenil 3. & Mes 16 a 20 \\
\hline Juvenil 4. & Mes 21 a 24 \\
\hline
\end{tabular}

Los resultados de este primer análisis discriminante canónico (Cuadro No. 6 y 7) demuestran que la emisión de las conductas corresponden en un $85.9 \%$ a las diferentes etapas. La primera variable canónica explica un $97.8 \%$ de la variación observada en este fenómeno. 
Las conductas que tienen una mayor aportación a la primera variable canónica son: mamar, huddling y hocico-piel.

Cuadro No. 6. Análisis de variables canónicas.

\begin{tabular}{|l|r|r|c|l|l|r|r|r|l|l|}
\hline Función & Eigenvalor & \% & \% acum & \multicolumn{1}{l|}{ Corr } & Corr2 & F & \multicolumn{1}{l|}{ gl } & \multicolumn{1}{l|}{ gl } & Prob & Lambda Wilks \\
\hline 1 & 6.6573 & 97.8 & 97.8 & 0.9324 & 0.8694 & 15.4 & 26. & 204.0 & 0.0000 & 0.113538 \\
\hline 2 & 0.1502 & 2.2 & 100.0 & 0.3614 & 0.1306 & 1.3 & 12. & 103.0 & 0.2361 & 0.869407 \\
\hline
\end{tabular}

Cuadro No. 7. Coeficientes estandarizados de las variables canónicas.

\begin{tabular}{|l|l|l|}
\hline Variable & $\begin{array}{l}\text { Coeficiente estandarizados } \\
\text { Variable canónica1 }\end{array}$ & $\begin{array}{l}\text { Coeficientes estandarizados } \\
\text { Variable canónica2 }\end{array}$ \\
\hline Huddling & -1.212433 & -0.483439 \\
\hline Mam & -1.245793 & 0.589391 \\
\hline mds_pzs & 0.065547 & -0.028206 \\
\hline sol_ali_gral & 0.019336 & 0.053785 \\
\hline j_c_contcorp & 0.489483 & -0.245946 \\
\hline am_of & 0.127813 & 0.029091 \\
\hline sum_act & 0.059840 & 0.003854 \\
\hline sol_juego & 0.060606 & 0.122267 \\
\hline j_persecut & -0.119816 & 0.128715 \\
\hline sum_pas & 0.010106 & 0.038853 \\
\hline sum_gpo & -0.014305 & -0.008487 \\
\hline j_c_objetos & 0.155816 & -0.044857 \\
\hline hoc_piel & 0.528084 & -0.157043 \\
\hline
\end{tabular}


El análisis canónico muestra que es posible hacer una clara separación entre las etapas neonatal y socialización con la primera variable canónica, mientras que para separar las etapas neonatal y de transición se requiere la segunda variable canónica (Figura No. 14).

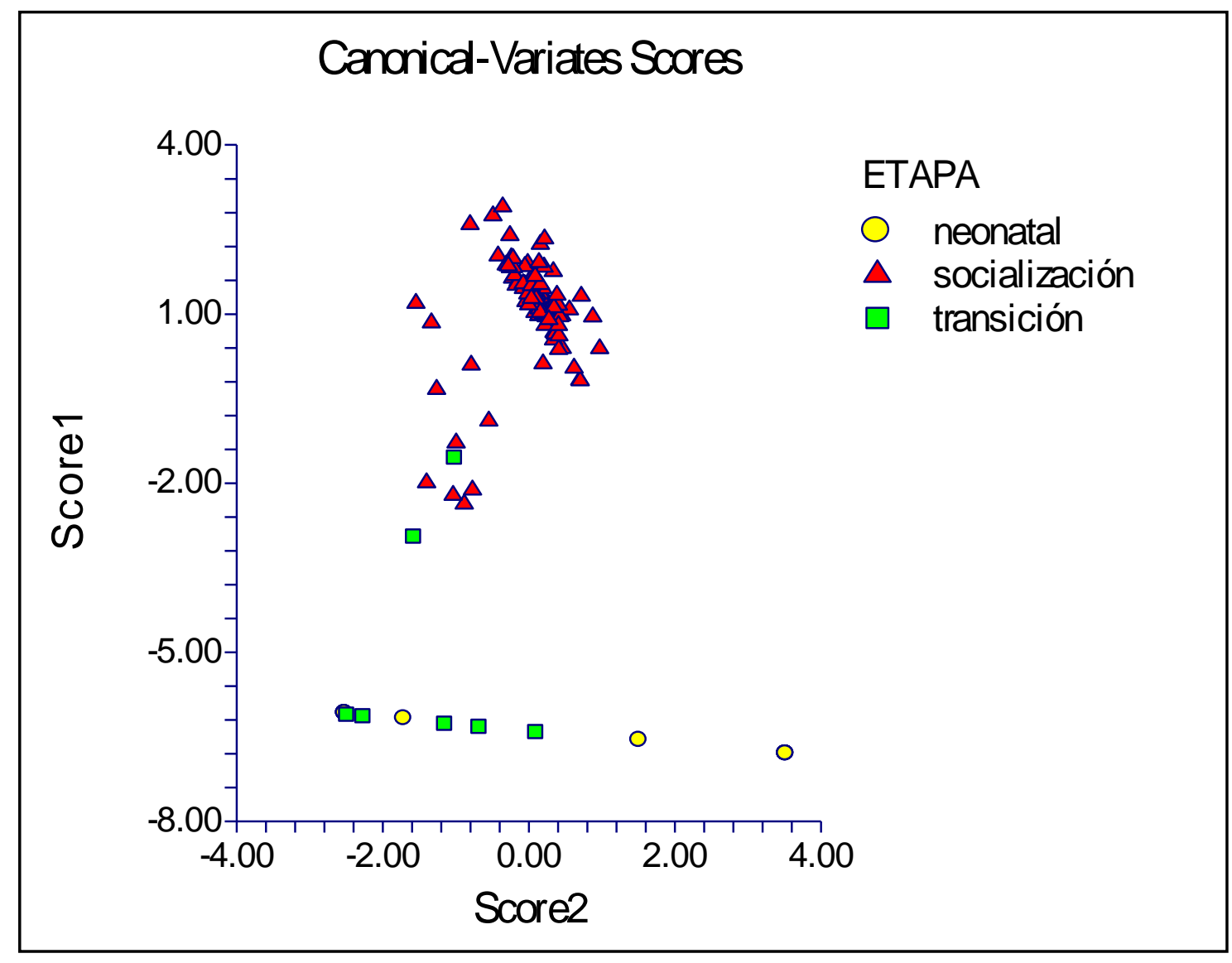

Figura No. 14. Análisis discriminante canónico. Etapas neonatal a socialización. Gráfica de la primera y segunda variables canónicas. 
Análisis de errores de clasificación discriminante

\section{Clasificación correctas y erróneas}

El resultado del análisis discriminante para las etapas neonatal, de transición y socialización indica que en general hay una correspondencia muy buena de los datos con la etapa de socialización (89.74\%), mientras que para la etapa de transición es del $71.42 \%$ y para la etapa neonatal del $45.45 \%$ (Cuadro No.8).

Cuadro No. 8. Análisis discriminante. Etapas neonatal a socialización.

\begin{tabular}{|l|l|l|l|}
\hline & No. Bien clasificados & No. Mal clasificados & Total \\
\hline Neonatal & 5 & 6 & 11 \\
\hline Transición & 5 & 2 & 7 \\
\hline Socialización & 95 & 4 & 99 \\
\hline Total & 105 & 12 & 117 \\
\hline
\end{tabular}




\section{Etapa Juvenil}

\section{Análisis discriminante canónico}

Los resultados indican que las conductas corresponden en un $100 \%$ a las subetapas propuestas. La primera variable canónica explica el $99.4 \%$ de la variación del fenómeno, mientras que la segunda el $0.5 \%$ de dicha variación. Las conductas que tienen una mayor aportación a la primera variable canónica son: sumisión pasiva, solicitud de juego, Sumisión activa y. juego persecutorio (Cuadros No. 9 y 10).

Cuadro No. 9. Análisis de variables canónicas. Etapa juvenil.

\begin{tabular}{|l|r|r|r|l|l|r|r|r|r|l|}
\hline Función & \multicolumn{1}{|c|}{ Eigenvalor } & \multicolumn{1}{|c|}{$\%$} & \%acum & Corr & Corr2 & F & \multicolumn{1}{|l|}{ gl } & gl & Prob & Lambda Wilks \\
\hline 1 & 10333.64664 & 99.4 & 99.4 & 1.0000 & 0.9999 & 10.9 & 48.0 & 3.8 & 0.0187 & 0.000000 \\
\hline 2 & 55.78097 & 0.5 & 100.0 & 0.9912 & 0.9824 & 1.9 & 30.0 & 4.0 & 0.2842 & 0.004331 \\
\hline 3 & 3.06681 & 0.0 & 100.0 & 0.8684 & 0.7541 & 0.7 & 14.0 & 3.0 & 0.7476 & 0.245893 \\
\hline
\end{tabular}

Cuadro No. 10. Coeficientes estandarizados de las variables canónicas. Etapa juvenil.

\begin{tabular}{|l|l|l|}
\hline Variable & $\begin{array}{l}\text { Coeficientes estandariza } \\
\text { Variable canónica1 }\end{array}$ & $\begin{array}{l}\text { Coeficientes estandariza } \\
\text { Variable canónica2 }\end{array}$ \\
\hline sol_ali_gral & -17.236105 & 1.108281 \\
\hline j_c_contcorp & 25.028513 & 1.256108 \\
\hline am_of & 8.839444 & 1.735897 \\
\hline sum_act & 26.918225 & 2.791627 \\
\hline sol_juego & -29.715911 & -1.926227 \\
\hline j_persecut & 26.090396 & 4.246202 \\
\hline sum_pas & -38.115217 & -1.897247 \\
\hline sum_gpo & -11.214203 & 2.554052 \\
\hline j_c_objetos & 9.573762 & 0.928629 \\
\hline hoc_piel & 1.873960 & -1.472672 \\
\hline Mont & 2.702395 & 2.242850 \\
\hline lev_mord & 17.630217 & 2.232108 \\
\hline dar_carne & 10.970693 & 0.646867 \\
\hline Reg & -0.402017 & 0.400395 \\
\hline disp_ali & -10.948202 & 0.512439 \\
\hline toque_hoc & 7.548896 & 0.670196 \\
\hline & & \\
\hline
\end{tabular}


El análisis canónico muestra una clara separación entre las diferentes subetapas de la etapa juvenil tomando en cuenta las primeras dos variables canónicas, aunque cabe señalar que la primera variable canónica no hace una separación muy clara entre las sub etapas 3 y 4, pero es con la segunda variable canónica que se puede observar una evidente separación entre éstas (Figura No. 15).

Estos resultados indican que existe una discriminación entre las subetapas propuestas para la etapa juvenil.

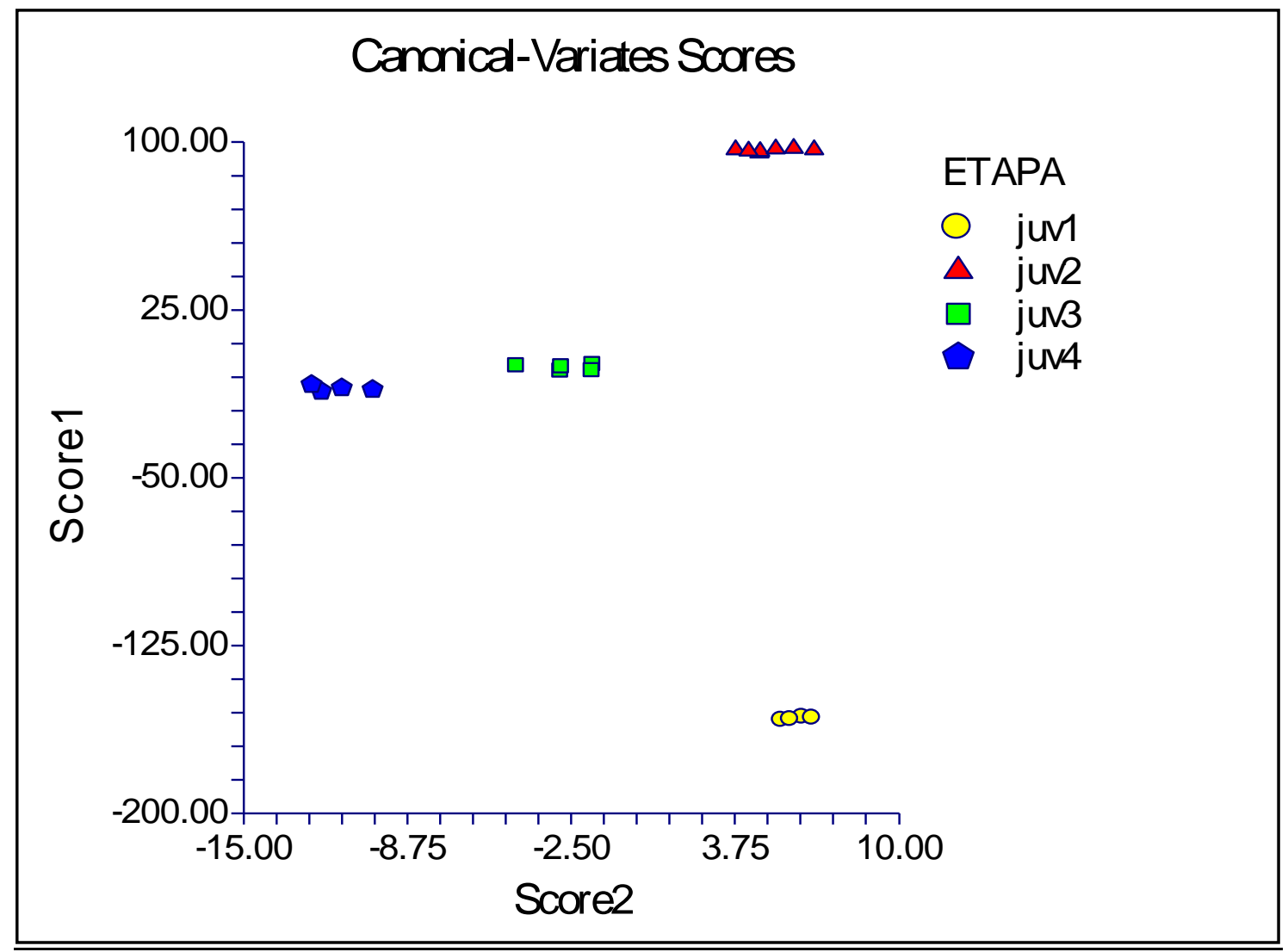

Figura No. 15. Análisis discriminante canónico. Etapa juvenil. Gráfica de la primera y segunda variables canónicas 
Análisis de errores de clasificación discriminante

\section{Clasificación correctas y erróneas}

Los resultados del análisis discriminante de la etapa juvenil indican que las sub etapas descritas fueron bien caracetizadas por los registros incluidos, ya que no se registró ningún elemento mal clasificado (Cuadro No. 11).

Cuadro No. 11. Análisis discriminante. Etapa juvenil.

\begin{tabular}{|l|l|l|l|}
\hline & No. Bien clasificados & No. Mal clasificados & Total \\
\hline Juvenil 1 & 4 & 0 & 4 \\
\hline Juvenil 2 & 7 & 0 & 7 \\
\hline Juvenil 3 & 5 & 0 & 5 \\
\hline Juvenil 4 & 4 & 0 & 4 \\
\hline Total & 20 & 0 & 20 \\
\hline
\end{tabular}




\section{Frecuencia mensual por conducta}

Las categorías conductuales más frecuentes durante el primer año de vida fueron las alimenticias -que se refieren a aquellos comportamientos por medio de los cuales obtienen su alimento y lo defienden- $y$ las de juego, en tanto que las menos frecuentes fueron las sexuales, defensivas y amistosas. Durante el segundo año de vida las más frecuentes fueron las de agresión y las sumisas, las menos frecuentes fueron las sexuales y marcaje. Esto indica que los juveniles se incorporan gradualmente a la manada presentando conductas de sumisión y agresión (Figura No 16).

Cada una de las 64 conductas siguió un patrón diferente a lo largo de los 24 meses del desarrollo. La frecuencia de las conductas puede ser dividida claramente aproximadamente en cada uno de los dos años estudiados. Durante los 12 primeros meses las conductas más frecuentes fueron solicitud de alimento

y juego con contacto corporal. Para el segundo año las conductas que más frecuentes son sumisión activa, sumisión de grupo y amenaza ofensiva.

Esto permite distinguir ambas etapas en la formación conductual de los lobos; así, el primer año está dominado por la necesidad de alimentarse y el juego con otros individuos, con todos los beneficios que se han reportado (fortaleza, crecimiento, sociabilidad); mientras que en el segundo la incorporación a la estructura social de la manada se vuelve más relevante, particularmente en las condiciones de estudio que no permiten la dispersión de los juveniles. 


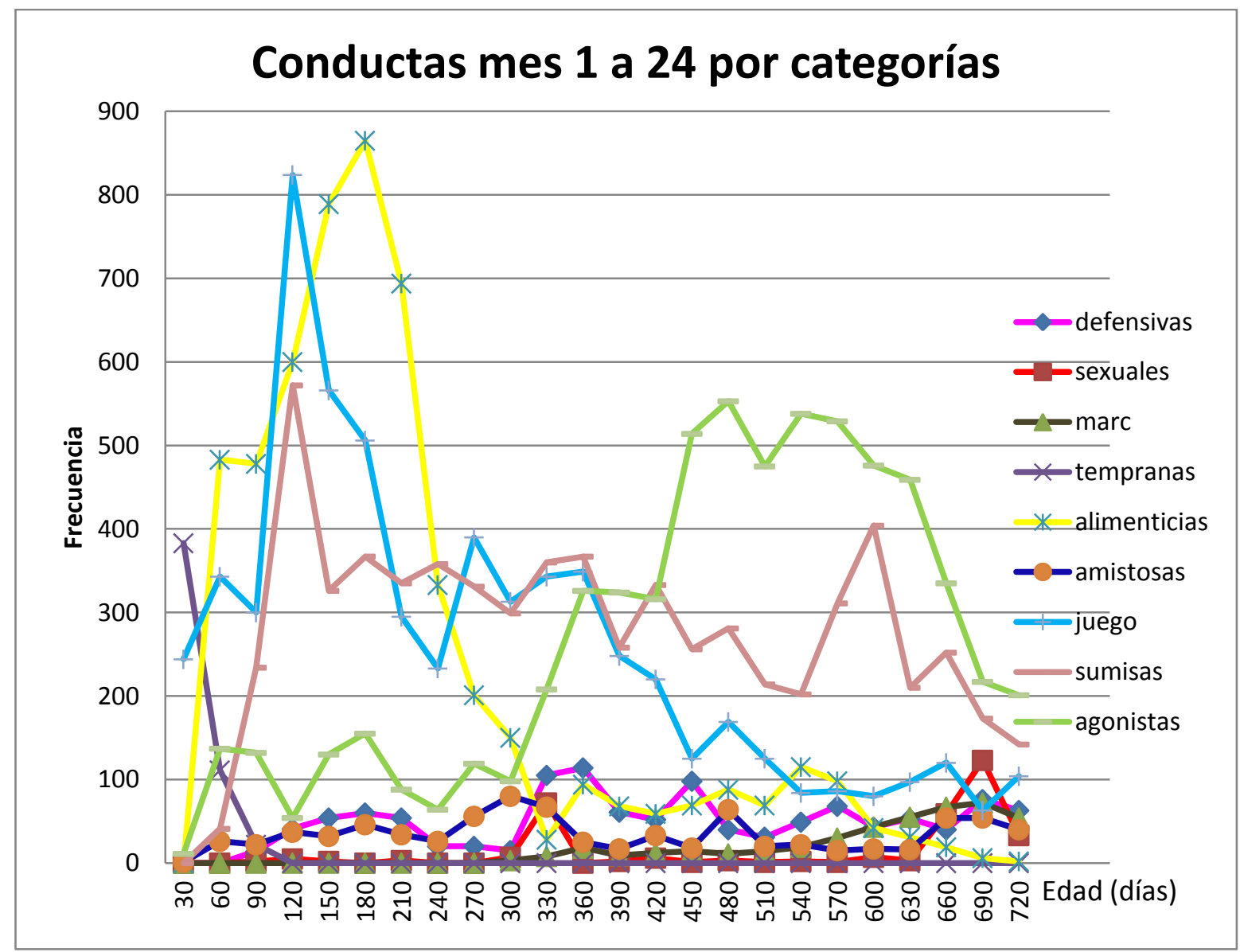

Figura No. 16. Frecuencias totales mensuales de las conductas por categorías.

En las conductas de los cachorros y juveniles machos, se pudo observar que en el primer mes de vida mamar y huddling fueron importantes, en los siguientes meses destacaron solicitud de alimento en general y juego con contacto corporal, y con una frecuencia menor se distinguieron solicitud de carne, solicitud de regurgitación, juego persecutorio, y sumisión de grupo; amenaza ofensiva incrementó su frecuencia entre los 2 y 3 meses, después disminuye. A partir de los 10 meses, las conductas más frecuentes fueron sumisión de grupo y sumisión activa, mientras que con menor frecuencia se pudieron apreciar amenaza ofensiva, buscar, trotar, correr por lámina y coger hocico. 
En las conductas exhibidas por los cachorros y juveniles hembras, se pudo observar que en el primer mes mamar y huddling son importantes, más adelante se destacaron solicitud de alimento en general y juego con contacto corporal, y con una frecuencia menor, solicitud de carne, solicitud de regurgitación, sumisión de grupo y sumisión activa. Amenaza ofensiva incrementó su frecuencia entre los 2 y 3 meses, pero disminuyó después. A partir de los 10 meses de edad las conductas más frecuentes fueron sumisión de grupo, sumisión activa. Amenaza ofensiva incrementó su frecuencia entre los 16 (480 días) y 20 meses. Coger hocico presentó sus mayores frecuencias a los 16 meses. Imposición por empujones e imposición parado se incrementaron a partir de los 19 meses (570 días).

Con estos datos no fue posible determinar una diferencia entre el comportamiento de los machos y las hembras, además, el número de ejemplares de uno y otro género en este estudio no fue equivalente, en varias camadas la proporción de sexos favoreció a los machos. Sin embargo estos resultados son explicables si se considera que el rol que jugarán ambos sexos en la vida adulta no será muy diferente, por lo que la ontogenia del comportamiento no parece tener diferencias.

\section{$\underline{\text { Conductas Tempranas }}$}

Las conductas llamadas tempranas sólo se presentan durante los primeros meses de vida y después desaparecen. 
Las conductas de mamar y mordisquear pezones son de tipo alimenticio, y huddling está relacionada con el mantenimiento de la temperatura corporal. La conducta de mamar tuvo una elevada frecuencia durante el primer mes de vida, descendió durante el segundo, llegó casi a cero en el tercer mes y desapareció en el cuarto (Figura No. 17).

Mordisquear pezones sólo se presentó durante el segundo y tercer mes, con muy bajas frecuencias: mientras que huddling se registró con una elevada frecuencia en el primer mes de vida, disminuyó notablemente durante el segundo, y desapareció en el tercero (Figura No. 17).

Las conductas manifiestan claramente la maduración física de los individuos que van dejando las conductas que físicamente lo ligan con la madre. 


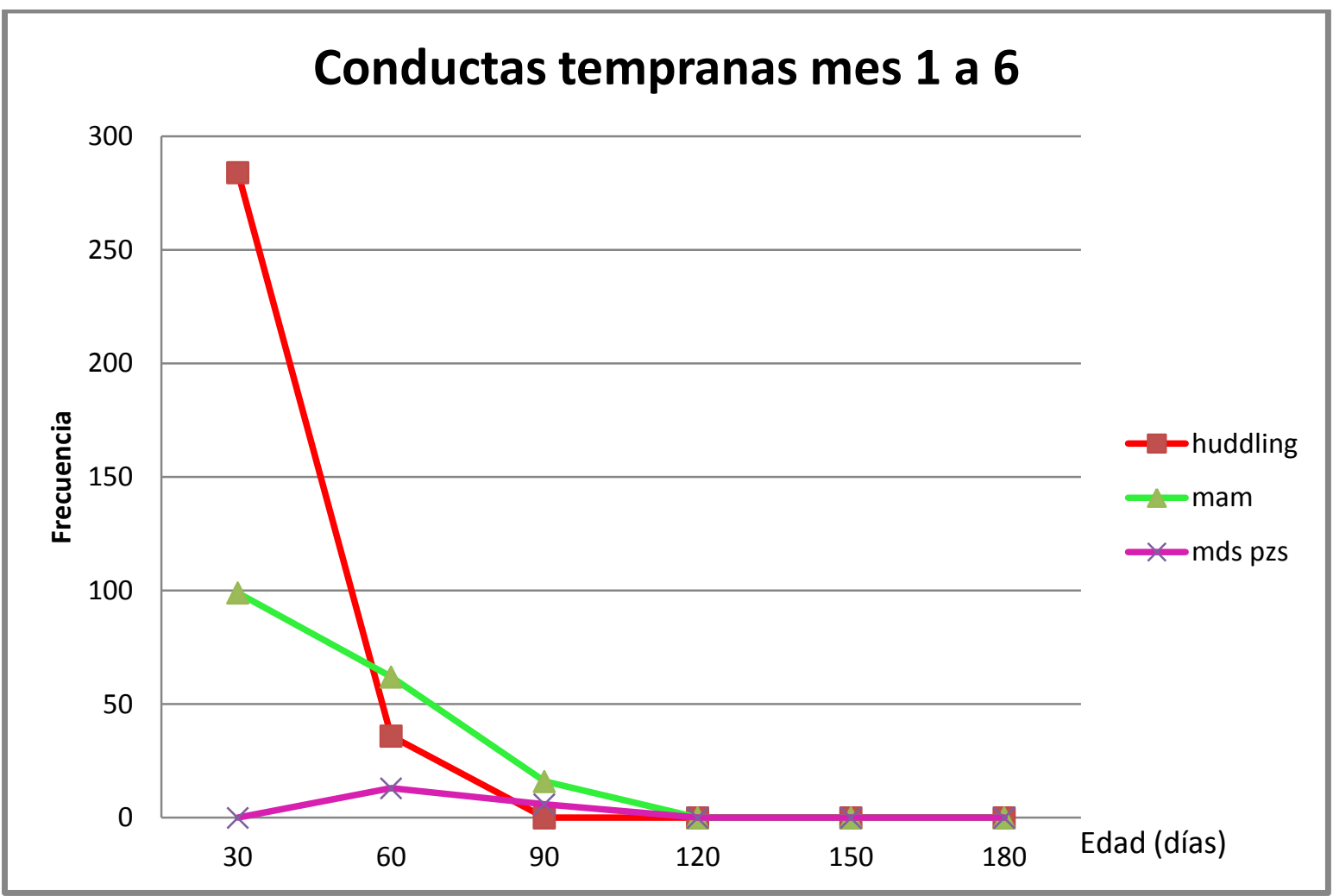

Figura No. 17. Frecuencias mensuales totales. Conductas tempranas

$\underline{\text { Conductas alimenticias }}$

Los cachorros y juveniles pueden obtener alimento solicitándolo a otros individuos de la manada, ya sea los trozos de carne o alimento semidigerido. Ambos tipos de conductas se registraron desde el segundo mes de vida, la solicitud de carne fue más frecuente que la de solicitud de regurgitación, pero más adelante, sus frecuencias fueron similares. Solicitud de carne se mantuvo elevada durante los primeros 7 meses de vida, pero a partir del octavo comenzó una tendencia a disminuir, hasta los 11 meses (330 días), después de lo cual tuvo un pequeño incremento que variaba a lo largo de los meses, pero se mantuvo con baja frecuencia hasta el mes 23, y desapareció en el mes 24 (Figura No. 18). 
La solicitud de regurgitación, se observó que se va incrementando, alcanzando un máximo a los 6 meses (180 días), después de lo cual mostró una tendencia a disminuir, y alcanzó una frecuencia mínima a los 11 meses (330 días), durante el segundo año, se registró un ligero incremento entre los 14 (420 días) y 19 meses (570 días); desapareció a los 21 meses. La conducta de mamar fue gradualmente substituida por la obtención de alimento sólido (Figura No. 18).

Entre los 14 y 19 meses se registró la conducta de dar carne, en la que los juveniles proporcionaban pedazos de carne cruda a los cachorros nacidos el año siguiente, mientras que entre el mes 15 y 23 les regurgitaban alimento, cabe mencionar que ambas conductas se registraron con bajas frecuencias. La conducta de disputa por alimento se observó a partir del segundo mes de vida y, a pesar que sus frecuencias fluctúan durante el periodo de estudio se mantuvieron con bajos valores (Figura No. 18).

La conducta de solicitud de alimentación general presentó una gran variación en los primeros meses de vida, pero el comportamiento de los datos es el mismo tanto en las frecuencias promedio como en las frecuencias totales, registrándose un incremento en los primeros 6 meses de vida, después de los cuales fue descendiendo hasta que casi cumplir el primer año de edad; durante el segundo año, se mantuvo en bajas frecuencias (Figura No. 19). 


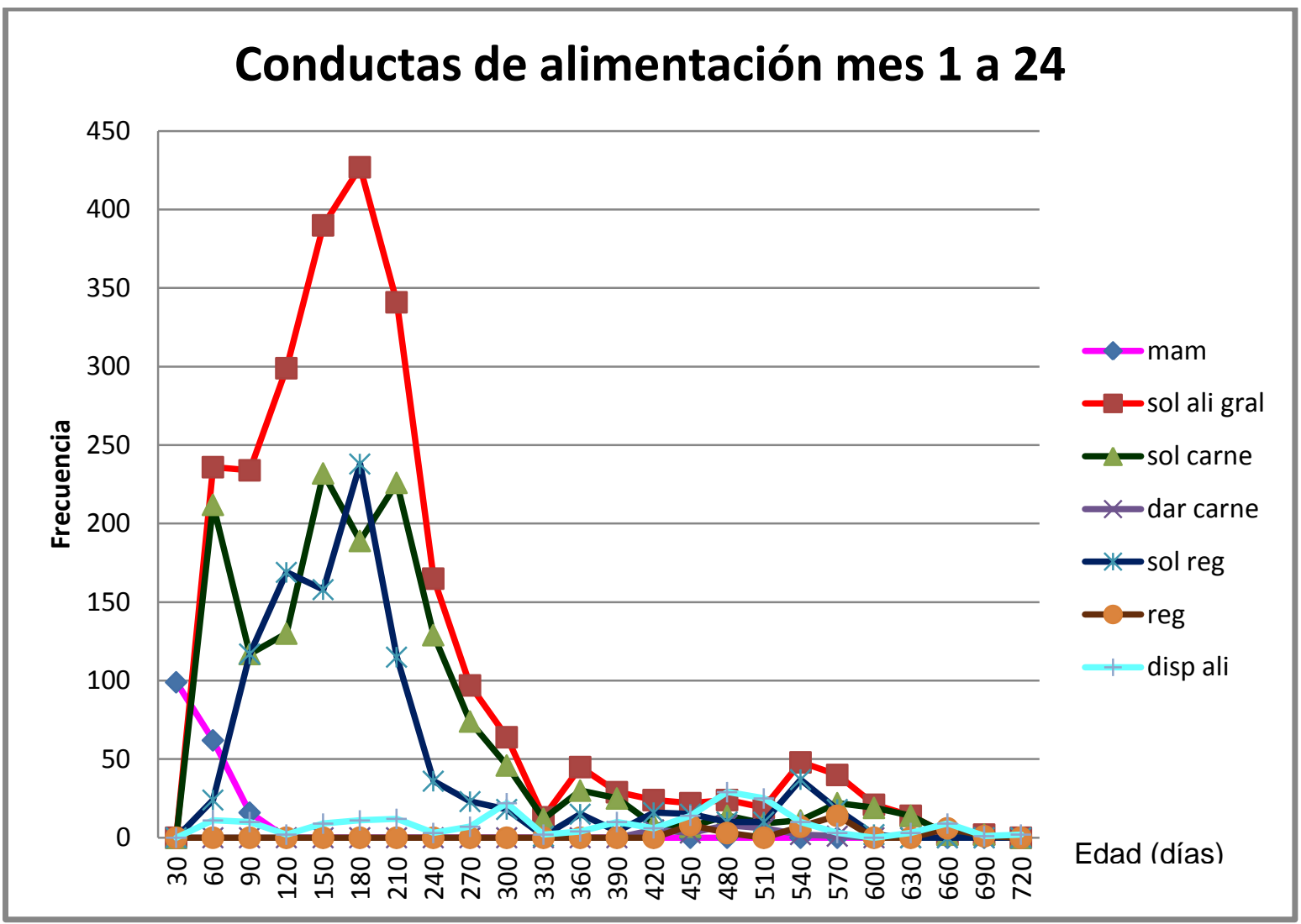

Figura No. 18.Frecuencias totales mensuales. Conductas de alimentación.

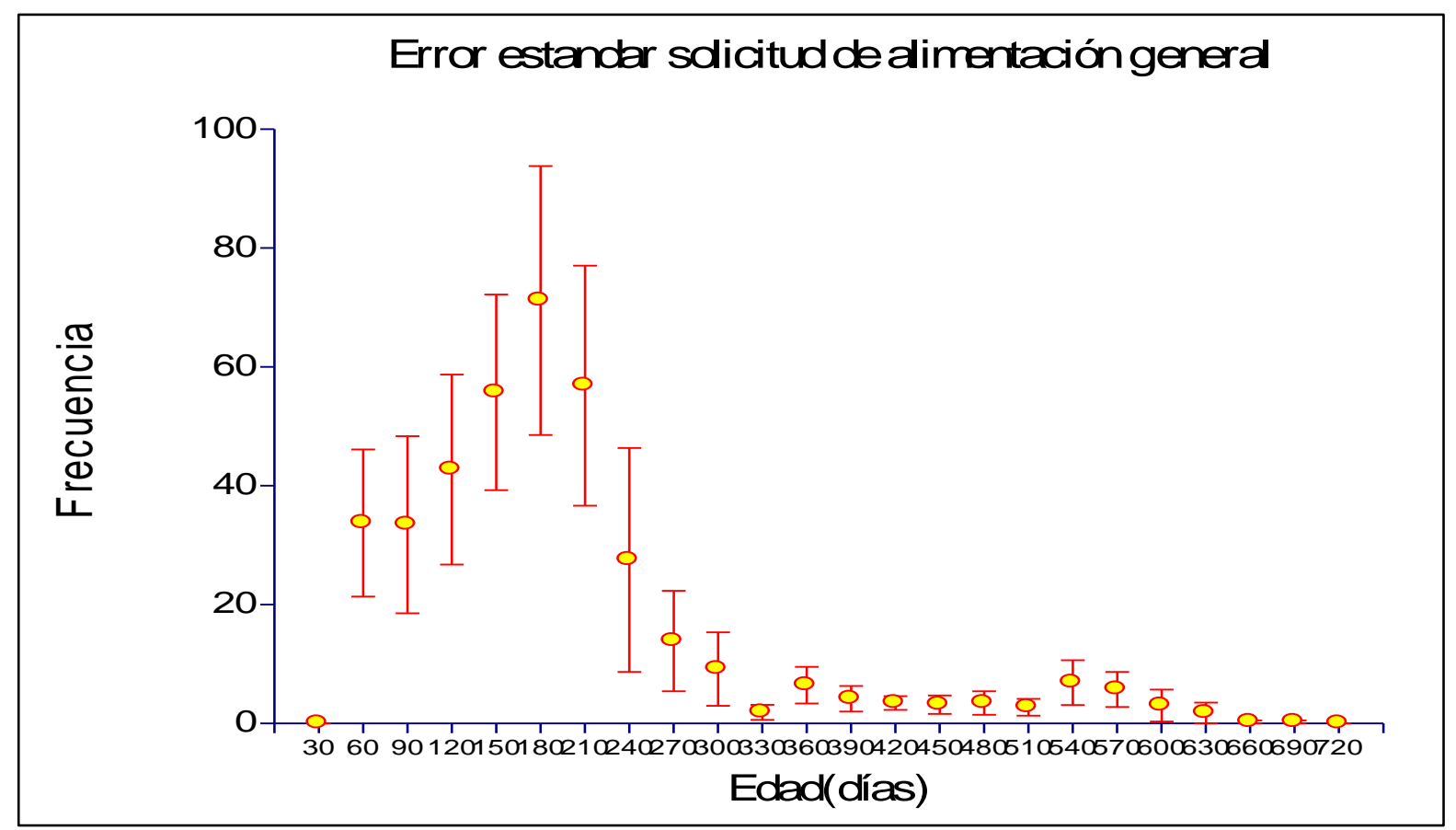

Figura No. 19. Frecuencias mensuales promedio por camada y error estandar. Solicitud de alimentación general 


\section{$\underline{\text { Conductas Amistosas }}$}

De las conductas amistosas exhibidas por los cachorros y juveniles durante los primeros 2 años de vida se registraron un total de 8 comportamientos en esta categoría, de los cuales, el más frecuente durante todo el periodo de estudio fue contacto hocico-piel, que se presentó desde el primer mes, se incrementó hasta el quinto mes, después disminuyó un poco y, posteriormente, tuvo un notable incremento a los 10 meses (300 días), después de lo cual su frecuencia fue variable, aunque se mantuvo con bajos valores, para el mes 22 tuvo un nuevo incremento y volvió a disminuir (Figura No. 20).

En el caso de la conducta olfateo de genitales, su mayor frecuencia ocurrió a los 16 meses (480 días), y que hubo dos incrementos menores a los 11 y 23 meses. La conducta de lamer genitales se exhibió ocasionalmente, y se incrementó hasta los 23 meses de edad (Figura No. 20). Estos valores están relacionados con la incorporación de las crías del año siguiente a la manada y con la época de celo. 


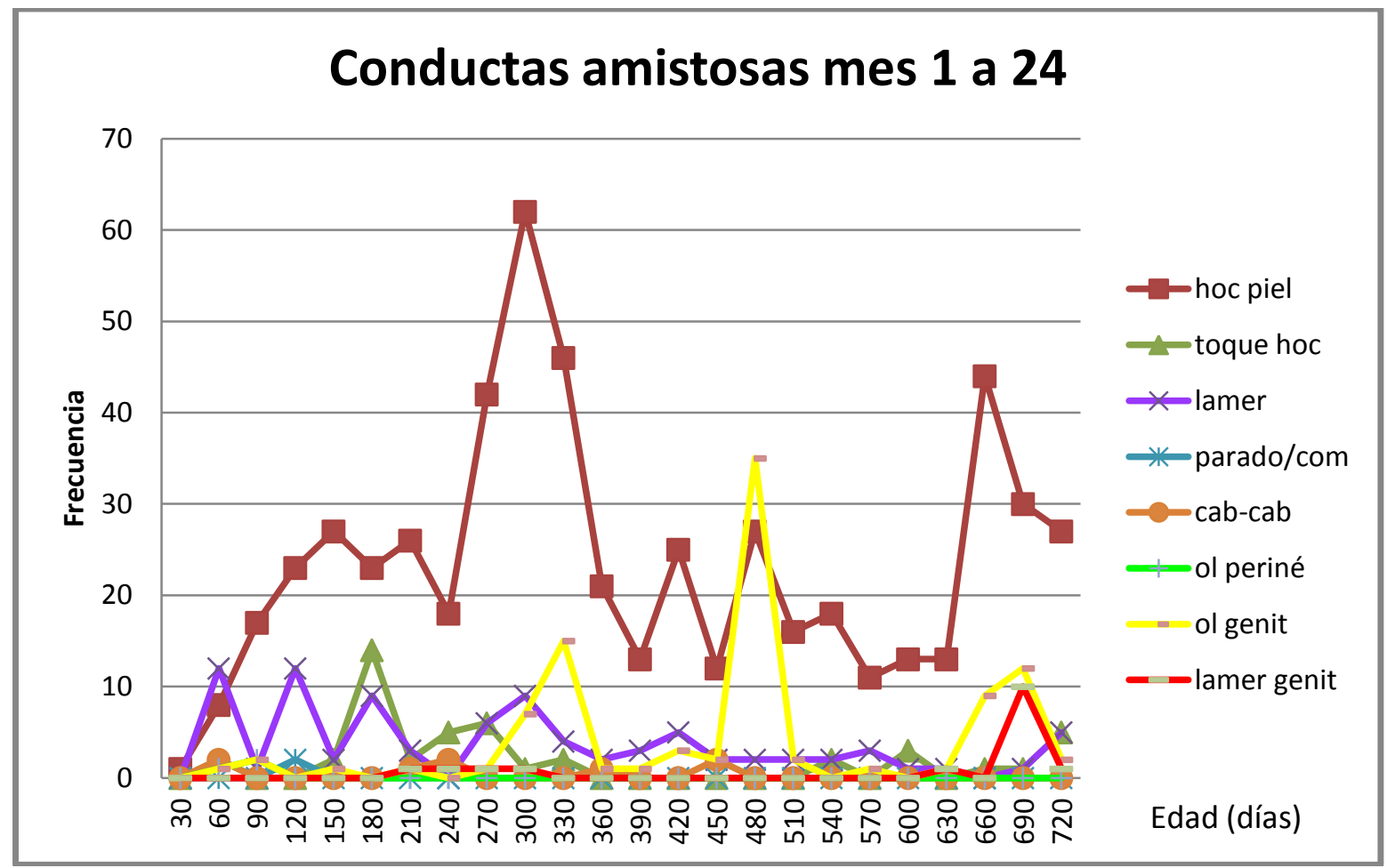

Figura No. 20. Frecuencias totales mensuales. Conductas amistosas.

$\underline{\text { Conductas de Juego }}$

En algunas conductas de juego se requiere la participación de más de un individuo (solicitud de juego, juego persecutorio y juego con contacto corporal), mientras que en el juego solitario, como su nombre lo indica, lo exhibe un solo animal, así como el juego con objetos, que es también individual, aunque pueden hacerlo varios animales de manera simultánea.

Estos comportamientos fueron más importantes en los primeros siete u ocho meses de vida que durante el resto del periodo de estudio, y las más altas frecuencias ocurrieron a los 120 días. La conducta de juego más frecuente fue 
juego con contacto corporal. El comportamiento de juego con objetos se fue incrementando hasta los 9-11 meses, después de lo cual se observó variable pero con menores frecuencias (Figura No. 21).

Las frecuencias promedio mensuales y las frecuencias totales mensuales de la conducta de juego con contacto corporal presentaron las mismas tendencias aunque se observó una mayor variación en el primer año. Dichas frecuencias fueron mayores durante los primeros meses de vida, siendo las más altas a los 120 días de edad (Figura No. 22).

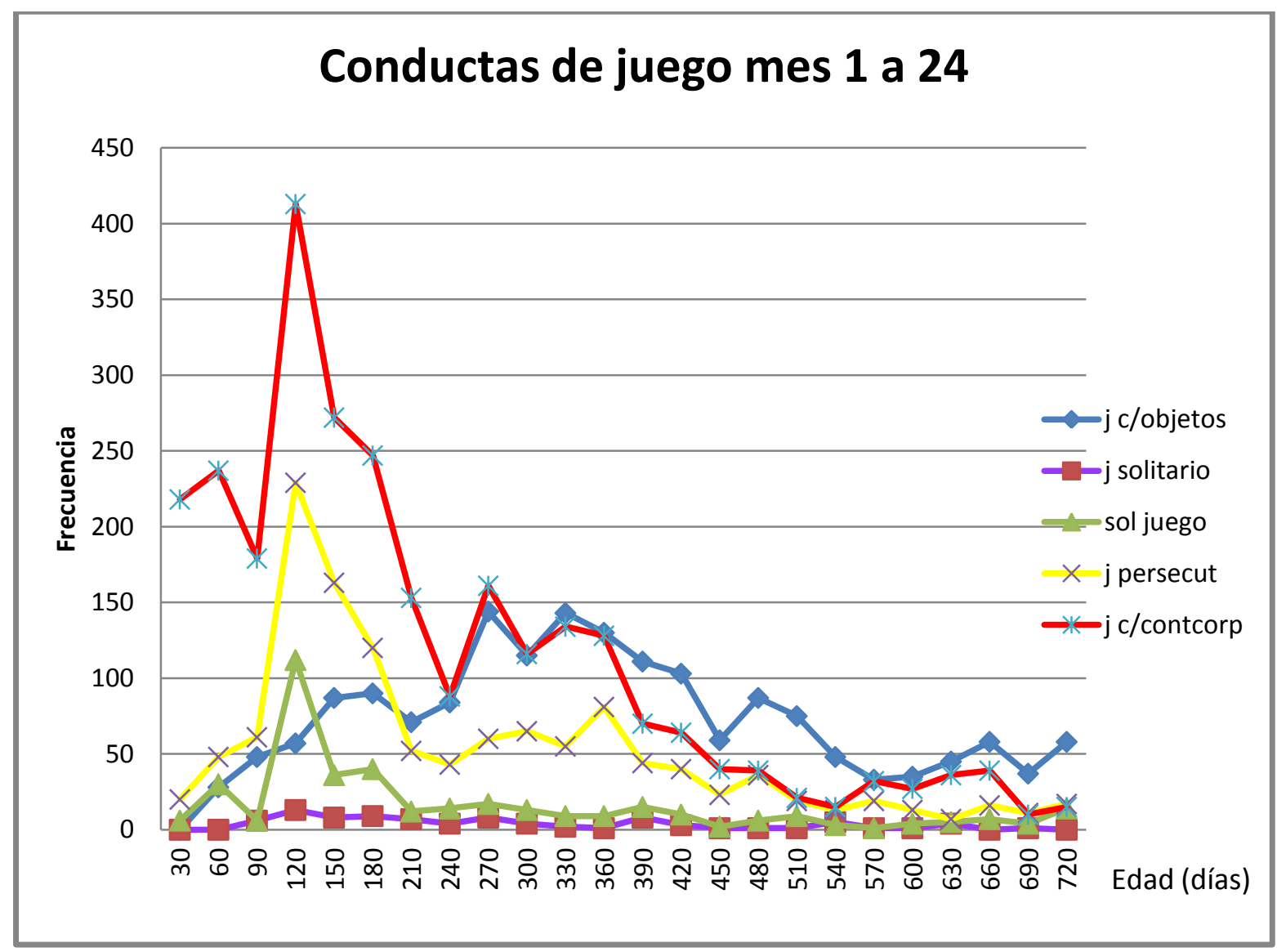

Figura No. 21. Frecuencias totales mensuales. Conductas de juego. 


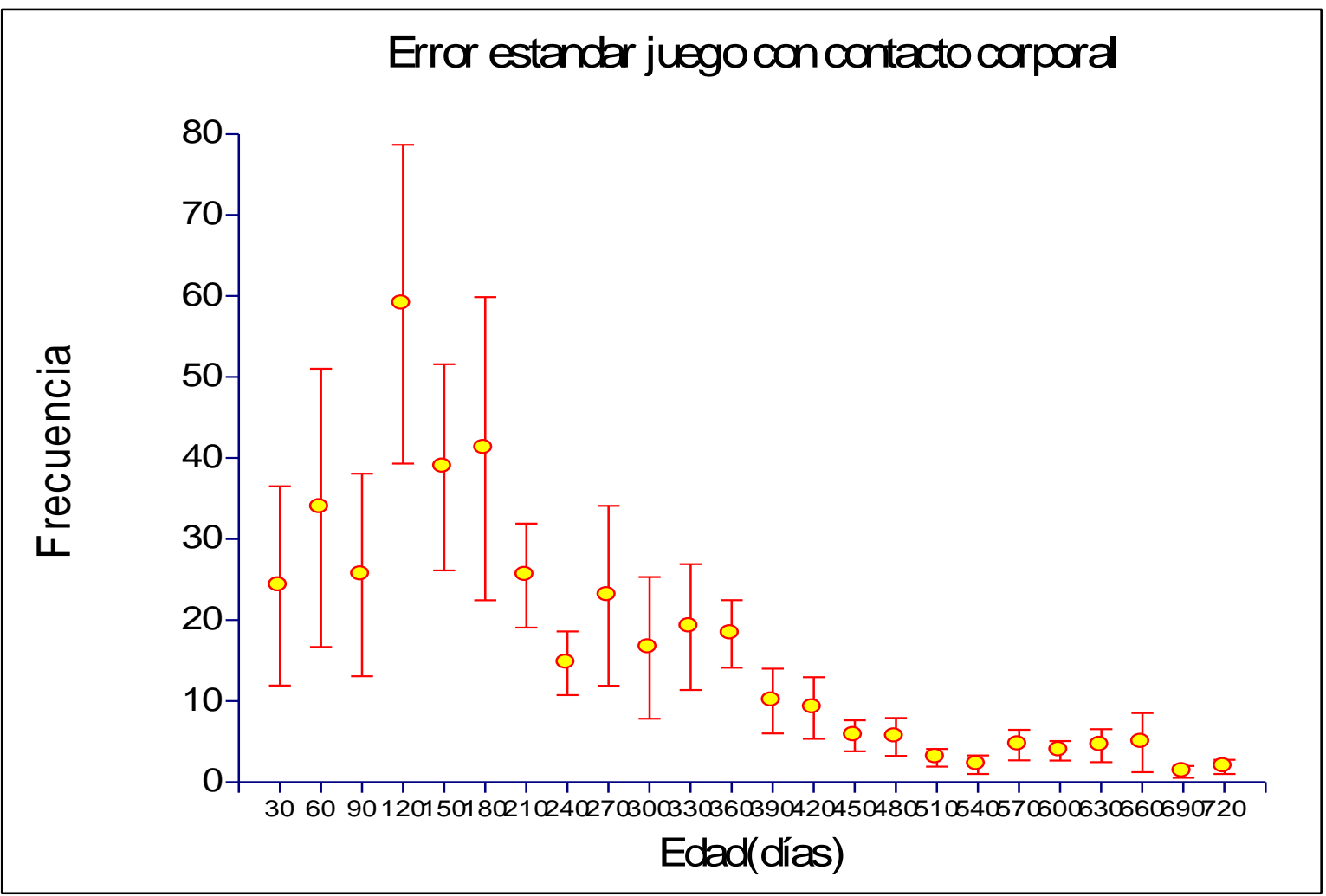

Figura No. 22. Frecuencias mensuales promedio por camada y error estandar. Juego con contacto corporal.

Conductas de Sumisión

De las conductas de sumisión exhibidas por los lobeznos durante los primeros dos años de vida se registraron un total de cuatro comportamientos.

Sumisión activa, sumisión pasiva y sumisión de grupo se fueron incrementando durante los primeros meses, y que las mayores frecuencias ocurrieron simultáneamente a los 120 días, después de lo cual, sumisión pasiva disminuyó considerablemente, y fluctuó durante los siguientes meses, pero se mantuvo con bajas frecuencias (Figura No. 23). 
La conducta de sumisión activa presentó también variaciones durante el resto del periodo de estudio pero con mayores frecuencias, mientras que sumisión de grupo en algunos meses tuvo una frecuencia elevada, mientras que en otros fue mucho más baja. La conducta de reunión se registró a partir de los 8 meses (240 días), fluctuó un poco, pero siempre con bajas frecuencias; a partir del mes 21 fue disminuyendo y para el mes 24 desapareció (Figura No. 23).

En la conducta de sumisión de grupo se observó una variabilidad tanto entre las diferentes edades como entre camadas, pero el patrón que siguieron los valores de la media fue el mismo que en el caso de las frecuencias totales mensuales; en algunos momentos se exhibió en altas frecuencias, mientras que en otros en bajas frecuencias (Figura No. 24). 


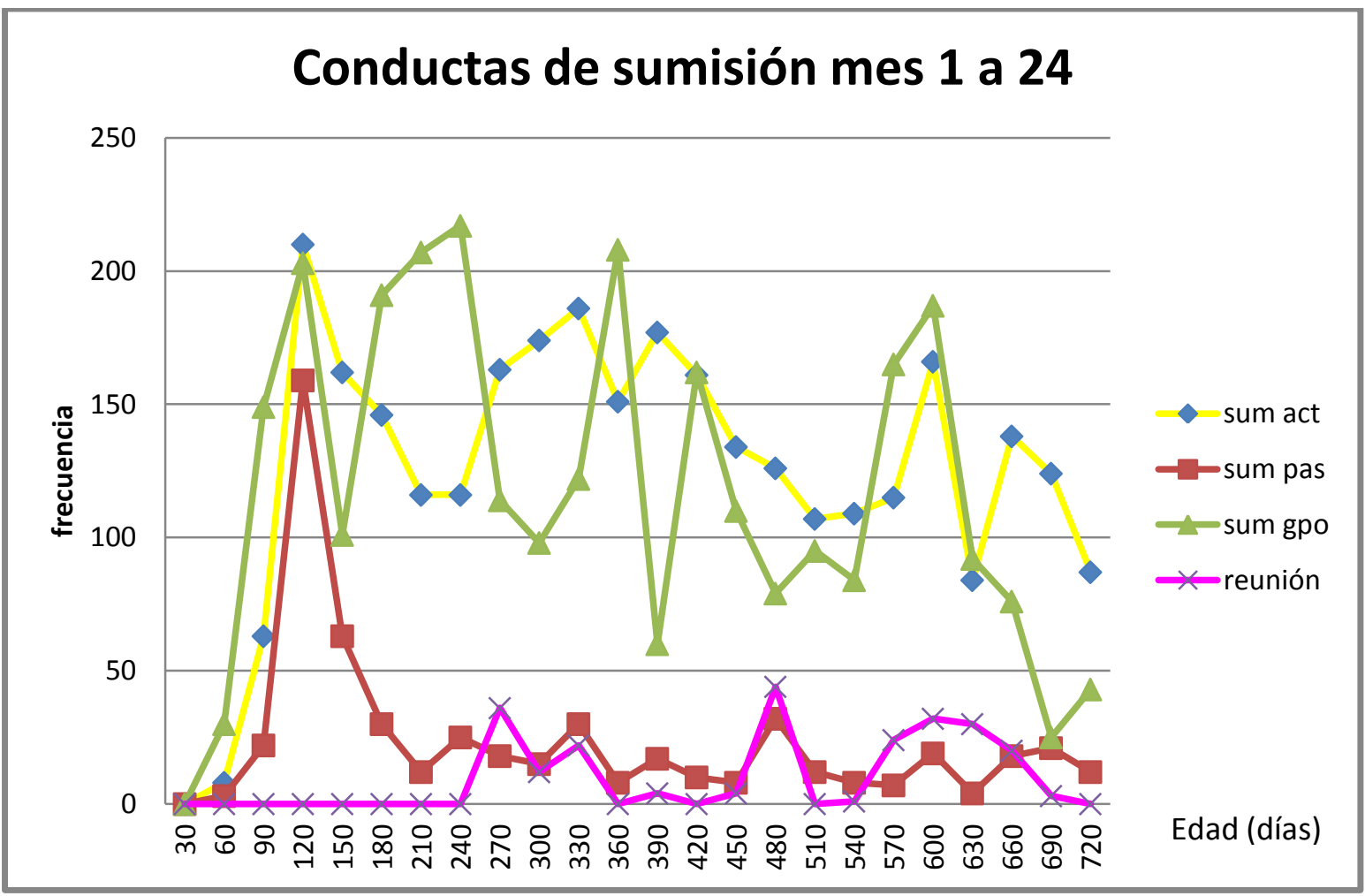

Figura No. 23. Frecuencias totales mensuales. Conductas de sumisión

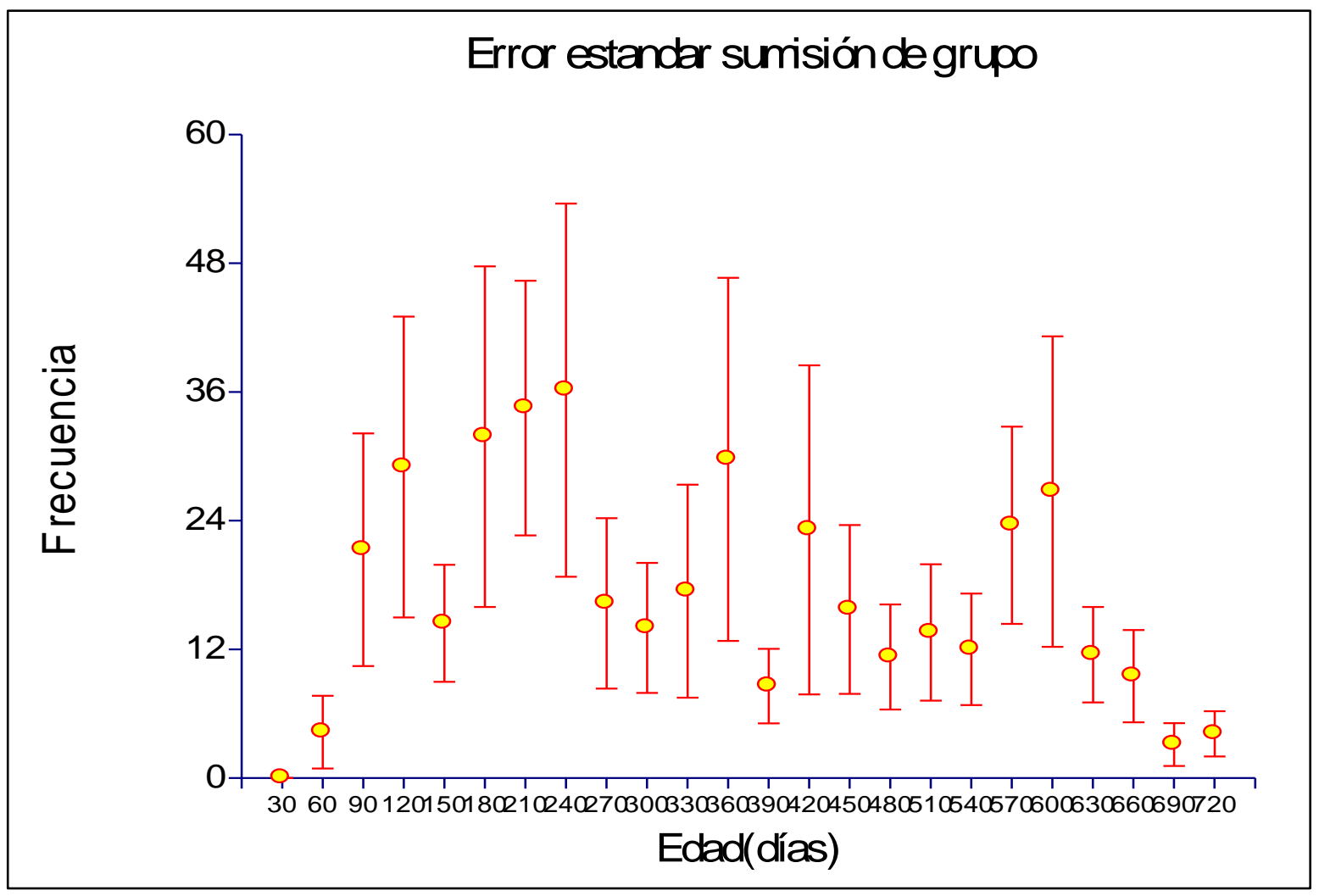

Figura No. 24. Frecuencias mensuales promedio por camada y error estandar. Sumisión de grupo 
Conductas Antagonistas

Se registraron un total de 21 conductas de tipo agresivo, divididas en 4 subcategorías: sin contacto corporal, con contacto corporal, con intento de mordida y con mordida. Durante casi todo el primer año de vida se presentaron pocas conductas agonistas, y todas ellas con bajas frecuencias. En el curso del segundo año, se registraron una gran variedad de este tipo de conductas, algunas siempre con bajas frecuencias, mientras que otras tuvieron incrementos en diferentes momentos. La conducta que tuvo mayor frecuencia fue amenaza ofensiva (Figura No. 25).

La conducta de buscar, trotar, correr a lo largo de lámina, apareció a los 11 meses, luego se incrementó y después fue variable. Coger hocico alcanzó su mayor frecuencia a los 15 meses, después de lo cual fue variable pero con menor frecuencia. Las conductas de imposición adquirieron importancia durante el segundo año, al igual que ataque, lanzar y morder, levantarse y morder, éstas últimas particularmente hacia el final del estudio (Figura No. 25).

Amenaza ofensiva, tuvo un incremento en los primeros meses del estudio, después, disminuyó considerablemente, y durante el segundo año se volvió a incrementar. El comportamiento de morder es el de mayor intensidad, pero fue también el de menor frecuencia, ya que sólo se registró en dos ocasiones diferentes durante todo el estudio (Figura No. 25). También se observó que las 
conductas de menor intensidad fueron las más frecuentes, mientras que las de mayor intensidad las menos frecuentes (Figura No. 26).

En la conducta de amenaza ofensiva se pudo apreciar que a pesar de la variación presente, la tendencia de las frecuencias promedio fue la misma que la de las frecuencias totales (Figura No. 27), mostrando un incremento en los meses 2 y 3 , que en ese momento representaba una agresión moderada hacia los coetaneos, y el otro incremento en el segundo año de vida, manteniéndose con valores elevados por varios meses, en los cuales se manifestó con una mayor intensidad; en este caso fue dirigida hacia los coetaneos o hacia otros adultos, lo cual va a ser importante en el establecimiento de la posición jerárquica del individuo. 


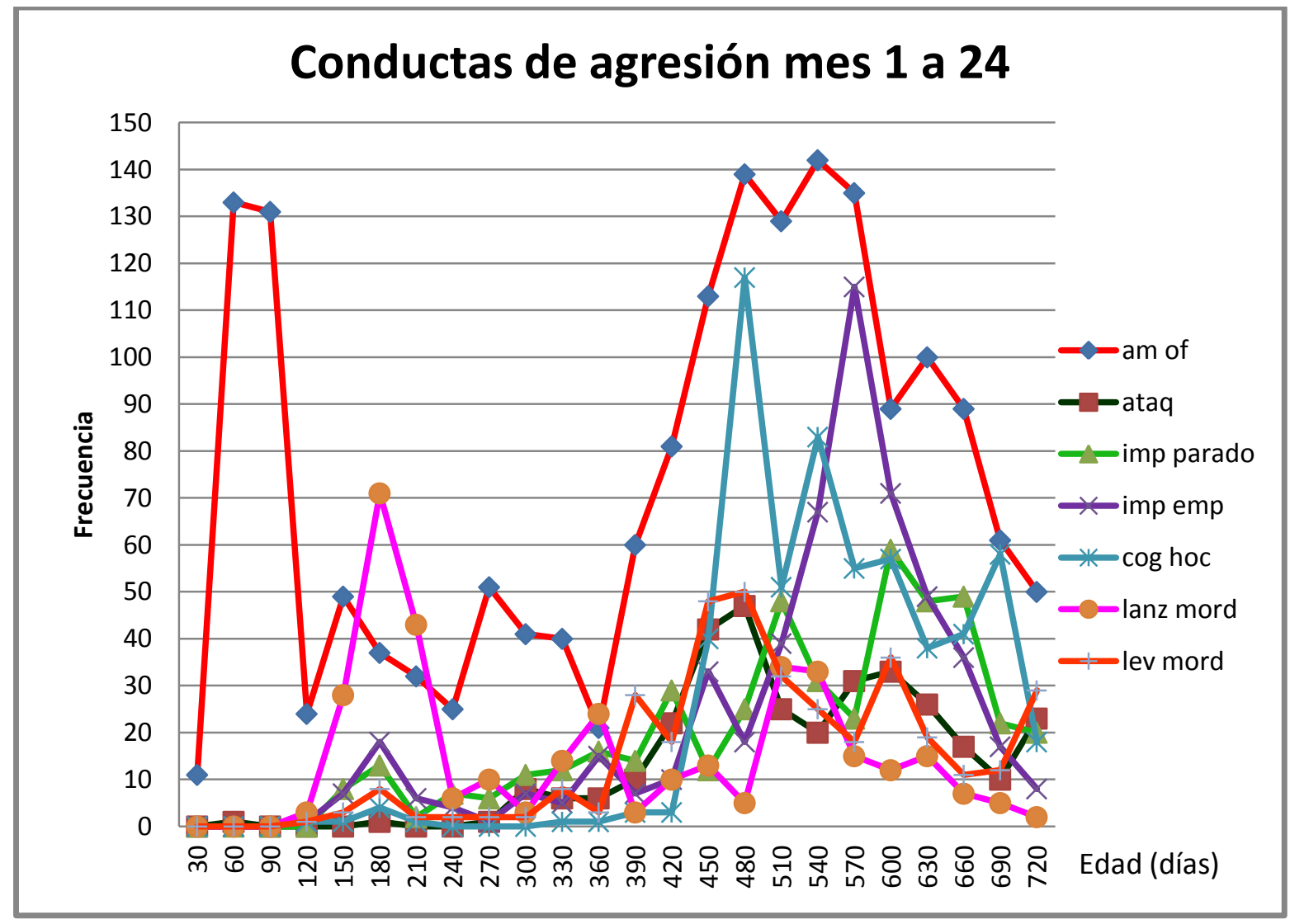

Figura No. 25. Frecuencias totales mensuales. Conductas de agresión.

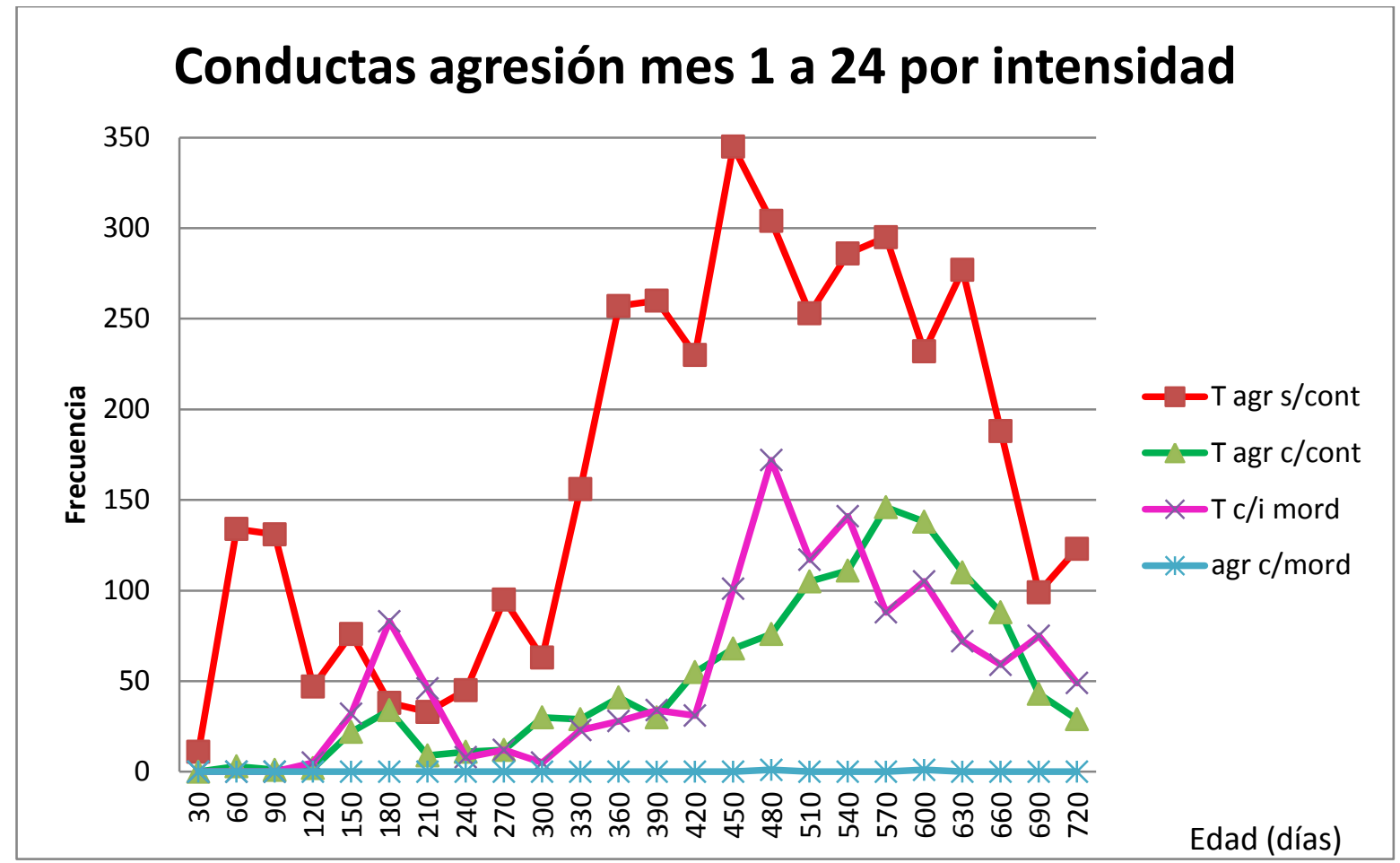

Figura No. 26. Frecuencias totales mensuales. Conductas de agresión por intensidad. 


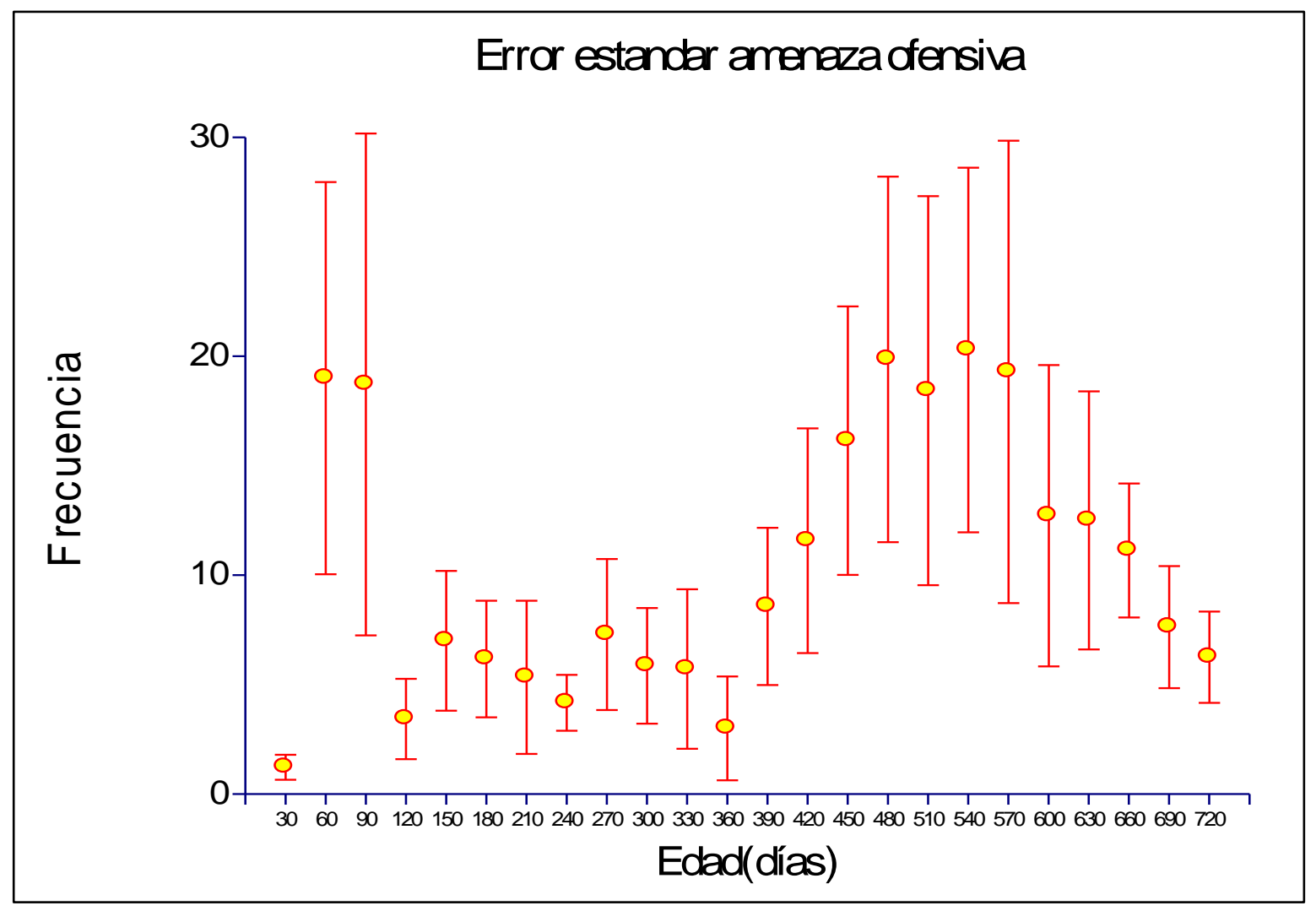

Figura No. 27. Frecuencias promedio mensuales por camada. Amenaza ofensiva.

Conductas Defensivas

De los 7 comportamientos defensivos exhibidos por los cachorros y juveniles durante el periodo de estudio, amenaza defensiva fue el más frecuente durante los 24 meses, aunque durante algunos momentos, como entre 3 y 6 meses, 10 y 14 meses, y 22 a 23 meses, tuvo una alta frecuencia, mientras que el resto del tiempo fue baja (Figura No. 28).

La conducta de huir se hizo importante a partir de los 10-11 meses, pero también tuvo fluctuaciones. Chasquido, mantener distancia, lanzar y morder defensiva se 
mantuvieron en baja frecuencia, aunque mostraron variaciones, mientras que defensa en círculo y mordida defensiva sólo se registraron en un par de ocasiones (Figura No. 28).

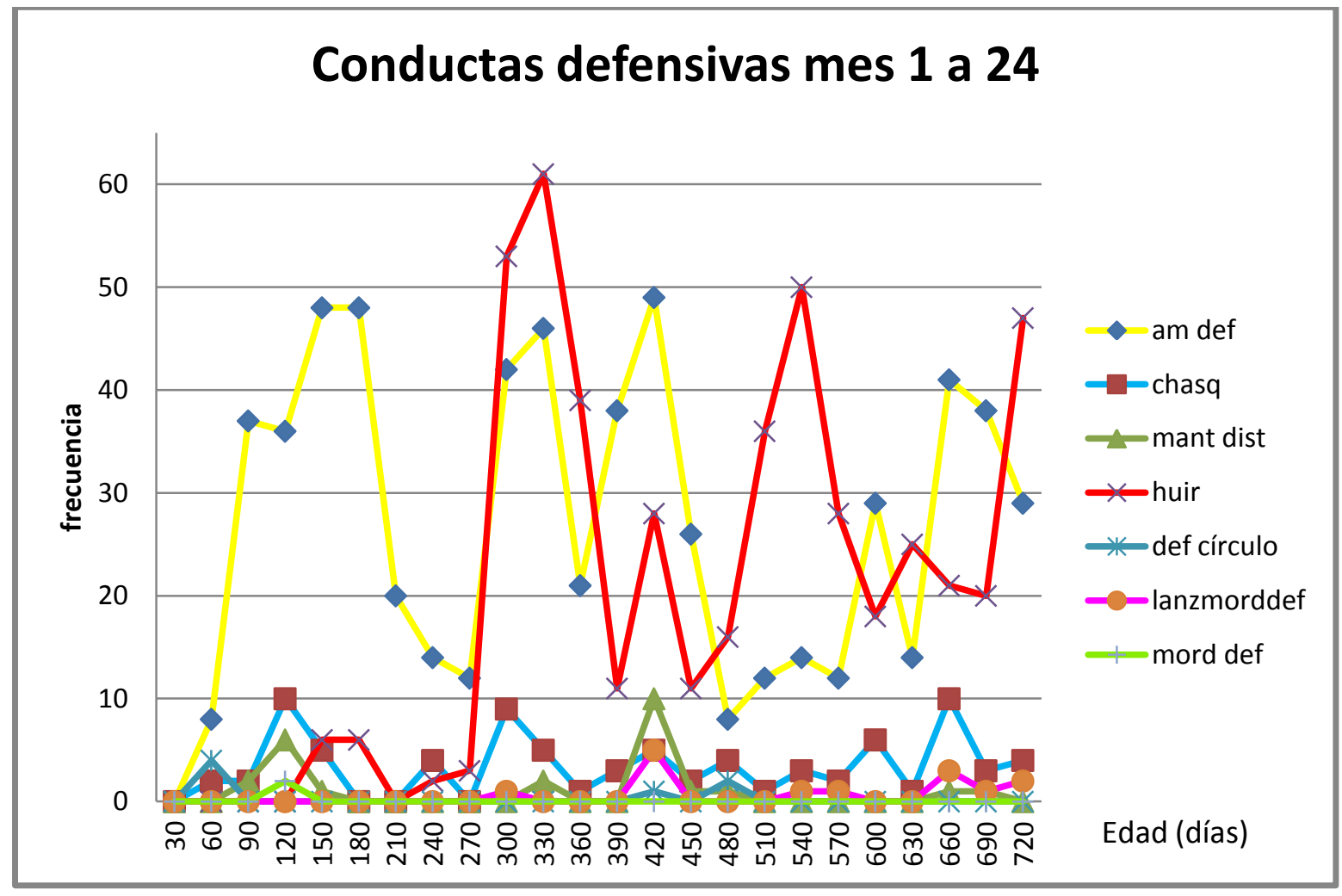

Figura No. 28. Frecuencias totales mensuales. Conductas defensivas

Conductas Sexuales y pseudosexuales

Se encontraron dos momentos en los cuales estas conductas se presentaron de manera importante, a los 11 meses (330 días) y de los 22 a 24 meses (660 a 720 días), particularmente seguir previo a cortejo, cortejo, monta y movimientos pélvicos (Figura No. 29). 
Solicitud amistosa apareció a los 13 meses (390 días), después fue variable, y se incrementó a partir de los 22 meses (660 días). Presentación de genitales sólo se registró a los 22 y 23 meses (660 y 690 días), y cópula a los 23 y 24 meses, ambas con una frecuencia muy baja (Figura No.29).

Con respecto a las conductas Pseudosexuales, se encontraron sólo dos: monta no sexual (montpre) y movimientos pélvicos no sexual (movpelvpre), que se presentaron en unas pocas ocasiones, entre los 3 y 5,7 y 11 meses (Figura No. 29).

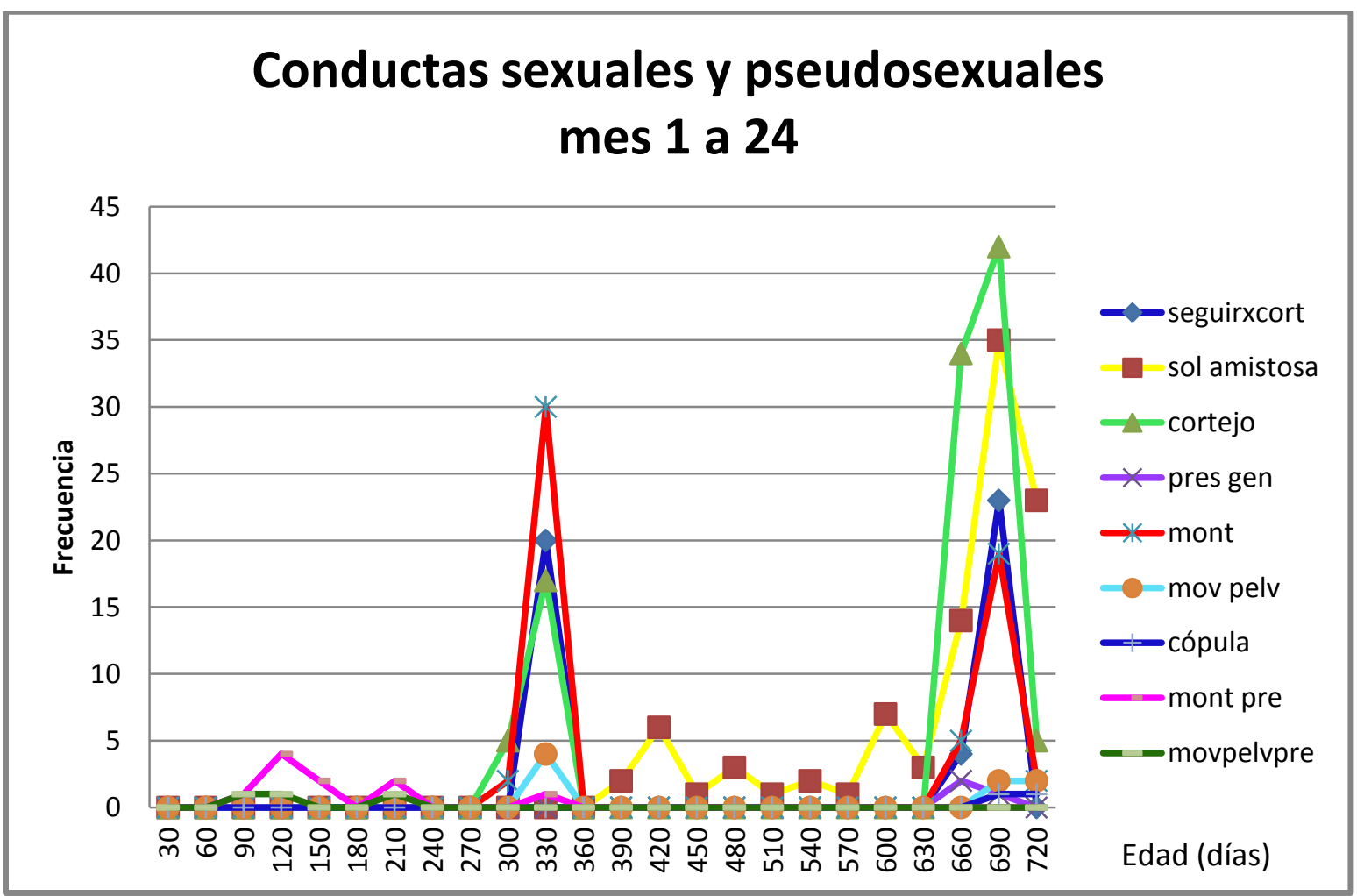

Figura No. 29.Frecuencias totales mensuales. Conductas sexuales y pseudosexuales 
$\underline{\text { Conductas de marcaje }}$

El comportamiento de marcaje de los lobos juveniles se presentó a partir de los 10 meses de edad (300 días), se mantuvo poco variable hasta los 16 meses, y a partir de los 17 se registró un notable incremento, que alcanzó sus máximos valores a los 23 meses (690 días) (Figura No. 30).

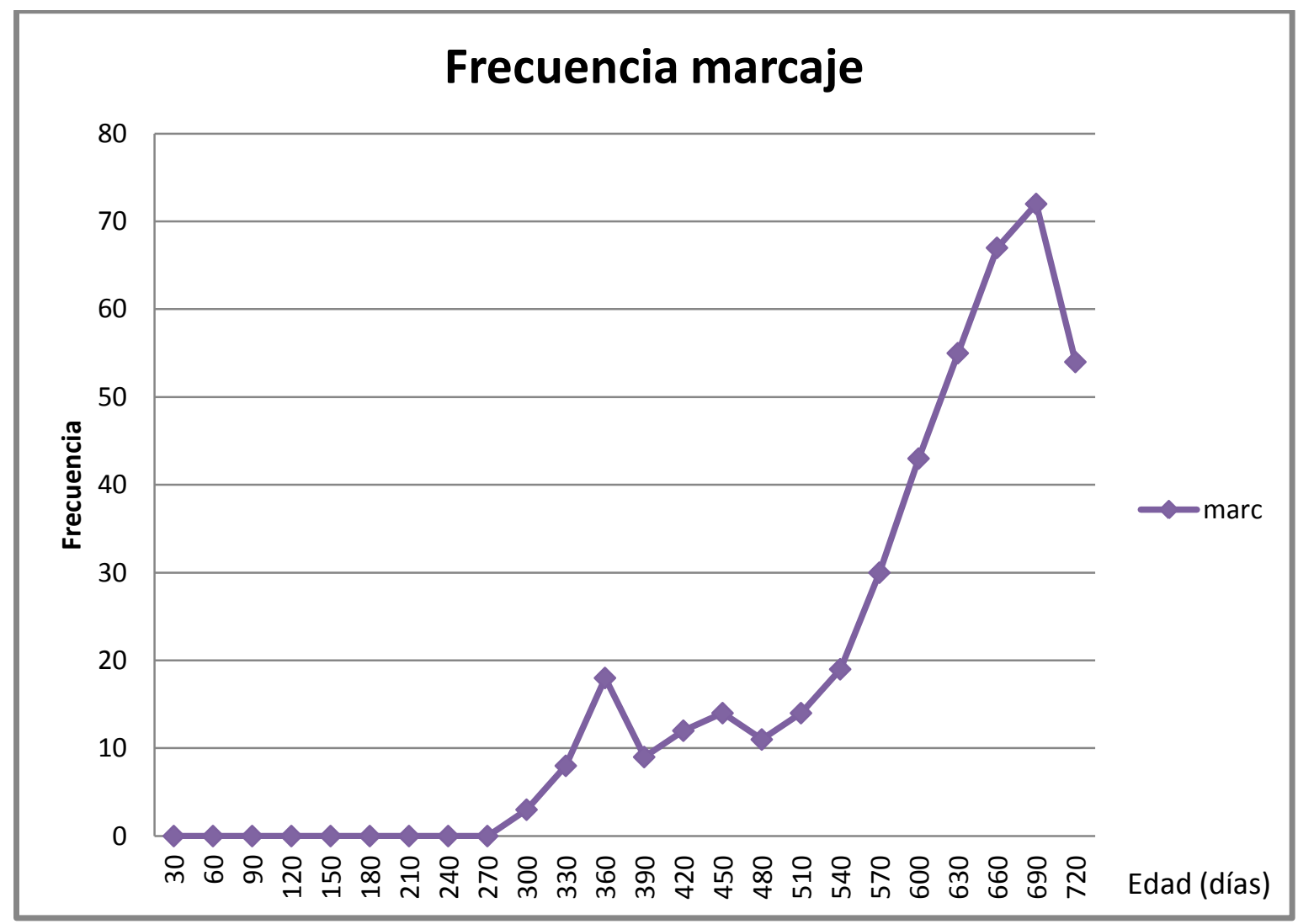

Figura No. 30. Frecuencias totales mensuales. Conductas de marcaje. 


\section{CUANTIFICACIÓN CONDUCTAS PARENTALES}

Las 50 conductas del etograma de los adultos estuvieron relacionadas con el desarrollo conductual de los lobeznos.

Los comportamientos parentales más frecuentes en el curso del primer año de vida de los cachorros fueron echada con crías, dar carne y regurgitar, que están relacionados con la provisión de alimento y calor a las crías durante los primeros meses de vida como elemento básico de sobrevivencia. Este proceso, sin embargo va acompañado de las conductas que enseñan a los nuevos integrantes de la manada las reglas de pertenecia a ella por lo que en el segundo año, la más frecuente fue amenaza ofensiva (Figura No. 31).

Las conductas parentales más frecuentes en el primer año de vida de los cachorros fueron las relacionadas con las tempranas de los cachorros, que comprende la conducta de echada con crías, y las alimenticias que incluyen los comportamientos por medio de los cuales proporcionan alimento entero o semidigerido a los lobeznos (dar carne y regurgitar). Contacto hocico piel tuvo sus mayores frecuencias en los primeros 3 meses de vida de las crías. En el segundo año de vida las más frecuentes fueron las agonistas, representada principalmente por la conducta de amenaza ofensiva. Las conductas englobadas en amistosas presentaron una gradual disminución en la frecuencia, haciendo ver que los adultos van generando un desapego hacia las crías y gradualmente los consideran como otros adultos en la manada (Figura No. 31). 
Durante el primer año de vida las conductas dar carne y regurgitar presentaron una mayor variación que en el segundo, y los valores de las medias exhibieron las mismas tendencias que las frecuencias totales, durante los primeros meses se fueron incrementando pero después de los 8 y 6 meses respectivamente, disminuyeron, manteniéndose en bajas frecuencias durante el segundo año, y desapareciendo a finales del mismo (Figura No. 32 y 33).

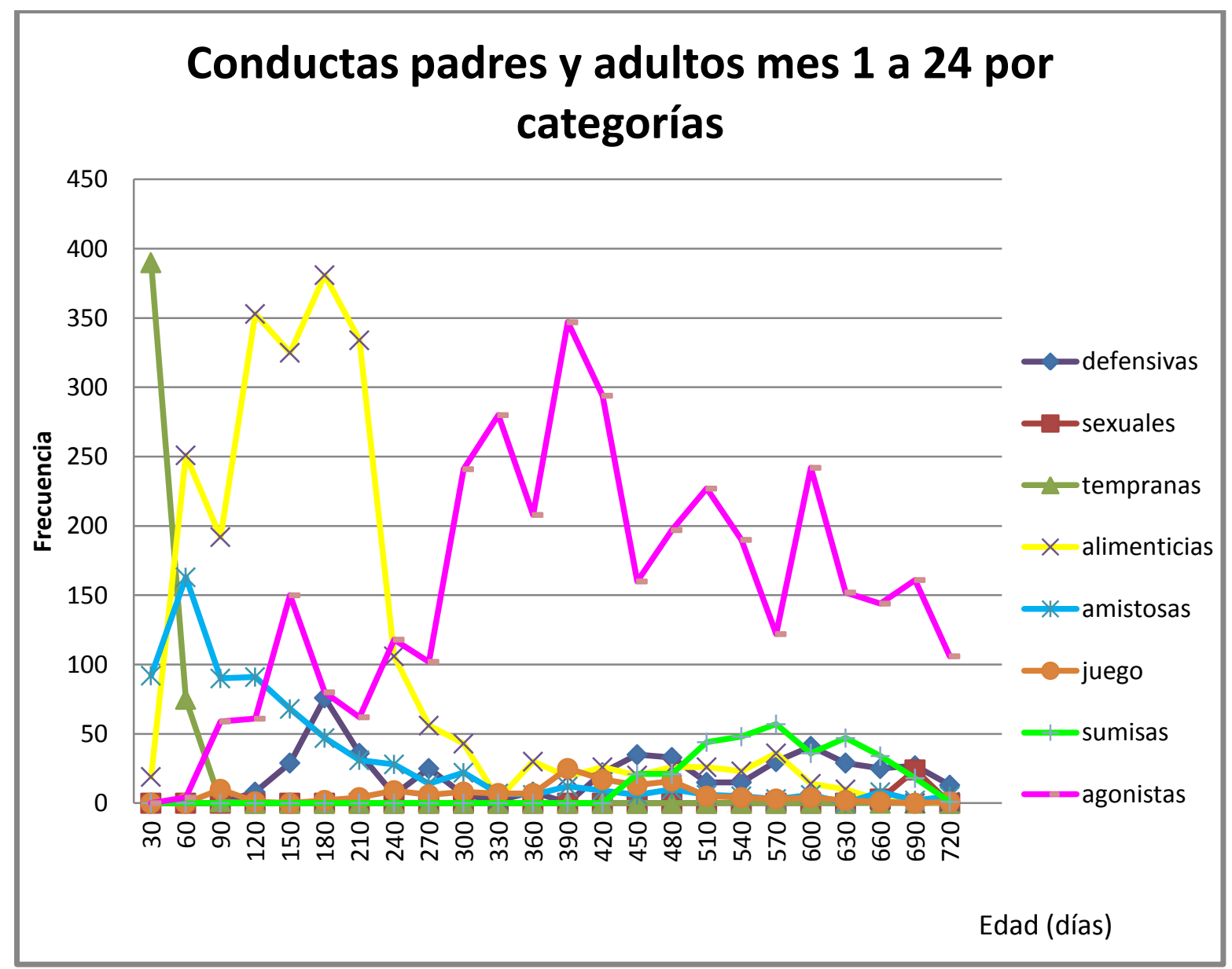

Figura No. 31. Frecuencias totales mensuales. Conductas parentales por categorías 


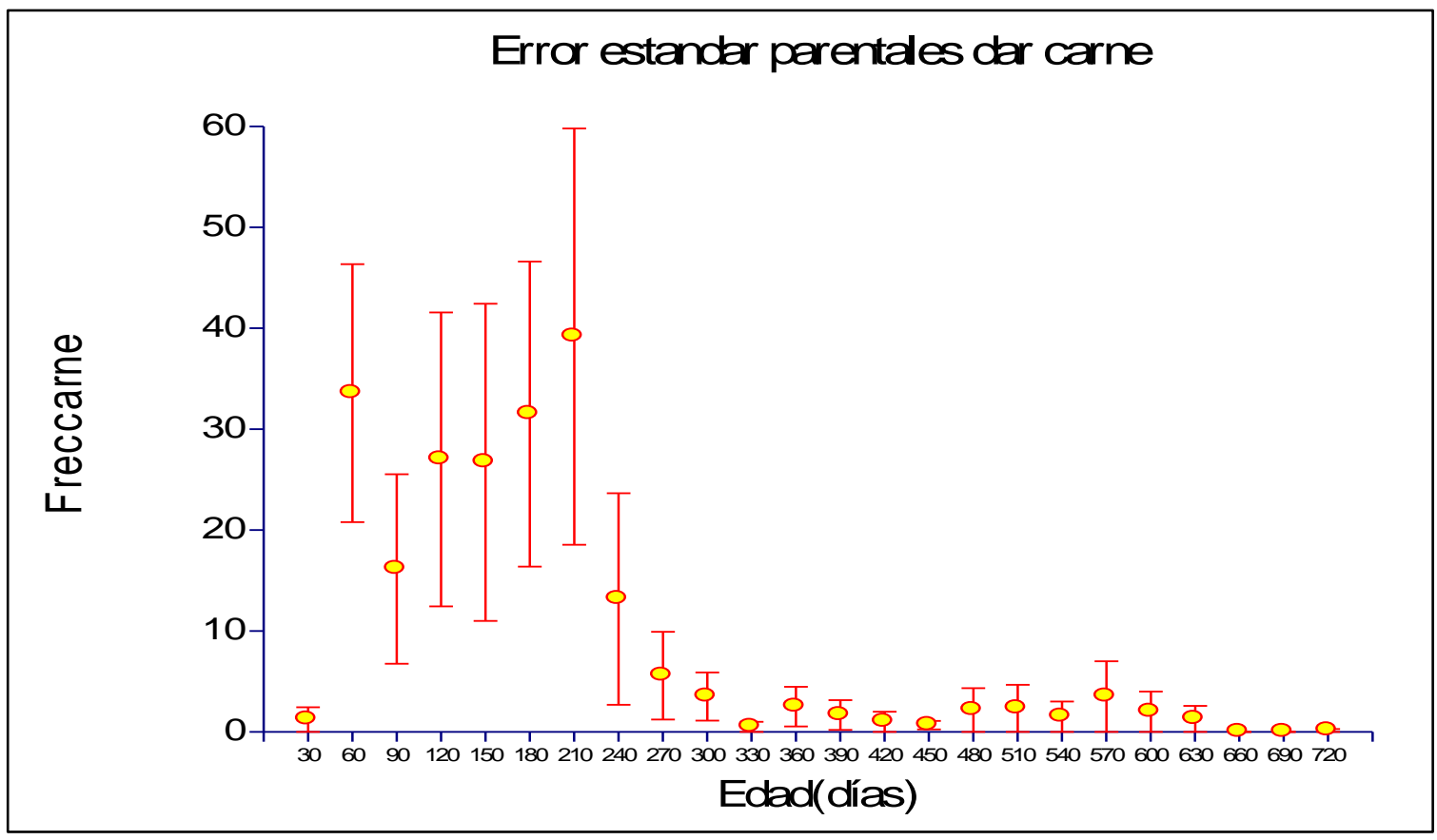

Figura No. 32. Frecuencias mensuales promedio por camada y error estandar. Dar carne

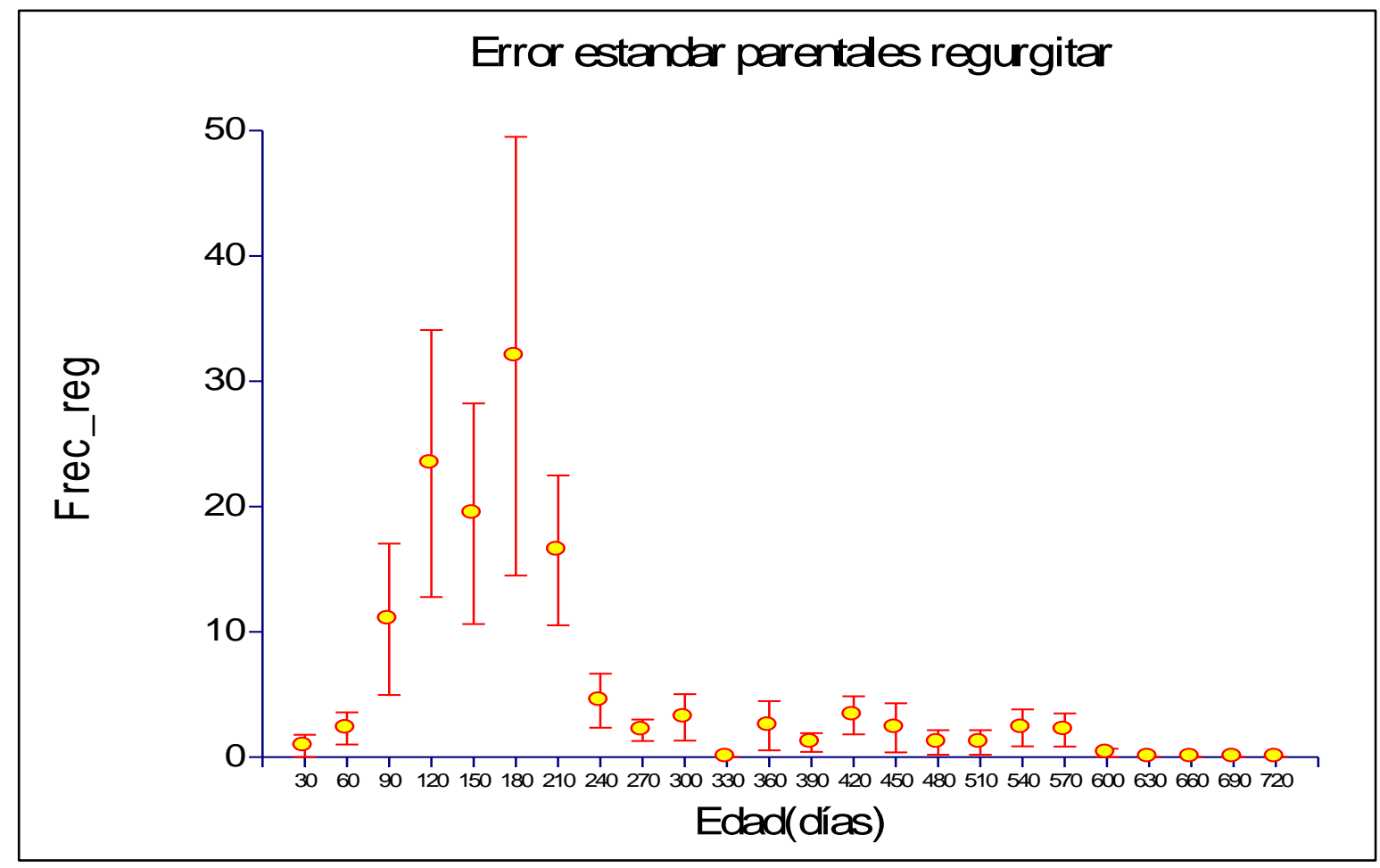

Figura No. 33. Frecuencias mensuales promedio por camada y error estandar. Regurgitar 


\section{DISCUSIÓN}

Cabe señalar que en algunos puntos de esta discusión se hace mención de algunas observaciones que fueron registradas durante el estudio, pero que no fueron consideradas para el diseño del análisis cuantitativo.

\section{Etograma}

Se puede apreciar que el etograma de crías-juveniles presenta un mayor número de conductas que el de los adultos, ya que en éstos últimos sólo se tomaron en cuenta las interacciones adulto-cría y adulto-juvenil, por tanto, la ausencia del registro de las conductas entre adultos en este estudio limita el espectro conductual de los mismos, especialmente en las categorías de agresión y sexual.

\section{Aparición y permanencia de las conductas}

Los resultados de este estudio siguieron patrones claramente identificables, por lo que se pudo seguir lo propuesto por Huntingford (1984) en cuanto a la siguiente fase en la descripción de la ontogenia del comportamiento. Consecuentemente, al obtener el patrón de aparición y permanencia de conductas en el tiempo se puede apreciar que, al inicio se registran unas pocas conductas, poco después aparece un gran número de ellas, durante los meses 2 a 4, que corresponden a la etapa de socialización. Esto apoya los resultados de Fentress, (1967), Scott y Fuller (1965) y Zimen (1981). 
La gran mayoría de las conductas permanece una vez que se presenta, en general, sólo las que corresponden a los neonatos y las sexuales desaparecen, en el primer caso debido a la maduración del individuo, como se explicará más adelante, y en el segundo, por la estacionalidad de la actividad reproductiva característica de esta especie (Asa y Valdespino, 1998, Kreeger, 2003, Seal et al., 1987).

De las primeras conductas en presentarse son las de alimentación, lo cual es de esperarse dada su importancia (Hiiemae, 2000); junto con éstas, las conductas de juego se presentan desde una temprana edad, este tipo de comportamientos son una característica de muchas crías de mamíferos, aunque no se comprende bien aún por qué (Thompson, 1998), en el caso de los lobos son muy importantes para la socialización (Packard, 2003, Zimen, 1981), Feddersen-Petersen (1991) señala que los lobos jóvenes se caracterizan durante su primer año de vida, y más, por considerables actividades de juego.

Las últimas categorías conductuales en aparecer completamente son las de agresión y las sexuales, en las primeras se puede explicar porque de acuerdo con Zimen (1975), los lobos jóvenes son muy amistosos, pero su agresividad aumenta constantemente conforme transcurre el tiempo, algunas disputas más en forma no se presentan sino hasta el primer invierno, pero comportamiento agresivo real no se observa antes de que los lobos alcancen su segundo año. Del mismo modo, en el caso de las conductas sexuales, los animales generalmente no llegan a la pubertad sino hasta los 22 meses de edad (Asa y Valdespino, 1998). 


\section{Etapas de desarrollo}

Validez de la división del desarrollo en etapas

Se coincide con Fentress (1967), Fox (1966), y Fuller y Fox (1969), en la conveniencia de considerar el desarrollo, para su estudio, como una serie de fases o etapas que se caracterizan por eventos importantes.

La propuesta desarrollada en este estudio, tomada de Scott y Fuller (1965) en su investigación con perros, ha sido ya utilizada de manera exitosa en algunos estudios con lobos (Fentress, 1967, Klinghammer y Goodman, 1987, Mech, 1970, Packard, 2003, Peters, 1980, Pulliainen, 1967, Wagener, 1998, Woolpy y Ginsburg, 1967, Zimen, 1981). Al igual que los autores originales, se ha podido apreciar la presencia de estas etapas de manera natural durante el desarrollo de los individuos estudiados.

Por tanto, tomando en cuenta lo señalado por estos autores y los resultados obtenidos en este estudio, se puede afirmar que esta clasificación en etapas es apropiada para el estudio de la ontogenia del comportamiento del lobo mexicano. Asimismo, se comparte la opinión de Bekoff (1989) con respecto a la utilidad de las técnicas estadísticas multivariadas para el análisis de datos de desarrollo, ya que este tipo de estudios necesita considerar numerosas variables simultáneamente. 
Por otro lado, se puede considerar que los diversos estudios relacionados llevados a cabo en perros son una referencia adecuada para investigar la ontogenia del comportamiento del lobo, dada la escasez de estudios específicos al respecto, además de la gran similitud en nacimiento, desarrollo y comportamiento que existe entre ambas subespecies (Lord, 2013, Packard, 2003, Peters, 1980, Pulliainen, 1967, Scott, 1967, Scott y Fuller, 1965, Wagener, 1998).

En el Anexo II se presenta una descripción detallada sobre las características de las etapas descritas en estudios anteriores, así como una recopilación del desarrollo físico de los perros que podrán ser utilizadas para facilitar la comprensión de esta parte de la discusión.

\section{Etapa neonatal}

Los resultados obtenidos sobre las conductas registradas en esta etapa concuerdan con los estudios previos, tanto en perros como en lobos. (Dehasse, 1994, Mech, 1970, Packard, 2003, Scott, 1958, Wagener, 1998, Zimen, 1981).

Se pudo apreciar que los neonatos tienen los ojos cerrados y las orejas cubren el canal auditivo, además de que emiten algunas vocalizaciones, y en un estudio previo (Vázquez González, 2008), se pudo registrar que estos animales se desplazan arrastrándose. 
En esta primera etapa, que comprende las dos primeras semanas de vida, se observaron tan sólo 2 conductas del etograma, mamar y huddling.

Esta conducta - mamar- es posible porque la rama del nervio trigémino que inerva el área de la boca es de lo poco que se encuentra ya mielinizado al nacimiento, al igual que los músculos de la boca, están ya desarrollados y son capaces de exhibir una actividad rítmica (Loubiere, 2010).

Por otro lado, Gilbert et al., $(2007,2010)$ señala que huddling permite a los individuos maximizar el ahorro de energía, y de acuerdo con Canals y Bozinovic (2011) es adaptativo, auto-organizable, no costoso, y por tanto tiene una mayor probabilidad de evolucionar por selección natural. En el Anexo III se encuentran algunas consideraciones teóricas sobre este comportamiento.

Conforme a lo descrito anteriormente, durante las primeras dos semanas de vida que corresponden a esta etapa, los lobeznos no tienen la capacidad de regular su temperatura, por lo que la exhibición de la conducta de huddling es por demás apropiada para ayudarlos a evitar la pérdida de calor cuando la madre los deja solos. Esto concuerda con lo señalado por Packard (2012).

Se puede considerar que a esta edad un cachorro es apenas algo más que una serie de reflejos (Packard, 2003, Scott, 1958, Scott y Fuller, 1965), su pobre estado de desarrollo, especialmente del sistema nervioso, lo mantiene en un especie de aislamiento con respecto a su medioambiente, y para satisfacer sus 
demandas depende por completo de su madre, de tal modo que esta condición hace imposible que el lobezno pueda ser capaz de expresar un mayor número de conductas, y por ello se han registrado sólo dos de ellas, sin embargo de gran importancia porque son el medio por el que obtiene alimento y evita la pérdida de calor.

\section{Etapa de transición}

De las observaciones llevadas a cabo en el presente estudio, en esta etapa se registraron 4 conductas, mamar, huddling, juego con contacto corporal y amenaza ofensiva. Estos resultados coinciden perfectamente con los estudios previos en perros y lobos (Fox, 1964a, Markwell y Thorne, 1987, Mech, 1970, Navarrete, 2004, Packard, 2003, Pal, 2008, Scott, 1958, Scott y Fuller, 1965).

Del mismo modo, se pudo observar también que aunque tenían los ojos abiertos la visión era pobre, y se pudo notar que parte del pabellón auricular se separaba de la cabeza para permitir la apertura del canal auditivo. También pudo apreciarse que el cambio más notable en general fue en la parte final de la etapa, las conductas de juego con contacto corporal y amenaza ofensiva se registran por vez primera hasta el día 20.

El comportamiento de mamar sigue teniendo un papel importante en la vida de los cachorros, ya que la leche materna es aún su única fuente de alimento. 
La conducta de huddling se registra en menor proporción que en la etapa neonatal, lo que refleja que empiezan a tener un control de su temperatura.

Lord (2013) propone que la etapa de socialización en los lobos inicie a las dos semanas y concluya a las 6 , y no como originalmente plantearon Scott y Fuller (1965), ya que se han observado algunos comportamiento que los perros exhiben posteriormente (Fentress, 1967, Woolpy y Ginsburg, 1967 y Zimen, 1987). Cabe señalar que aunque Lord (2013) utiliza las observaciones de estos autores, ellos no consideran que esta etapa inicie antes de las 3 semanas de vida.

Durante esta etapa la capacidad sensorial y locomotora no se encuentra completamente desarrollada, por lo que las conductas y habilidades correspondientes no pueden ser exhibidas en la forma característica del adulto, lo que no ocurre antes de las 8 semanas (Ehret, 1980, Fox, 1966, Fuller y Fox, 1969, Gross et al., (2010), Loubiere, 2010, Parry, 1953).

Fox (1966) menciona que es sólo hasta el periodo de socialización que el desarrollo sensorial y locomotor ha alcanzado un cierto nivel en el que las relaciones primarias pueden establecerse. Del mismo modo, McLeod (1996) señala que durante las primeras dos o tres semanas los lobeznos no parecen distinguir entre los "objetos" sociales y no sociales con los que empiezan a interactuar. Klinghammer y Goodman (1987), consideran que los cachorros de lobo pueden sufrir un aprendizaje de reconocimiento en cada una de las 
modalidades sensoriales y que el reconocimiento no es confiable hasta que lo aprendido a través de cada una de estas modalidades pueda ser integrado.

Los resultados del presente trabajo concuerdan con lo señalado por Ehret (1980), Fox (1966), Fuller y Fox (1969), Gross et al., (2010), Klinghammer y Goodman (1987), Loubiere (2010), McLeod (1996), Parry (1953), indican que la capacidad de los cachorros para socializar se empieza a apreciar sólo hasta el final de la etapa de transición.

En esta etapa los cachorros pasan de un estado cercano al aislamiento sensorial, a uno en el que, a pesar de sus limitaciones, pueden no sólo percibirlo, sino interactuar con éste, y las experiencias que de ello resulten, van a afectar el desarrollo subsiguiente, siendo principalmente con su madre y hermanos de camada. Los resultados de este trabajo no concuerdan con la propuesta de Lord (2013).

También hay que recordar que el comportamiento es un continuo, y que existe una variación individual, aunado a la pequeña diferencia de tiempo entre ambas etapas, sería muy aventurado establecer que las afirmaciones de Lord (2013) prueban de manera contundente el inicio de la socialización a una edad más temprana en lobos. Este tipo de estudios fue popular en los años sesentas y setentas (Fentress, 1967, Klinghammer y Goodman, 1987, Woolpy y Ginsburg, 1967), pero ahora se encuentran descontinuados y se realizaban bajo condiciones 
artificiales, hace falta investigar más el proceso de socialización en situaciones más naturales.

\section{Etapa de socialización}

Los resultados obtenidos se ajustan muy bien con los estudios previos (Mech, 1970, Murie, 1944, Packard, 2003, Packard et al., 1992, Zimen, 1981). En esta etapa se pudo observar que tanto el aspecto como las capacidades sensorial y locomotora de los cachorros llegan a ser muy similares a las del adulto, se registró el cambio del tipo de alimentación de líquida a sólida, apareció un gran número de patrones conductuales, se registraron 38 comportamientos de diferentes categorías, a diferencia de las 4 de la etapa de transición; se empezaron a establecer las relaciones sociales con los demás miembros de su manada, además de continuar aquéllas con la madre y hermanos de camada.

La madre y las crías se encontraban separadas en una caseta y no en una madriguera; por razones médicas, en vez de juntarse a las 3 semanas, que correspondería a la edad en la que suelen salir de la madriguera (Mech, 1970, Murie, 1944, Zimen, 1981), se reunieron entre los 56 y 106 días, a pesar de estar encerrados los cachorros tenían contacto olfativo, auditivo y visual (limitado) con el exterior, por lo que se puede considerar que la socialización con el resto del grupo inició a la edad esperada aunque de manera limitada y se completó al estar toda la manada reunida, aunque a una edad posterior. 
Cabe mencionar que se tienen registros de otras camadas de lobos mexicanos que empezaron a salir de la madriguera a las 3 semanas de edad.

Woolpy y Ginsburg (1967) señalan que es posible socializar a un lobo a cualquier edad, y, en este estudio se pudo apreciar que existe una cierta plasticidad en cuanto a la edad límite para que se pueda llevar a cabo la socialización en los lobos, lo que concuerda también con el trabajo de Markwell y Thorne (1987), en el que señala que el final de esta etapa parece estar determinado por lo que haya ocurrido en ella, y por lo tanto, está sujeto a modificación.

La importancia de esta etapa no es su duración, sino que representa importantes procesos de desarrollo, su temporalidad puede variar entre individuos según la experiencia que hayan adquirido en las circunstancias particulares en que se encuentren, .sin embargo, es necesario reunir mayor información para poder establecer qué tan plástica puede ser así como las condiciones que lo determinan.

La mejoría en las capacidades motoras fue evidente, se concuerda con McLeod (1996) y McLeod y Fentress (1997) en que tanto los componentes posturales como las secuencias de los patrones conductuales van siendo más estructurados con la edad, lo que está relacionado con la maduración del electroencefalograma (EEG), la mielinización final de la médula espinal (Fox, 1964b, 1966, Gorska, 1974), y en general, con la maduración sensorial y motora (Loubiere, 2010), por lo que el cachorro es capaz de percibir y reaccionar ante su entorno en la forma 
adulta, lo que le permite aprender de su ambiente a través de la experiencia y asociación (Markwell y Thorne, 1987).

Esta es una etapa de un rápido desarrollo de patrones conductuales, en contraste con la etapa de transición, en la cual los cambios son principalmente en las capacidades sensoriales y motoras (Fentress, 1967, Fuller y Fox, 1969, Scott y Fuller, 1965, Zimen, 1981).

\section{Etapa juvenil}

Los resultados de este estudio coinciden con Fentress et al., (1987), Mech (1970), Fritts y Mech (1981), Markwell y Thorne (1987), Scott y Fuller (1965), Woolpy (1968), Zimen (1975) en que se durante esta etapa se observa un incremento gradual en las habilidades motoras, aprenden la relevancia de su comportamiento y exhiben conductas conforme a la situación y pasan a ocupar su posición en la jerarquía social de la manada. Dada su condición de cautiverio, no se pudo hacer comparaciones en lo que respecta al aprendizaje de la cacería de grupo ni la dispersión.

Como ya se había mencionado, al estar separados los lobeznos con la madre en las casetas, con contacto limitado con el resto del grupo, y reunirlos después de los dos meses de edad, hizo que la etapa de socialización se extendiera hasta el 4ํㅡㄹ (se hace la indicación hasta esta edad porque los datos del estudio están divididos en meses, no se hizo el análisis por semanas o días), sin embargo, ésto 
no se contrapone con el hecho de que esta etapa termina cuando los cachorros comienzan a tener mayores desplazamientos y a tener posible contacto con elementos ajenos al entorno familiar; esta plasticidad no parece ser ilimitada, porque se ha observado que existe un mejor acoplamiento del grupo cuando se reúnen a una menor edad de las crías.

Esta etapa suele ser descrita como se mencionó al inicio de este apartado, lo que puede dar lugar a que se piense que es homogénea desde los 3-4 meses hasta los 22-24 meses de edad. Haber (1977) es el único que menciona que al inicio los juveniles son muy tímidos, después intrépidos, y que posteriormente alcanzan una actitud más prudente. Al analizar los resultados de este estudio se ha encontrado que no sólo la etapa es heterogénea, sino que el análisis multivariado indica que de manera natural se presentan 4 sub etapas, que a continuación se describen en base a lo observado.

La primera sub etapa propuesta, que pudiera ser Ilamada "Infantil", se caracteriza por una gran dependencia de alimento de los padres, incluso en cautiverio, a pesar de que los cachorros tienen acceso directo a éste, siempre están solicitándolo a los padres o a otros miembros de la manada, también se observa una gran cantidad de juego y en los padres se detecta una gran tolerancia hacia los lobeznos, así como poca agresión de baja intensidad entre éstos.

Esta subetapa termina aproximadamente a los 8 meses de edad, y fue en este momento cuando se registra ya un escenario diferente al anterior, pero es un 
cambio gradual, no abrupto ni marcado por un solo evento. En el caso de animales silvestres esta etapa podría terminar un poco antes, en el momento en el que los juveniles empiezan a cazar con los padres y dejan de ser alimentados, pero no hay estudios respecto a si en este momento la tolerancia hacia y entre ellos disminuye.

La segunda sub etapa, que comprende de los 9 a los 15 meses de edad, podría ser llamada "de Independencia", ya que en este periodo los juveniles dejan de ser alimentados por los miembros de la manada, la tolerancia hacia ellos disminuye, especialmente durante la época de celo, que coincide cuando los adultos llegan a ella, la rivalidad entre ellos comienza a ser más o menos evidente, aunque la agresión es todavía de baja intensidad en su mayoría y muy ritualizada, y hacia finales de esta etapa pueden empezar a participar de los conflictos sociales del grupo cuando éstos ocurren, hasta ahora se ha observado que participan como apoyo a los padres en contra de algún otro miembro adulto de la manada; ésto ha sido ya reportado por Fentress et al., (1987) y Zimen (1975).

Cabe señalar que esta sub etapa coincide con la edad a la que más comúnmente se empiezan a dispersar en vida silvestre (Mech y Boitani, 2003). El juego está más o menos presente dependiendo de la composición y particular situación social de la manada, pero de manera general ya no es tan importante como en la sub etapa anterior. 
La tercera sub etapa va de los 16 a los 20 meses de edad, puede ser llamada "de cuidado aloparental". Cuando los nuevos cachorros que se encuentran con la madre se reúnen con el resto de la manada, la conducta de los juveniles abre un nuevo espacio dedicado a la integración con las crías, exhibiendo conductas amistosas, de juego, alimentación y agresivas de baja intensidad, que se adiciona a las interacciones ya existentes entre los mismos juveniles y entre éstos con los adultos, pero que resulta en un cambio en la frecuencia total y proporción de los diferentes comportamientos durante esta sub etapa; las conductas que se presentan por vez primera son aquéllas relacionadas con el aporte de alimento a los lobeznos.

En este estudio la madre y crías se encontraban separadas del resto del grupo, por lo que el proceso de integración fue más abrupto y posterior que cuando nacen en madriguera, pero en esencia fue el mismo en ambas situaciones.

Esta sub etapa no depende de la edad exacta de los juveniles, sino más bien de cuándo nazcan los nuevos lobeznos y cuándo comiencen a interactuar con ellos. En el caso en el que se perdieron los cachorros a una temprana edad o no hubo una nueva camada en este trabajo se ha observado que los padres pueden volver a alimentar a los juveniles aunque de manera menos rigurosa, además de lo que éstos consuman por su cuenta; sin embargo es posible que en vida silvestre este comportamiento en las mismas circunstancias sea reprimido debido a la diferencia en la disponibilidad de alimento entre ésta y el cautiverio. 
La cuarta y última sub etapa comprende de los 21 a los 24 meses de edad, pudiera ser llamada "Incorporación a la vida adulta", ya que es cuando los lobos jóvenes tratan de lograr una posición social bien definida, tanto entre los hermanos de camada como con los demás miembros de la manada, buscando siempre tener el sitio más alto posible; éste ha sido un proceso largo y gradual, que inició al menos desde la etapa de socialización, en este momento se refleja en una mayor proporción de conductas de agresión, y un posible incremento en la frecuencia de aquéllas de mayor intensidad; pero no hay una edad exacta a la que ésto ocurre, sino que depende de las particulares circunstancias por las que cada grupo haya pasado, el oportunismo es un factor importante, alguna lesión o enfermedad no fatal pueden contribuir a inclinar la balanza a favor de algún animal; tampoco se trata necesariamente de un resultado definitivo, ya que una manada es un sistema dinámico.

En el caso de los lobos silvestres, esta sub etapa también correspondería a uno de los momentos de mayor probabilidad de dispersión del grupo familiar, no sólo por el aumento de la tensión social entre los individuos, sino por la otra característica importante de este periodo, que es la pubertad, cuando los individuos empiezan a madurar sexualmente se manifiesta la búsqueda y establecimiento de la pareja, ya sea en cautiverio o en vida silvestre, en este estudio, en algunos casos se formaron las parejas artificialmente, mientras que en el caso en que no fueron separados del grupo, los juveniles dirigieron su atención hacia el padre o la madre, pero en todas las situaciones se observó la aparición de conductas sexuales y la presencia de aquéllas relacionadas con el cortejo. 
En este aspecto, tampoco se puede establecer una edad exacta para estos comportamientos, ya que dependería también de la fecha de nacimiento y del momento en que las hembras inician el ciclo estral, aunque es aceptado generalizarlo a los 22 meses (Asa y Valdespino, 1998, Kreeger, 2003).

Este estudio coincide con Ginsburg (1987) en cuanto a que el lobo juvenil es diferente al lobo puberto, en cuanto a que tiene una mayor capacidad locomotora e intelectual.

A pesar de que se han realizado algunos estudios sobre la dispersión de algunos de los miembros de la manada (Fritts y Mech, 1981, Fuller, 1989, Gese y Mech, 1991, Mills, 2006, entre otros), se ha encontrado un amplio intervalo de edad en el que los lobos pueden abandonar su manada natal, de manera general desde los 5 meses hasta adultos de 3 años (Mech y Boitani, 2003), lo que significa que individuos en edad juvenil pueden ser capaces de dispersarse, y aunque se considera que la tensión social y la disponibilidad de alimento pueden ser factores importantes (Zimen, 1976), la variación en las condiciones detonantes es muy grande y no se han hecho estudios sobre las condiciones particulares que llevan a cada individuo a separarse de su familia. 


\section{Conductas de las crías y juveniles}

Juego

En el Anexo IV se presenta información adicional sobre este comportamiento que servirá de complemento a la presente discusión.

Acerca de las conductas de juego, los resultados de este estudio concuerdan con Caro (1988), Fedderson-Petersen (1991), Martin y Caro (1985), Peters (1980), Yachmennikova y Poyarkov (2011), quienes reportan que las conductas de juego son la actividad principal dentro de los patrones sociales de los cachorros de lobo, y en general, de mamíferos en desarrollo; Scott y Fuller (1965) señalan que el juego en perros aparece al principio de la etapa de socialización, es decir, el primer mes de vida. Pal $(2008,2010)$ estudió el juego en perros asilvestrados en India, y menciona que el comportamiento social de los cachorros comienza a desarrollarse a las 3 semanas.

Del mismo modo, Bekoff (1974b), Fox (1970a), McLeod y Fentress (1997), Mech (1970), Murie (1944), Pal (2008, 2010), Scott y Fuller (1965), Ward et al., (2008), Young y Goldman (1944) han reportado la aparición de juego al inicio de la etapa de socialización, a las 3 semanas de vida, en perros, lobos y coyotes.

Todos estos trabajos se ajustan muy bien con los resultados de este estudio, y se puede apreciar que están relacionados con el estado de desarrollo que han 
alcanzado los cachorros a esta edad, y los cambios subsiguientes, por lo que se concuerda con Bekoff (1972) y Loubiere (2010) en que la expresión de un comportamiento sólo es posible si las capacidades subyacentes están lo suficientemente desarrolladas.

Se considera que todas las características que definen el juego (Bekoff, 1974b, Burghardt, 2010, Packard, 2003, Zimen, 1981) fueron observadas, incluso si el término "placentero" es subjetivo, corresponde muy bien a la actitud exhibida por los cachorros y juveniles.

Del mismo modo, se pudo apreciar que la asociación entre los componentes posturales se incrementaba con la edad; lo que concuerda con lo señalado por McLeod (1996) y Fentress (1983) con respecto a que durante la ontogenia se presenta una progresión jerárquica, de tal modo que con la edad se van expresando combinaciones de acciones más elaboradas.

Se observa, al igual que Maier (1998), que el tipo de juego que se exhibe está relacionado con el comportamiento de los adultos, en los lobos se pueden apreciar en el juego elementos relacionados con la conducta agonista y de depredación.

De manera similar Alekseeva et al., (2014), Biben (1983) y Kleiman (2011) consideran que el juego está relacionado con el tipo de sistema social, por lo que las especies más sociales exhibirían una mayor proporción de juego social que 
individual, en este trabajo se pudo apreciar claramente que la frecuencia del juego social fue mayor que el juego individual.

Este estudio concuerda con Bekoff (1974b), McLeod (1996) y Zimen (1982) en cuanto a que en el juego de los cachorros de lobo no se establecen relaciones de dominancia.

Las conductas de juego analizadas en el presente estudio -solicitud de juego, juego persecutorio, juego con contacto corporal, juego solitario y juego con objetos-, ya han sido analizadas en estudios anteriores con lobos, perros, coyotes y hienas manchadas.

Servín (1991), y Zimen (1982) analizan la solicitud de juego, el juego persecutorio y el juego con contacto corporal, Bekoff (1974b) cuantifica la solicitud de juego, Feddersen-Petersen (1991) incluye en su estudio una conducta llamada Mimic Play, que implica un juego con el compañero sin contacto corporal, se caracteriza por una comunicación lúdica por imitación principalmente de algunos gestos, en el presente trabajo no fueron registrados los diferentes gestos de los animales, pero quedaron incluidos durante los diferentes eventos de juego.

Cordoni (2009) separa el juego en solitario y social, pero en el primero incluye tanto el juego solitario y juego con objetos de este estudio. Lo que Pal (2010) denomina play-mounting y play fighting corresponden conjuntamente al juego con contacto corporal, mientras que aggressive play se refiere al juego persecutorio. 
En el estudio de Tanner et al., (2007) la conducta de romping es el equivalente al juego solitario, y el juego con objetos es considerado sólo para aquéllos que son restos de alimento, como huesos, plumas o piel, y para el resto, como palos, y plantas utiliza el término non-nutritive chewing, mientras que aquí se considera cualquier tipo de objeto.

Los comportamientos de pseudosexual play en Pal (2010) y mounting play en Tanner et al., (2007) no corresponden a ninguna de las conductas de juego de este estudio, sino que fueron incluidas en otra categoría conductual, como se verá más adelante.

En este trabajo se observó que el juego solitario se presenta en menor frecuencia que el juego con otros compañeros, además de que el juego con contacto corporal aparece primero y es el de mayor frecuencia, lo que coincide con lo reportado por Feddersen-Petersen (1991) y Zimen (1982).

El patrón de frecuencias de los diferentes tipos de juego encontrado en este estudio es similar al reportado por Tanner et al., (2007) en hienas manchadas. Los resultados de la investigación de Feddersen-Petersen (1991) coinciden con este trabajo solamente en la categoría de juego con contacto corporal.

Probablemente el incremento inicial de la frecuencia de juego está relacionado al desarrollo físico de los cachorros, mientras que posteriormente sea más 
importante la composición y organización social particular de la manada a la que pertenecen.

Es interesante mencionar que Bekoff (1974b) encuentra mayores frecuencias de juego y menores de comportamientos agonistas en perros que en lobos, mientras que Fedderson-Peterson (1991) reporta lo opuesto. Este estudio solo trata con lobos, por lo que no puede coincidir con ninguno de ellos, pero es posible que la raza, que fue diferente, así como la composición de sus grupos o el manejo de los ejemplares sea al menos en parte responsable de esta diferencia.

Pal (2010) y Ward et al., (2008) reportan una asimetría en el juego de cachorros de perros, exhibiendo los machos mayores frecuencias, mientras que Bekoff (1974) no las encuentra en lobos coyotes y beagles, ni Cordoni (2009), en otros perros, Tanner et al., (2007) en hienas manchadas, y Wagener (1998) en lobos rojos. En este trabajo, de manera general se considera que tampoco se encontraron asimetrías por sexo, lo que, de acuerdo a estos últimos investigadores, puede deberse a que en los lobos el papel que desempeñan ambos sexos en el mantenimiento de las manadas es muy similar, pero para poder tener resultados más precisos, sería necesario cuantificar el juego en varias camadas de composición similar en condiciones similares y tener en cuenta la variación del carácter individual de los lobeznos.

En este estudio sólo se cuantificó un comportamiento como solicitud de juego, sin embargo, Bekoff (1974b) describe varios patrones adicionales utilizados por 
cachorros de lobos, coyotes y beagles para iniciar el juego social: aproximación exagerada, aproximación/retirada, movimientos generales, face-pawing, leap-leap y ladrido; algunos de los cuales fueron observados pero considerados parte de solicitud de juego, como movimientos generales, aproximación exagerada y aproximación/retirada, mientras que face-pawing se registró junto con otros patrones de juego con contacto corporal. Un patrón muy similar a leap-leap fue observado durante el juego solitario, mientras que en ningún momento se detectó ladrido para solicitar juego al compañero.

$\underline{\text { Juego con objetos }}$

Las definiciones utilizadas por Fagen (1981) concuerdan con la de este estudio; del mismo modo, se pudo apreciar también que es una actividad bulliciosa y que parecen disfrutar.

Hall (1998), Pal (2010) y Tanner et al., (2007), encuentran, en perros y en hienas manchadas, al igual que este estudio, que el juego con objetos se exhibe en menor frecuencia que el juego social. Del mismo modo, en Pal (2010), Tanner et al. (2007), y este trabajo, se aprecia que el patrón ontogenético en las 3 investigaciones es menos claro que en las otras formas de juego, y sugieren que depende también de la disponibilidad de objetos que tengan en su entorno. Estos resultados difieren de lo reportado por Wagener (1998) en lobos rojos, que encuentra una mayor frecuencia de juego con objetos y en un patrón diferente al antes mencionado. 
En Vázquez González (2008) se presenta una relación de objetos con los que jugaban los lobos mexicanos, la mayoría de los cuales no eran parte del albergue, sino que eran arrojados al interior del mismo por el público visitante; es posible que la novedad de estos objetos favorezca que los cachorros muestren interés por ellos.

Tanner et al.; (2007) no encuentran relación de esta conducta con la erupción dental en las hienas manchadas, pero Pal (2008) encuentran una posible relación, en este estudio, desde que aparece este comportamiento, ya presentan la dentición de leche, por lo que no se aprecia una posible relación a esta edad ni cuando mudan a la dentición permanente.

Ambos autores coinciden en que esta conducta puede ser un medio para obtener información de su medioambiente, lo que puede ser aceptable también para los lobos mexicanos. Además de facilitar las interacciones con sus hermanos de camada, perfeccionar sus destrezas sensoriales y motoras.

Se puede decir que el comportamiento observado en estos lobos mexicanos concuerda bien con lo señalado por Hall (1998), quien menciona que estudios previos presumen que el juego con objeto en animales jóvenes debe tener efecto a corto y/o largo plazo en el desarrollo de las destrezas y el comportamiento, proporciona a estos animales la oportunidad de aprender y practicar destrezas que serán vitales para ellos al llegar a la edad adulta. 
A pesar de haberse llevado a cabo numerosos estudios sobre el juego, existe aun discrepancia entre los diferentes autores en cuanto a su función (Bekoff, 1972, 1974b, 1989, Bekoff y Allen, 1998; Burghardt, 2010, Byers, 1998; Byers y Walker, 1995, Caro, 1988, Cordoni, 2009, Held y Spinka, 2011, Maier, 1998, Packard, 2003, Pal, 2010, Pellegrini et al., 2007, Pellis e Iwaniuk, 2000, Pellis y Pellis, 1998, Tanner et al., 2007, Thompson, 1998; Ward et al., 2008, Zimen, 1982).

De manera general, se considera todas las posibles funciones pueden tener al menos parte de verdad en el caso de los lobos, probablemente porque es algo muy complejo, de índole multifactorial y difícil de demostrar científicamente. El hecho de que las frecuencias obtenidas hayan sido casi tan altas como las conductas alimenticias denota la gran importancia que tienen para el desarrollo de las crías de esta especie.

\section{Conductas agonísticas y sumisas}

En el Anexo $\mathrm{V}$ se presenta información complementaria relativa a esta categoría conductual.

La conducta agresiva en los cachorros no se presentó sino hasta el día 20, que prácticamente ya es el inicio de la etapa de socialización; en un principio puede ser difícil distinguirla de la conducta de juego con contacto corporal, pero gradualmente las pautas van siendo bien reconocibles, lo que coincide con Aguilera et al., (1982), McLeod (1996) y McLeod y Fentress (1997) en que tanto 
los componentes posturales como las secuencias de los patrones conductuales van siendo más estructurados con la edad.

En este estudio se pudo apreciar claramente que las primeras manifestaciones de agresión en los cachorros son realmente amenazas y no expresan agresividad de alta intensidad, sino que está principalmente ligada al acceso a la comida, ésto se registró principalmente en el periodo de socialización y juvenil 1, lo que concuerda con lo señalado por Zimen $(1976,1982)$ en cuanto a que dichas interacciones no suelen estar relacionadas con la jerarquía, y no coincide con lo señalado por Fox (1969), McDonald (1987) y Yamechnnikova y Poyarkov (2011), quienes consideran que los lobeznos establecen la jerarquía entre ellos durante el periodo de socialización.

Zimen $(1975,1976)$ reporta que la agresión en los lobos juveniles va incrementándose con la edad, y que los primeros conflictos serios comienzan a partir de los 9 meses. En este estudio se registra un incremento de agresión ya dentro de un contexto serio durante el segundo año de vida, lo que se debe a las diferentes composiciones de las manadas estudiadas y no a un desacuerdo con lo afirmado por Zimen, ya que como afirma Yachmennikova (2012) cada manada presenta un conjunto de relaciones único.

Los padres, los otros adultos y juveniles de la manada son bastante tolerantes con las crías durante la etapa de socialización, sin embargo a partir de la sub etapa juvenil 2 dicha tolerancia va disminuyendo y la agresión empieza a incrementarse. 
Los cachorros y juveniles suelen responder con conductas de sumisión. Al llegar a la sub etapa juvenil 4 conforme crece recibe mayor agresión pero a su vez tiene mayor capacidad de respuesta, pudiendo desatar peleas relevantes cerca de la edad adulta, el resultado esta relación establece el papel que jugará más adelante en la estructura grupal; gradualmente el individuo encuentra su lugar en la manada.

Estos resultados van de acuerdo con lo encontrado por Allen (1979), Zimen (1975, 1981, 1982) y Woolpy (1968) en cuando a la tolerancia, incremento de la agresión y establecimiento de la jerarquía durante el segundo año de vida; coinciden también con Mech (1999) en que existe una relación de dominancia natural de padres a hijos, y con Schenkel (1967) en cuanto a que las conductas de sumisión sólo se expresan cuando existe una distancia social bien establecida entre los individuos.

Concuerdan con Zimen (1982), que encuentra un porcentaje relativamente bajo de conductas agresivas pero un gran número de patrones de esta categoría: así como en cuanto a que los cachorros tienen la capacidad de reconocer las relaciones de dominancia entre los lobos mayores a partir del final de la etapa de socialización y principio de la juvenil.

Al igual que Fentress et al., (1987) y Zimen (1982) se observa la participación de los lobos juveniles en los ataques de grupo iniciados por animales adultos y dirigidos a otros adultos. Este comportamiento se registra a partir de la sub etapa 
juvenil 2. Observaciones realizadas en este trabajo permiten aseverar que en la estructuración jerárquica, la agresividad asociada puede ser un tanto oportunista.

En datos no cuantificados se pudo apreciar la exhibición de patrones de agresión mostrando dominancia por parte de un cachorro a otro cuando éste último sufría alguna lesión por causas externas al grupo, esta situación puede ser reversible o permanente. Del mismo modo algunas hembras juveniles agredieron a su progenitora cuando ésta se encontraba en una situación vulnerable.

\section{Conductas pseudosexuales}

Los patrones conductuales descritos en este estudio como pseudosexuales han sido reportados por otros autores en cánidos y hienas manchadas, sin embargo ellos los han incluido en la categoría de juego:

Bekoff (1974b), y Fox (1969) estudian la presencia de patrones de conductas sexuales durante los eventos de juego de los cachorros de lobos, coyotes, zorras y perros en cautiverio). Pal (2010) registra y cuantifica diversos tipos de juego en cachorros de perros asilvestrados de la India, incluido el juego pseudosexual.

Asimismo, Scott y Fuller (1965) y Ward et al., (2008) aluden a la conducta sexual Iúdica en los cachorros de perro. En lobos grises, Fentress (1967) señala que un cachorro de lobo presentaba movimientos pélvicos y sujetar. En cachorros de 
hiena manchada se han cuantificado varios tipos de juego, entre los cuales se considera la monta lúdica (Tanner et al., 2007). En todos estos estudios la frecuencia de las conductas mencionadas fue muy baja.

Las conductas pseudosexuales se registraron en muy baja frecuencia durante el presente estudio, y no se observaron durante las sesiones de juego, sino cuando estaban relajados; por otro lado, los datos son insuficientes como para poder determinar si es apropiado considerarlas como parte del juego o como una categoría aparte. Sin embargo, estos resultados concuerdan con Bekoff (1974b), Fentress (1967), Fox (1969), Pal (2010), Scott y Fuller (1965), Tanner et al., (2007) y Ward et al., (2008) en la baja frecuencia y a la edad en la que se presentaron.

En este trabajo se registra a los 7 meses de edad una monta no sexual durante una agresión entre dos hermanas de camada por parte de un hermano de camada macho hacia una de estas cachorras, interrumpiendo la agresión entre ellas, lo que sugiere que pudo presentarse en un contexto diferente al resto de los registros del estudio, sin embargo sería muy precipitado sacar conclusiones con tan poca información.

Independientemente de la categoría a la que se asignen estos patrones motores, se considera que su presencia está relacionada con lo que señala Fentress (1967, 1983), que ciertos componentes conductuales básicos parecen estar presente en patrones funcionales divergentes; así, conforme el lobo se desarrolla las secuencias conductuales llegan a ser más estables y predecibles. 
Este autor considera que hay evidencia de que en la ontogenia existe una progresión jerárquica, en la que los sistemas pasan de un estado de estructuras sueltas a otro de estructuras simples bien definidas y posteriormente a una combinación más elaborada de acciones. Menciona también que patrones motores similares pueden ser usados para lograr diferentes objetivos.

Del mismo modo, Aguilera et al., (1982) y McLeod (1996) señalan que los patrones conductuales llegan a ser más estructurados con la edad. Todo parece indicar que en este caso, se presentan primero los patrones motores correspondientes a estas conductas sexuales en un contexto diferente, y más adelante se integran al patrón característico del comportamiento sexual de los adultos.

$\underline{\text { Conductas sexuales }}$

Todos los autores en general consideran que los lobos alcanzan la pubertad aproximadamente a los 22 meses de edad, aunque en ocasiones, las hembras la alcanzan hasta el tercer invierno.

Lo observado en los animales durante este estudio corresponde bien con lo señalado por investigadores como Asa y Valdespino (1998), Kreeger (2003), Mech (1970), Paquet et al., (1982), Rausch (1967), Seal et al., (1979), Schotté y Ginsburg (1978, 1987), Woolpy (1968), Young y Goldman (1944), Zimen (1975, 
1981); la mayor parte de los lobos llegaron a la madurez sexual durante la sub etapa juvenil 4.

Dado que el programa de reproducción en cautiverio de lobo mexicano lleva a cabo cruzas seleccionadas (Siminski, 2016a), en diversas ocasiones las hembras fueron separadas para evitar que se aparearan, y no se pudieron registrar todos los comportamientos sexuales posibles. De los animales que han formado parte de este programa se han observado algunas lobas que tienen su primer parto a los 2 años de edad (Siminski, 2016b), sin embargo, ésto depende de la edad a la que fueron seleccionadas para reproducción, el tiempo que tarde el acoplamiento con el macho, y el albergue, no solo de la edad a la que alcanzan la pubertad.

En el caso de las hembras incluidas en este estudio, se observaron algunas con sangrado y edema vulvar, así como atractividad y proceptividad a los 22 meses, pero otras que aunque presentaron a esta edad sangrado en la vulva, no exhibieron atractividad ni proceptividad. Sin embargo, al año siguiente ya presentaron un celo normal, e incluso algunas de ellas se reprodujeron exitosamente más adelante. Estas observaciones coinciden con lo hallado en los estudios de Schotté y Ginsburg $(1978,1987)$ y Zimen $(1976,1981)$, quienes han observado lobos que no exhiben conductas sexuales a pesar de presentar el sangrado de la vulva.

En el caso de los machos estudiados, todos ellos presentaron un comportamiento sexual normal aproximadamente a los 22 meses, aunque no todos pudieron 
exhibir el repertorio completo debido a que fueron reprimidos mediante agresiones de diferente intensidad por individuos que se encontraban por encima de ellos en la jerarquía; Asa (1997) y Packard et al (1985) también han reportado supresión del comportamiento reproductivo en lobos sexualmente maduros.

Por otro lado, hay reportes de observaciones de comportamiento sexual en lobos grises en cautiverio, tanto machos como hembras de 10 meses de edad (Medjo y Mech (1976), Mech y Seal (1987), Packard et al, 1983, 1985, y Seal et al., 1979, 1987) y un lobo mexicano macho de 10 meses exhibió conductas sexuales y se obtuvo semen de buena calidad (expediente Lobo mexicano No. 950, ZSJA-2016).

Ninguno de los machos de este estudio presentó el comportamiento sexual característico a los 10 meses de edad, que corresponde a la sub etapa juvenil 2. Sin embargo, se registraron en estos lobos machos algunos patrones motores sexuales dirigidos a la madre cuando ésta se encontraba en celo, pero no se consideraron verdaderas conductas sexuales, porque fueron de muy baja intensidad y frecuencia. Shotté y Ginsburg (1978) y Zimen (1981) también han observado machos juveniles de 10 meses que muestran interés por la hembra dominante durante el celo pero sin llegar a aparearse.

Ninguna de las hembras del estudio presentó comportamiento sexual, sangrado ni edema vulvar a los 10 meses de edad. Sería conveniente que en un futuro se estudie la ontogenia del patrón hormonal en los lobos para complementar el conocimiento sobre la ontogenia de la conducta sexual. 
En este trabajo de investigación se obtuvieron registros conductuales del repertorio sexual completo aproximadamente a los 22 meses de edad en dos casos, ambos machos; en cuanto a las hembras se pudo observar en algunas la mayor parte del repertorio, sin incluir la cópula, ya que fueron encerradas para impedir que ocurriera. La secuencia de eventos exhibida corresponde con las descritas por Fuller y Fox (1969), Mech (1970), Peters (1980), Rabb et al., (1967), Woolpy (1968) y Zimen (1981).

En los lobos de 22 meses, de ambos sexos se pudo apreciar que sus conductas sexuales eran dirigidas principalmente a sus padres, lo que es acorde con lo reportado por Jenks (2011), Schotté y Ginsburg $(1978,1987)$ y Zimen (1982) en cuanto a que los individuos que reciben mayor atención durante la época de celo son los de mayor jerarquía.

\section{Cuidados parentales y conductas alimenticias}

Las observaciones reportadas en este trabajo sobre las actividades de cuidado parental de los cachorros de lobo mexicano coinciden con las reportadas para otras subespecies de lobo gris en Norteamérica y Europa, tanto en cautiverio como en vida silvestre (Norteamérica-cautiverio: Fentress y Ryon, 1982, Woolpy, 1968; vida silvestre: Allen, 1979, Ballard et al., 1991, Ballard y Dau, 1983, Fritts y Mech, 1981, Fuller, 1989, Haber, 1977, Joslin, 1967, Kolenosky y Johnston, 1967, Mech, 1970, 1987, Murie, 1944, Potvin, 2004, Ruprecht et al., 2012, Young y 
Goldman, 1944. Europa cautiverio: Altmann, 1987, Zimen, 1981; vida silvestre: Alfredéen, 2006, Jedrzejewski et al., 2001, Kusak et al., 2005, Theuerkauf, et al., 2003, Tsunoda et al., 2009).

El comportamiento de los padres se ajusta a las conductas que las crías exhiben en las diferentes etapas de desarrollo, de tal modo que las conductas alimenticias de los cachorros y las de cuidado parental serán tratadas en esta sección.

En las etapas neonatal y de transición la madre provee todo el cuidado, el cual está enfocado a la alimentación y termorregulación de los cachorros, mientras que el padre concentra su actividad alrededor del recinto en el que se encuentra la loba con las crías, llevando incluso trozos de carne a la entrada del mismo, o regurgitando cerca de ahí, a pesar de estar separados por una puerta. Esto coincide con lo reportado para lobos en cautiverio y silvestres (Fentress y Ryon, 1982, Mech, 1970, Packard, 2003, Paquet, et al., 1982, Ruprecht et al., 2012, Young y Goldman, 1944, Zimen, 1981).

Posteriormente, en la etapa de socialización, la madre continua proporcionando alimento a los cachorros, pero poco a poco va sustituyendo la leche materna por regurgitaciones de comida semi-digerida. Al mismo tiempo, va pasando menos tiempo con ellos, que a su vez van interactuando más con los demás miembros de la manada, el padre, los hermanos nacidos el año anterior u otros adultos (cuando están presentes). Esto ha sido reportado tanto en cautiverio como en vida silvestre (Fentress y Ryon, 1982, Mech et al., 1999, Paquet et al., 1982, Vázquez González, 
2008, Zimen, 1981), lo que demuestra que se trata de conductas férreamente establecidas en la dinámica del desarrollo de los lobos.

En esta etapa el padre interactúa directamente con los cachorros, quienes lo reconocen como miembro relevante de la manada, de manera recurrente y entusiasta lo saludan y lamen sus belfos, en respuesta a lo cual el padre regurgita. Esto refuerza los lazos grupales, ya que los jóvenes reconocen en él una segunda fuente de alimento, similar a la madre, lo que también han observado Harrington et al., (1983), Mech (1970, 1999), Packard (2003), Peters (1980), Tsunoda et al., (2009), Young y Goldman (1944).

También se puso de manifiesto el carácter defensivo de los padres, que en algunas ocasiones se mostraron agresivos hacia el personal al entrar en el albergue y estar cerca de los cachorros, la intensidad de la conducta fue variable, según el individuo en cuestión. Mech (1970, 1987), Murie (1944) y Zimen (1981) reportan comportamientos similares.

En diversas ocasiones los ejemplares juveniles trataron de estimular a los padres para obtener alimento de éstos por regurgitación, del mismo modo éstos fueron a su vez receptores de la solicitud de alimento por parte de las crías. Éste comportamiento ha sido ya reportado por Fentress y Ryon (1982), Mech et al., (1999), Ruprecht et al., (2012), y Zimen (1982). Como lo han mencionado Mech (1970), y Zimen $(1981,1982)$, en esta etapa los cachorros se incorporan a la dinámica social de la manada. 
Durante la etapa juvenil, los padres muestran un desapego gradual a las crías, permitiendo que éstas se alejen cada vez más de ellos, explorando su ambiente e interactuando más con los otros miembros de la manada, lo que ya ha sido observado por Mech (1970), Packard (2003) y Zimen (1981).

En la sub etapa juvenil 1 se observa un incremento inicial en la tasa y cantidad de alimento regurgitado, que está relacionado con el crecimiento de los cachorros, pero posteriormente sigue un importante descenso gradual en la solicitud de alimento y en la tolerancia por parte de los adultos mientras se alimentan, al mismo tiempo los lobos juveniles están ya en condiciones de empezar a procurarse su alimento, en este estudio los animales van gradualmente comiendo por su cuenta la comida que se les proporciona, mientras que en estado silvestre van aprendiendo a cazar pequeñas presas y a seguir a los adultos hacia los sitios donde han matado a la presa (Packard, 2003), lo que eventualmente lleva a la independencia alimenticia y al orden jerárquico de alimentación.

Es interesante que la edad en la que se presenta la caída final en la frecuencia de regurgitación por parte de los padres coincide con la edad mínima en la que se ha registrado con más frecuencia la dispersión de los lobos (Gese y Mech, 1991, Mech y Boitani, 2003).

Hace tiempo que se ha cuestionado la contribución de algunos de los miembros de las manadas a la crianza de los cachorros o si permanecen cerca de ellos para interceptar las regurgitaciones de los padres para su beneficio, además de no 
exponerse directamente para defender a las crías (Harrington et al., 1983, Potvin et al., (2004). Con los resultados aquí reportados se apoya la tesis de los aloparientes tienen un papel importante en la crianza de los lobeznos, que también ha sido soportada por los estudios de Haber (2006), Mech et al., (1999) y Stahler et al., (2013) en animales silvestres.

Es interesante apuntar que en este trabajo los animales socialmente marginados (llamados omegas, excedentes, periféricos) suelen ser restringidos por los padres en la alimentación de las crías y coincide con lo reportado por Fentress y Ryon (1982) y Zimen (1981).

No se pudo apreciar que los padres manifestaran preferencias hacia las crías en términos de alimentación o agresividad; son los mismos juveniles quienes por medio de conductas de juego y agresión establecen relaciones jerárquicas entre ellos, esto coincide con lo reportado por Wagener (1998) en lobos rojos y Zimen $(1975,1981)$ en lobos grises.

Genes y medioambiente

Es importante señalar que se concuerda con aquellos autores que consideran la ontogenia como un proceso epigenético, en el cual hay una interacción continua y recíproca entre los factores genéticos y medioambientales, dejando atrás las controversias surgidas en los inicios de la Etología como ciencia (Dewsbury, 1978, Drickamer y Vessey, 1992, Fox, 1966, 1970b, Loubiere, 2010, McFarland, 1987, 
Pellegrini et al., 2007, Timbergen, 1963). Del mismo modo, Scott y Fuller (1965) en su estudio de desarrollo con perros comparten también este punto de vista.

Por otro lado, se pudo apreciar al igual que Fentress (1983) en sus estudios con cachorros de lobo, que algunas características conductuales del organismo pueden permanecer notablemente consistentes bajo circunstancias superficialmente diferentes.

Se encontraron también coincidencias con el trabajo de Moran (1987), quien de similar manera menciona que los patrones de conducta social de los lobos durante la ontogenia pueden ser producto de una compleja combinación de varios procesos, como la configuraciones relativamente estables de los patrones descritos que considera podrían ser primariamente de origen endógeno, especieespecíficas e independientes de la experiencia previa, Mientras que las diferentes relaciones que establecen los individuos podrían ser resultado de la historia particular entre éstos o de momentos particulares experimentados por ellos.

Validez de los estudios de comportamiento en cautiverio

La importancia de este tipo de estudios ha sido señalada anteriormente en los programas de recuperación de especies en peligro, tanto en la parte de reproducción en cautiverio como en la conservación ex situ (Wielebnowski, 1998). Contribuyen tanto en la mejoría de las condiciones de cautiverio que favorezcan 
su reproducción como en la planeación de las reintroducciones para que tengan una mayor probabilidad de ser exitosas.

Se considera, al igual que otros autores (Bekoff, 1972, 1989, Fentress et al., 1987, Harrington y Paquet, 1982, Packard, 2003), que los estudios detallados de comportamiento en cautiverio de los lobos contribuyen para clarificar e interpretar las observaciones fragmentarias obtenidas de los estudios de animales silvestres, ya que con los primeros se pueden obtener datos que serían prácticamente imposibles conseguir en campo.

Que factores como las relaciones sociales existentes en las manadas se ven menos afectadas por factores medioambientales, a diferencia de otros como la disponibilidad de territorio o presas. Los estudios de cautiverio, al tener condiciones más controladas, tienen menos variables a considerar, por lo que la interpretación de los resultados puede ser más sencilla.

Investigadores como Fox (1973), Harrington et al., (1982, 1983), Jenks (2011), Packard (2003), y Zimen (1976) han utilizado información sobre el comportamiento de los lobos tanto de cautiverio como de vida silvestre sin que la veracidad de sus hallazgos se vea comprometida. Así mismo, Ginsburg (1987) señala que a pesar de las diferencias en las condiciones de los estudios de comportamiento de los lobos en cautiverio han emergido generalidades que son extremadamente robustas y que son congruentes con las observaciones hechas en vida silvestre. 
Se coincide con Fentress et al., (1987), Ginsburg (1987), y Harrington y Paquet., (1982), en cuanto a que los estudios de la conducta de los lobos en cautiverio tienen limitaciones, que no pueden proporcionar información sobre todos los aspectos del comportamiento, pero que si se tiene consciencia de ello, la información obtenida no será equivocada. Además, se podrá lograr un mejor entendimiento del comportamiento de esta especie si se consideran complementarios ambos tipos de estudios y existe una cooperación entre los investigadores de las poblaciones cautivas y silvestres.

Con todo el conjunto de datos obtenidos, se apoya la hipótesis presentada al inicio de este escrito en cuanto a que la ontogenia de la conducta de los lobos mexicanos implica un proceso heterogéneo de aparición y desaparición de comportamientos que se ve reflejado en cambios cualitativos y cuantitativos de las diferentes conductas durante su desarrollo, desde el nacimiento hasta alcanzar la edad adulta; además, si bien la ontogenia del comportamiento es un proceso continuo, existen elementos conductuales clave que permiten describir etapas bien definidas de dicho proceso. 


\section{CONCLUSIONES}

$>$ De acuerdo a lo encontrado en este trabajo sí es posible establecer etapas bien definidas en el proceso ontegenético de la conducta del lobo mexicano.

> La mayoría de los comportamientos aparecen durante la etapa de socialización, algunos se presentan temporalmente, pero la gran mayoría permanecen por el resto de su vida, con lo que estas etapas quedan definidas inicialmente por cambios cualitativos, mientras que en etapas posteriores por cambios cuantitativos y de intensidad.

$>$ En las primeras etapas el número de conductas es límitado, asociado al pobre desarrollo psicomotriz y conforme se alcanza la madurez del sistema nervioso las conductas van siendo más complejas y estructuradas.

$>$ Del mismo modo, el comportamiento en la primera etapa (neonatal) se compone de patrones innatos, y conforme van creciendo, en etapas posteriores se presentan elementos aprendidos, lo que permite una mayor plasticidad conductual.

$>$ En las primeras dos etapas (neonatal y transición) el individuo presenta un pequeño número de comportamientos, después sigue un periodo en el cual aparece la gran mayoría del repertorio conductual, y más adelante los 
cambios se pueden apreciar principalmente en frecuencia absoluta y relativa, así como en intensidad.

> Para que tenga lugar el proceso de socialización de los cachorros es necesario que alcancen un nivel de desarrollo del sistema nervioso y locomotor que les permita interactuar con sus congéneres, lo que ocurre en la etapa de socialización.

$>$ Las diferentes conductas que aparecen secuencialmente llevan a los cachorros a establecer el papel que jugará, de manera individual, en la manada. Además, la participación de los lobos juveniles en los conflictos jerárquicos de los adultos puede influir en su resultado.

> Las conductas asociadas al cuidado parental pueden relacionarse directamente con las etapas de desarrollo de los juveniles.

$>$ Cuando hay familiares u otros adultos relacionados, éstos participan directamente en la conformación del comportamiento de los cachorros.

$>$ El proceso ontogenético del comportamiento es esencial para la incorporación de los juveniles al grupo familiar de los lobos, lo cual ha demostrado ser uno de los atributos más relevantes en la sobrevivencia y evolución de esta especie. 


\section{BIBLIOGRAFIA}

Abdelmonem, A., V. A. Clark, y S. May. 2004. Computer-Aided Multivariate Analysis. $4^{\text {th }}$ ed. Chapman \& Hall/CRC. USA. 489 pp.

Aguilera, E., F. Alvarez, M. J. Fernandez, y J. Blázquez. 1982. Estructuración de las interacciones en una camada de lobos (Canis lupus). Doñana, Acta Vertebrata 9: 353-368.

Alekseeva, G. S., A. L. Antonevich, M. N. Erofeeva, y S. V. Naidenko. 2014. Social Play in the Development of Sibling Relations in Eurasian Lynx (Lynx lynx). Biology Bulletin 41(4): 382-390.

Alfredéen, A. C. 2006. Denning behavior and movement pattern during summer of wolves Canis lupus on the Scandinavian Peninsula. Doctoral Dissertation. Thesis No. 164. Departament of Conservation Biology. Swedish University of Agricultural Sciences. $36 \mathrm{pp}$.

Allen, D. L. 1979. The Wolves of Minong: Isle Royal Wild Community. University of Michigan Press. USA. 499 pp.

Altmann, J. 1974. Observational study of behavior: Sampling methods. Behaviour, 49: 227-267.

Altmann, D. 1987. Social behavior patterns in three wolf packs at Tierpark, Berlin. Pp 415-424 en: Man and Wolf. Advances, Issues, and Problems in Captive Wolf Research H. Frank. (Ed). Dr. Junk Publishers. The Netherlands. 439 pp.

Ames, N. 1980. Mexican Wolves in Captivity. A Review of the Lineage originating in the 1960's at the Arizona-Sonora Desert Museum. Unpublished report. New Mexico Department of Game and Fish. Santa Fe, New Mexico. 36 pp.

Asa, C. S. 1997. Hormonal and Experiential Factors in the Expression of Social and Parental Care Behavior in Canids. Pp. 129-149 en: Cooperative Breeding in Mammals. N. G. Solomon y J. A. French (Eds). Cambridge University Press. USA. $408 \mathrm{pp}$.

Asa, C. S., y C. Valdespino. 1998. Canid reproductive biology: An integration of proximate mechanisms and ultímate causes. American Zoologist 38: 251-259.

Atisko, J. J. 1976. Communication by Chemical Signals in Canidade. Pp 283-293 en: Mammalian Olfaction, Reproductive Processes, and Behavior. R. L. Doty (Ed.). Academic Press. USA. 344 pp. 
Baker, A. J., A. Baker, y K. V. Thompson. 1996. Pp 497-512 en: Wild Mammals in Captivity. Principles and Techniques. D. G. Kleiman, M. E. Allen, K. V. Thompson, y S. Lumpkin (Eds). The University of Chicago Press. USA. 639 pp.

Baker, R., y B. Villa. 1959. Distribución geográfica y población actuales del lobo gris en México. Anales del Instituto de Biología, UNAM 30: 369-374.

Ballard, W. B., L. A. Ayres, C. L. Gardner, y J. W. Foster. 1991. Den site activity patterns of gray wolves, Canis lupus, in South-Central Alaska. Canadian Field Naturalist 105: 497-504.

Ballard, W. B., y J.R. Dau. 1983. Characteristics of gray wolf (Canis lupus) den and rendezvous sites in South-Central Alaska. Canadian Field Naturalist 97: 299-302.

Barrows, E. M. 2000. Animal Behavior desk reference. 2nd ed. CRC Press. USA. 922 pp.

Bekoff, M. 1972. The development of social interaction, play, and metacommunication in mammals: An ethological perspective. The Quarterly Review of Biology 47: 413434.

Bekoff, M. 1974a. Social Play in coyotes, wolves, and dogs. BioScience, 24:225-230.

Bekoff, M. 1974b. Social Play and Play Soliciting by Infant Canids. American Zoologist 14: 323-340.

Bekoff, M. 1989. Behavioral Development of Terrestrial Carnivores. Pp 89-124 en: Carnivore Behavior, Ecology and Evolution (J. L. Glittelman Ed.). Cornell University Press. USA. 620 pp.

Bekoff, M. y J.A. Allen. 1998. Intentional communication and social play: how and why animals negotiate and agree to play. Pp 97-114 en: Animal Play: Evolutionary, Comparative, and Ecological Perspectives. M. Bekoff y J. A. Byers (Eds.). Cambridge University Press. Cambridge. 274 pp.

Bernal S., J., and J. M. Packard. 1997. Winter activity, courtship, and social behavior of two captive family groups of Mexican wolves (Canis lupus baileyi). Zoo Biology, 16: 435-443.

Biben, M. 1983. Comparative ontogeny of three South American canids, the maned wolf, crab eating fox, and bushdog. Implications for sociality. Animal Behaviour 31: 814826.

Boitani, L. 2003. Wolf Conservation and Recovery. Pp 317-340 en: Wolves. Behavior, Ecology and Conservation. L. D. Mech y L. Boitani (Eds.). University of Chicago Press. USA. 448 pp. 
Bogan, M. A., y P. Melhop. 1983. Systematic relationships of gray wolves (Canis lupus) in Southwestern North America. Occasional papers, University of New Mexico, Museum of Southwestern Biology 1: 1-21

Bolhuis, J. J., y L. A. Giraldeau. 2005. The Behavior of animals. Mechanisms, Function and Evolution. Blackwell Publishing. 511 pp.

Brown, D. E. 1983. The Wolf in the Southwest: the making of an endangered species. University of Arizona Press, Tucson, Arizona, USA, 195 pp.

Burghardt, G. M. 2010. The Comparative Reach of Play and Brain: Perspective, evidence and implications. American Journal of Play 2: 338-356.

Busch, R. H. 2007. The Wolf Almanac. New and Revised. A Celebration of Wolves and Their World. The Lyons Press. China. 274 pp.

Byers, J. A. 1998. Biological effects of locomotory play: Getting into shape or something more specific? Pp 205-220 en: Animal Play: Evolutionary, Comparative, and Ecological Perspectives. M. Bekoff y J. A. Byers (Eds.). Cambridge University Press. Cambridge. 274 pp.

Byers, J. A. y C. Walker. 1995. Refining the Motor Training Hypothesis for the Evolution of Play. The American Naturalist 146(1): 25-40.

Canals, M., y F. Bozinovic. 2011. Huddling behavior as critical phase transition triggered by low temperatures. Complexity 17(1): 35-43.

Carbyn, L. N, S. H. Fritts, y D. R. Seip (Eds.). 1995. Ecology and Conservation of Wolves in a Changing World. Canadian Circumpolar Institute. Alberta, Canada. 620 pp.

Caro, T. M. 1988. Adaptative significance of play. Are we getting closer? TREE 3(2): 5054.

Carreón, D. E. 2014. Análisis de la distribución espacial de las presas del Lobo Mexicano (Canis lupus baileyi) encontradas en la prospección del invierno de 2008. Tesis de Maestría en Biología. UAM Iztapalapa. 152 pp.

Clutton-Brock, T. H. 1991. The Evolution of Parental Care. Princeton University Press, USA, $352 \mathrm{pp}$.

Cordoni, G. 2009. Social play in captive wolves (Canis lupus): not only an immature affair. Behaviour 146(10): 1363-1385.

Chambers, S. M, S. R. Fain, B.Fazio, y M. Amaral. 2012. An Account of the North American Wolves From Morphological to Genetical Analysis. North American Fauna 77: 1-67. 
Czarkowska, J. 1983. Changes of some postural reflexes during the first postnatal weeks in the dog. Acta Neurobiologiae Experimentalis 43: 27-35.

Dehasse, J. 1994. Sensory, emotional and social development of the young dog. The Bulletin for Veterinary Clinical Ethology 2(1-2): 6-29.

Dewsbury, D. A. 1978. Comparative Animal Behavior. McGraw-Hill Book Co. USA. 452 pp.

Drickamer, L. C., y S. H. Vessey. 1992. Animal Behavior. Mechanisms, Ecology and Evolution. W. M. W. Brown Publishers, USA, 479 pp.

Ehret, G. 1980. Development of sound communication in mammals. Advanced Studies of Behavior 11: 179-255.

Fagen, R. 1981. Animal Play Behavior. Oxford University Press. New York. 684 pp.

Feddersen-Petersen, D. 1991. The ontogeny of social play and agonistic behavior in selected canid species. Bonner Zoologische Beiträge 42: 97-114.

Fentress, J. C. 1967. Observations on the Behavioral Development of a Hand-Reared Male Timber Wolf. American Zoologist, 7: 339-351.

Fentress, J. C. 1983. A View of Ontogeny. Pp 24-63 en: Advances in the Study of Mammalian Behavior (J. T. Eisenberg, and D. G. Kleiman, eds.). Special publication No. 7. The American Society of Mammalogists USA. 753 pp.

Fentress, J. C., and J. Ryon. 1982. A long-term study of distributed pup feeding incaptive wolves. Pp. 238-261, en: Wolves of the World (F. H. Harrington, and P. C. Paquet, eds). Noyes Publications, USA, $474 \mathrm{pp}$.

Fentress, J. C., J. Ryon, P. McLeod, y G. Z. Havkin. 1987. A multidimensional approach to agonistic behavior in wolves. Pp 253-274 en: Man and Wolf. Advances, Issues, and Problems in Captive Wolf Research. H. Frank. (Ed). Dr. Junk Publishers. The Netherlands. 439 pp.

Fox, M. W. 1964a. The Ontogeny of Behavior and Neurologic Responses of the Dog. Animal Behaviour 12(2-3): 301-310.

Fox, M. W. 1964b. A phylogenetical analisis of behavioral neuro-ontogeny in precocial and nonprecocial mammals. Canadian Journal of Comparative Medicine and Veterinary Science 25:197-202.

Fox, M. W. 1966. Neuro-behavioral Ontogeny. A Synthesis of Ethological and Neurophysiological Concepts. Brain Research 2: 3-20. 
Fox, M. W. 1969. The anatomy of aggression and its ritualization in Canidae: A developmental and comparative study. Behaviour, 35: 242-258.

Fox, M. W. 1970a. A comparative study of the development of facial expression in Canids: wolf, coyote and foxes. Behaviour, 36: 49-73.

Fox, M. W. 1970b. Neurobehavioral Development and the Genotype-Environment Interaction. The Quarterly Review of Biology 45 (2): 131-147.

Fox, M. W. 1972a. Socio-Ecological Implication of individual Differences in Wolf Litters: A Developmental and Evolutionary Perspective. Behaviour 41 (3/4): 298-313.

Fox, M. W. 1972b. The Social Significance of Genital Licking in the Wolf Canis lupus. Journal of Mammalogy 53 (3): 637-640.

Fox, M. W. 1973. Social Dynamics of Three Captive Wolf Packs. Behaviour 47 (3/4): 290301.

Fritts, S. H., and L. D. Mech. 1981. Dynamics, movements and feeding ecology of a newly protected wolf population in Northwestern Minnesota. Wildlife Monographs No. 80.79 pp.

Fuller, T. K. 1989. Population dynamics of wolves in North-central Minnesota. Wildlife Monographs No. 105. The Wildlife Society. Bethesda, MD. 41 pp.

Fuller, J. L. y M. W. Fox. 1969. The Behavior of Dogs. Pp 438-480 en: The Behavior of Domestic Animals. E. S. E. Hafez (Ed). $2^{\text {nd }}$ Ed. Williams \& Wilkins. Baltimore. 418 pp.

García-Moreno, J., M. D. Matocq, M. S. Roy, E. Geffen, y R. K. Wayne. 1996. Relationships and genetic purity of the endangered Mexican wolf based on analysis of microsatellite loci. Conservation Biology, 10 (2): 376-389.

Gese, E. M. y L. D. Mech. 1991.Dispersal of wolves (Canis lupus) in Northeastern Minnesota. 1969-1989. Canadian Journal of Zoology 69: 2946-2955.

Gil, J., E. García, y G. Rodríguez. 2001. Análisis Discriminante. La Muralla. Madrid. 128 pp.

Gilbert, C., S. Blanc, S. Giroud, M. Trabalon, Y. L. Maho, M. Perret, y A. Ancel. 2007. Role of huddling on the energetic of growth in a newborn altricial mammal. American Journal of Physiology. Regulatory, Integrative and Comparative Physiology 293(2): R867-R876.

Gilbert, C., D. McCafferty, Y. L. Maho, J-M. Martrette, S. Giroud, S. Blanc, and A. Ancel. 2010. One for all an all for one: the energetic benefits of huddling in endoterms. Biological Reviews 85: 545-569. 
Ginsburg, B. 1987. The wolf pack as a socio-genetic unit. Pp 401-413 en: Man and Wolf. Advances, Issues, and Problems in Captive Wolf Research. H. Frank. ( Ed). Dr. Junk Publishers. The Netherlands. 439 pp.

Goodwin, G. G. 1969. Mammals of the State of Oaxaca, Mexico in the American Museum of Natural History. Bulletin of the American Museum of Natural History 141: 1-312.

Gorska, T. 1974. Functional organization of cortical motor areas in adult dogs and puppies. Acta Neurobiologiae experimentalis 34(1): 171-203.

Grier, J. W. 1984. Biology of Animal Behavior. Times Mirror/ Mosby College Publishing. USA. 747 pp.

Gross, B., D. Garcia-Tapia, E. Riedesel, N. M. Ellinwood, y J. K. Jens. 2010. Normal Canine Brain Maturation at Magnetic Resonance Imaging. Veterinary Radiology and Ultrasound 51(4): 361-373.

Guarner, V. 1996. Ontogeny and Phylogeny of the Functions. Información Profesional Especializada. México. $195 \mathrm{pp}$.

Haber, G. C. 1977. Socio-ecological dynamics of wolves and prey in a subarctic system. $\mathrm{PhD}$ dissertation. University of British Columbia. Vancouver. 824 pp.

Haber, G. C. 2006. The Wolves of Denali Park, Alaska. Social Organization and Implications of Explotation. Exhibit provided to the Natural Museum of Natural Sciences, Madrid. $15 \mathrm{pp}$.

Hall, E. R, y K. R. Kelson. 1959. The mammals of North America. Vol. 2. Ronald Press. New York. 536 pp.

Hall, S. L. 1998. Object play by adult animals. Pp 45-60 en: Animal Play: Evolutionary, Comparative, and Ecological Perspectives. M. Bekoff y J. A. Byers (Eds.). Cambridge University Press. Cambridge. 274 pp.

Harrington, F. H., L. D. Mech, and S. H. Fritts. 1983. Pack Size and Wolf Pup Survival: Their Relationship under Varying Ecological Conditions. Behavioral Ecology and Sociobiology 13(1): 19-26.

Harrington, F. H, y P. C. Paquet. 1982. Behavior of Wolves in Captivity. Introduction. Pp 206-208 en: Wolves of the World. F. H. Harrington, and P. C. Paquet, ( Eds.). Noyes Publications, USA, $474 \mathrm{pp}$.

Harrington, F. H., P. C. Paquet, J. Ryon, y J. C. Fentress. 1982. Monogamy in wolves: A Review of Evidence. Pp 209-222 en: Wolves of the World. F. H. Harrington, and P. C. Paquet, ( Eds.). Noyes Publications, USA, 474 pp. 
Hedrick, P. W, P. S. Miller, E. Geffen, y R. K. Wayne. 1997. Genetic evaluation of the tree captive Mexican Wolf Lineages. Zoo Biology, 16: 47-69.

Held, S. D. E., y M. Spinka. 2011. Animal play and animal welfare. Animal Behaviour 81: 891-899.

Heymer, A. 1982. Diccionario Etológico. Ediciones Omega, Barcelona, 286 pp.

Hiiemae, K. M. 2000. Feeding in Mammals. Pp 411-448 en: Feeding, Form, Function and Evolution in Tetrapod Vertebrates. K. Schwenk (Ed). Atlantic Press. USA. 537 pp.

Holaday, B. 2003. Return of the Mexican Gray Wolf. Back to the Blue. The University of Arizona Press. Tucson, Arizona, USA. 221 pp.

Huntingford, F. 1984. The Study of Animal Behavior. Chapman and Hall. USA. 411 pp.

Immelmann, K., y C. Beer. 1989. A dictionary of ethology. Harvard University Press, 336pp.

INEGI. 2015. Anuario estadístico y geográfico del Distrito Federal. INEGI. México. 469 pp.

Jedrzejewski, W., K. Schmidt, J. Theuerkauf, B. Jedrzejewska, y H. Okarma. 2001. Daily movements and territory use by radio-collared wolves (Canis lupus) in Bialowieza Primeval Forest in Poland. Canadian Journal of Zoology 79: 1993-2004.

Jenks, S. M. 2011. A Longitudinal Study of the Sociosexual Dynamics in a Captive Family Group of Wolves: The University of Connecticut Wolf Proyect. Behavior Genetics 41(6): 810-829.

Johnson, D. E. 1998. Métodos multivariados aplicados al análisis de datos. International Thompson Editores. México. 566 pp.

Joslin, P. W. B. 1967. Movements and home sites of timber wolves in Algonquin Park. American Zoologist 7(2): 279-288.

Kintze, J. 2007. NCSS, LLC Kaysville Utah USA.

Kleiman, D. G. 2011. Canid Mating Systems, Social Behavior, Parental Care and Ontogeny: Are they Flexible? Behavioral Genetics 41:803-809.

Klinghammer, E. y P. A. Goodman. 1987. Socialization and management of wolves in captivity. Pp 31-69 en: Man and Wolf. Advances, Issues, and Problems in Captive Wolf Research (H. Frank. Ed). Dr. Junk Publishers. The Netherlands. 439 pp.

Klopfer, P. H. 1981. Origins of Parental Care. Pp 1-11 en: Parental Care in Mammals (D. J. Gubernick, and P. H. Klopfer, eds). Plenium Press, New York, USA, 478 pp. 
Kolenosky, G. B., y D. Johnston. 1967. Radio-tracking wolves in Ontario. American Zoologist 7(2): 289-303.

Krebs, J. R., y N. B. Davies. 1997. Behavioural Ecology. An Evolutionary Approach. Fourth Edition, Blackwell Publishing, 416 pp.

Kreeger, T. 2003. The Internal Wolf: Physiology, Pathology, and Pharmacology. Pp 192217 en: Wolves. Behavior, Ecology and Conservation L. D. Mech, and L. Boitani, (Eds.). The University of Chicago Press, USA, 448 pp.

Kusak, J, A. Majic, y, D. Huber. 2005. Home ranges, movements, and activity of wolves (Canis lupus) in the Dalmatian part of Dinarids, Croatia. European Journal of Wildlife Research 51(4): 254-262.

Lara Díaz, N. E., C. A. López González, H. Coronel Arellano, y J. L. Cruz Romo. 2015. Nacidos libres: en el camino a la recuperación del lobo mexicano. CONABIO. Biodiversitas 119: 1-6.

Leopold, A. L. 1990. Fauna Silvestre de México. Ed. Pax. México. 675 pp.

Logan, C. A., and T. D. Johnston. 2007. Synthesis and Separation in the History of "Nature" and "Nurture". Developmental Psychobiology 49 (8): 758-769.

Long, K. 1996. Wolves. A Wildlife Handbook. Johnson's Nature Series. Johnson. Books, Colorado, USA. 180 pp.

Lopez, B. 1978. Of wolves and Men. Touchtone Book, Simon \& Schuster (publ.). New York, $309 \mathrm{pp}$.

López Islas, G., Y C. Vázquez González. 1993. Linaje de Lobos Mexicanos "San Juan de Aragón": historia, evidencias de su autenticidad y posibilidades de certificación. Memorias del Primer Simposio sobre el Lobo Gris Mexicano. Secretaría de Desarrollo Social, Instituto Nacional de Ecología y FES-Cuautitlán-UNAM. México. Pp 65-72.

Lord, K., 2013. A Comparision of the Sensory Development of Wolves (Canis lupus lupus) and Dogs (Canis lupus familiaris). Ethology 119: 110-120.

Loubiere, A. S. D. 2010. L'e Ontogenese chez une Espece "nidicole", le Chien, Canis familiaris. These pour le Doctorat Veterinaire. La Faculte de Medecine de Creteil. École Nationale Veterinaire D’Alfort. France. 48 pp.

Maier, R. 1998. Comportamiento Animal. Un enfoque evolutivo y ecológico. McGraw-Hill. España. 582 pp.

Malm, K. 1995. Regurgitation in relation to weaning in the domestic dog: a questionnaire study. Applied Animal Behaviour Science 43: 111-122. 
Markwell, J. P. y C. J. Thorne. 1987. Early behavioral development of dogs. Journal of Small Animal Practice 28(11): 984-991.

Martin, P, y P. Bateson. 1991. La medición del comportamiento. Alianza Universal 222 pp.

Martin, P. y T. Caro. 1985. On the function of play and its role in behavioural development. Pp 59-103 en: Advances in the Study of Behavior. Vol. 15. J. Rosemblatt, C. Beer, M. Bushnel, y P. Slater (Eds.). 278 pp.

Martínez, P. 2007. Detección de áreas potenciales para la reintroducción del Lobo Mexicano (Canis lupus baileyi) en México. Tesis de Maestría en Ciencias. Instituto de Ecología, A.C. Xalapa. 144 pp.

Martínez-Meyer, E., A. T Peterson, J. Servin, and L. F. Kiff. 2006. Ecological niche modeling and prioritizing areas for species reintroduction. Oryx 40 (4): 411- 418.

McBride, R. T. 1980. The Mexican Wolf Canis lupus baileyi: a historical review and observations on its status and distribution. Endangered species Report 8. USFWS, Albuquerque, New Mexico, 38 pp.

McDonald, K. B. 1987. Development and stability of personality characteristics in prepubertal wolves: Implications for pack organization and behavior. Pp 293-312 en: Man and Wolf. Advances, Issues, and Problems in Captive Wolf Research $\mathrm{H}$. Frank. ( Ed). Dr. Junk Publishers. The Netherlands. 439 pp.

McFarland, D. (Ed). 1987. The Oxford Companion to Animal Behavior. The Oxford University Press, New York, 685 pp.

McLeod, P.J. 1996. Developmental changes in associations among timber wolf (Canis lupus) postures. Behavioural Processes, 38: 105-118.

McLeod, P. J., y J. C. Fentress. 1997. Developmental changes in the sequential behavior of interacting timber Wolf pups. Behavioural Processes 39: 127-136.

Mech, L. D. 1970. The Wolf. The Ecology and Behavior of an endangered species. The University of Minnesota Press, USA, 384 pp.

Mech, L. D. 1987. At home with the Arctic wolf. National Geographic 171(5): 262-593.

Mech, L. D. 1999. Alpha status, dominance, and division of labor in wolf packs. Canadian Journal of Zoology, 77:1196-1203.

Mech, L. D. 2006. Urine marking and Ground-scratching by Free-ranging Artic Wolves, Canis lupus arctos, in Summer. Canadian Field Naturalist 120 (4): 466-470. 
Mech, L. D. y U. S. Seal. 1987. Premature reproductive activity in wild wolves. Journal of Mammalogy 68(4): 871-873.

Mech, L. D., P. C. Wolf, y J. M. Packard. 1999. Regurgitative food transfer among wild wolves. Canadian Journal of Zoology, 77: 1192-1195.

Mech, L. D., y L. Boitani. 2003. Wolves. Behavior, Ecology and Conservation. The University of Chicago Press. USA. 448 pp.

Medjo, D. C. y L. D. Mech. 1976. Reproductive Activity in Nine and Ten month old Wolves. Journal of Mammalogy 57(2): 406-408.

Mills, J. K. 2006. Wolf (Canis lycaon) pup survival, dispersal, and movements in Algonquin Provincial Park, Ontario. Master Thesis. Trent University. Ontario, Canada. 67 pp.

Moran, G. 1987. Dispensing with "the fashionable fallacy of dispensing with description" in the study of wolf social behavior. Pp 205-218 en: Man and Wolf. Advances, Issues, and Problems in Captive Wolf Research. H. Frank. (Ed). Dr. Junk Publishers. The Netherlands. 439 pp.

Murie, A. 1944. The Wolves of Mount McKinley. 5th Edition (2001). University of Washington Press. U. S. A. 238 pp.

Musiani, M., L. Boitani, y P. C. Paquet (Eds.). 2010. The World of Wolves. New Perspectives on Ecology, Behavior and Management. Energy, Ecology and Enviroment Series. University of Calgary Press. Canada. 398 pp.

Navarrete, A. C. 2004. El periodo de impronta en los cánidos domésticos (Canis familiaris), Revisión bibliográfica. Tesis Medicina Veterinaria. Universidad Austral de Chile. Facultad de Ciencias Veterinarias. Instituto de Patología Animal. 51pp.

Nelson, E. W., and, E. A. Goldman. 1929. A new wolf from Mexico. Journal of Mammalogy, 10: 165-166.

Nowak, R. M. 1995. Another look at the wolf taxonomy. Pp 375-397 en: Ecology and Conservation of Wolves in a Changing World. L. N. Carbyn, S. H. Fritts, y D. R. Seip, (Eds.). Canadian Circumpolar Institute. Alberta, Canada. 620 pp.

Packard, J. M. 2003. Wolf Behavior: Reproductive, Social, and Intelligent. Pp. 35-65 en: Wolves. Behavior, Ecology and Conservation. L. D. Mech, and L. Boitani, (Eds.). The University of Chicago Press, USA, $448 \mathrm{pp}$.

Packard, J. M. 2012. Wolf Social Intelligence. Pp 1-48 en: Wolves: Biology, Behavior and Conservation. A. P. Maia and H. F. Crussi (Eds). Nova Science Publishers. Hauppauge, New York. 221 pp. 
Packard, J. M., L. D. Mech, y U. S. Seal. 1983. Social influences on reproduction in wolves. Pp 78-85 en: Wolves in Canada and Alaska: their status, biology and management. L. N. Carbyn (Ed). Report Series No. 45. Canadian Wildlife Service. Edmonton, Canada. 135 pp.

Packard, J. M., L. D. Mech, y E. D. Plotka. 1985. Causes of Reproductive Failure in two Family Groups of Wolves. Zeitschrift für Tyerpsychologie 68(1):24-40.

Packard, J. M., L. D. Mech, y R. R. Ream. 1992. Weaning in the artic wolf pack: behavioral mechanisms. Canadian Journal of Zoology 70: 1269-1275.

Pal, S. K. 2008. Maduration and development of social behavior during early ontogeny in free-ranging dog puppies in West Bengal India. Applied Animal Behavior Science 111: 95-107.

Pal, S. K. 2010. Play behavior during early ontogeny in free-ranging dogs (Canis familiaris). Applied Animal Behavior Science 126: 140-153.

Paquet, P. C., S. Bragdon, y S. McCusker. 1982. Cooperative Rearing of Simultaneous Litters in Captive Wolves. Pp 223-237 en: Wolves of the World. Perspectives of Behavior, Ecology and Conservation. F. H. Harrington and P. C. Paquet (Eds). Noyes Publications. USA. 474 pp.

Parry, H. B. 1953. Degenerations of Dog Retina. I. Structure and Development of the Retina of the Normal Dog. British Journal of Ophtalmology 37(7): 385-404.

Parsons, D. 1996. Case Study: The Mexican Wolf. en: New Mexico's Natural Heritage: Biological diversity in the land of enchantment. (E. A. Herrera y L. F. Huenneke Eds.). New Mexico Journal of Science 36: 101-126.

Parsons, D. 1998. "Green Fire" Returns to the Southwest: Reintroduction of the Mexican Wolf. Wildlife Society Bulletin 26 (4): 799-807.

Pellegrini, A. D., D. Dupuis, y P. K. Smith. 2007. Play in evolution and development. Developmental Review 27: 261-276.

Pellis, S. M, y V. Pellis. 1998. Structure-function interface in the analysis of play fighting. Pp 115-140 en: Animal Play: Evolutionary, Comparative, and Ecological Perspectives. M. Bekoff and J. A. Byers (Eds.). Cambridge University Press. Cambridge. 274 pp.

Pellis, S. M., y A. N. Iwaniuk. 2000. Comparative analysis of the role of postnatal development on the expression of play fighting. Developmental Psychobiology 36(2): 136-147.

Peters, R. 1980. Mammalian Communication. Books/Cole Publishing Company. USA. $341 \mathrm{pp}$. 
Peters, R., y L. D. Mech. 1975. Scent Marking in Wolves. American Scientist 63 (6): 628637.

Phemister, R. D, y S. Young. 1968. The postnatal development of the canine cerebellar cortex. Journal of Comparative Neurology 134 (2): 243-253.

Potvin, M. J., R. O. Peterson, y J. A. Vucetich. 2004. Wolf homesite attendance patterns. Canadian Journal of Zoology 82(9): 1512-1518.

Pulliainen, E. 1967. A Contribution of the Study of the Social Behavior of the Wolf. American Zoologist 7 (2): 313-317.

Quera-Jordana, V. 1997. Los métodos observacionales en la Etología. Pp 43-83 en: Etología, bases biológicas de la conducta animal y humana. F. Peláez del Hierro y J. Vea (Eds.). Pirámide. Madrid. 400 pp.

Rabb, G. B., J. H. Woolpy, y B. E. Ginsburg. 1967. Social relationships in a group of captive wolves. American Zoologist 7(2): 305-312.

Rausch, R. A. 1967. Some Aspects of the Population of Wolves, Alaska. American Zoologist 7(2): 253-265.

Ruprecht, J. S., D. E. Ausband, M. S. Mitchell, E. O. Garton, y P. Zager. 2012. Homesite attendance based on sex, breeding status, and number of helpers in gray wolf packs. Journal of Mammalogy 93(4): 1001-1005.

Scott, J. P. 1958. Critical Periods in the Development of Social Behavior in Puppies. Psychosomatic Medicine 20(1): 42-54.

Scott, J. P. 1967. The Evolution of Social Behavior in Wolves and Dogs. American Zoologist 7(2): 373-381.

Scott, J. P., y J. L. Fuller. 1965. Genetic and Social Behavior of the Dog. The University of Chicago Press. 468 pp.

Schenkel, R. 1947. Ausdrucks-studien an wolfen. Behaviour 1:81-129.

Schenkel, R. 1967. Submission: Its Features and Function in the Wolf and dog. American Zoologist, 7(2): 319-329.

Schotté, C. S., y B. Ginsburg. 1978. Continuing development of social organization and mating in captive wolf pack. Paper presented at the Annual Meeting of the Animal Behavior Society. June 1978. Seattle, Washington. 15 pp. 
Schotté, C. S., and B. Ginsburg. 1987. Development of social organization and mating in a captive wolf pack. Pp 349-374 en: Man and Wolf. Advances, Issues, and Problems in Captive Wolf Research. H. Frank. (Ed). Dr. Junk Publishers. The Netherlands. $439 \mathrm{pp}$.

Seal, U. S., E. D. Plotka, J. M. Packard,y L. D. Mech. 1979. Endocrine correlates of reproduction in the wolf. I. Serum progesterone, estradiol and LH during the estrous cycle. Biology of Reproduction 21: 1057-1066.

Seal, U. S., E. D. Plotka, D. Mech, y. J. M. Packard. 1987. Seasonal metabolic and reproductive cycles in wolves. Pp 190-125 en: Man and Wolf. Advances, Issues, and Problems in Captive Wolf Research (H. Frank. Ed). Dr. Junk Publishers. The Netherlands. $439 \mathrm{pp}$.

SEMARNAP. 1997. Programa de conservación de la vida silvestre y diversificación productiva en el sector rural 1997-2000. SEMARNAP. México. 206 pp.

SEMARNAP. 2000. Proyecto de recuperación de lobo mexicano (Canis lupus baileyi). SEMARNAP. México. $120 \mathrm{pp}$.

SEMARNAT. 2009. Programa de Acción para la Conservación de la Especie (PACE) Lobo Gris Mexicano (Canis lupus baileyı). SEMARNAT. México. 50 pp.

Servín M., J. I. 1984. Algunos aspectos de la conducta social del Lobo Mexicano Canis lupus baileyi en cautiverio. Tesis de Licenciatura en Biología. Facultad de Ciencias, Biología, UNAM, 112 pp.

Servín, J. I. 1991. Algunos aspectos de la conducta social del lobo mexicano (Canis lupus baileyi). Acta Zoológica Mexicana (n. s.), 45: 1-44.

Servín, J. I., E. Martínez-Meyer, y T. Peterson. 2003. Sobre la distribución histórica del lobo mexicano (Canis lupus baileyi) y un análisis de paisaje regional para reintroducirlo en México. Memorias del Simposio sobre Fauna Silvestre. Facultad de Medicina Veterinaria y Zootecnia, UNAM, México, 20: 241-248.

Siminski, P. 2016a. Mexican Wolf SSP Master Plan. 93 pp.

Siminski, P. 2016b. International Mexican Wolf Studbook. 150 pp.

Snowdown, C. T. 1996. Development and learning: Genetic influences, learning and instinct. Pp 261-275 en: Foundations in animal behavior. L. D. Houck y L. C. Drickamer, (Eds.). The University of Chicago Press, USA. 843 pp.

Soto, M. A., A. Salame, J. Ramírez, L. Yañez, y. M. A. Armella. 2004. Valoración de esteroides sexuales en heces de una pareja de lobo mexicano mexicano (Canis lupus baileyi) en cautiverio. Acta Zoológica Mexicana (n.s) 20(2): 187-196. 
Stahler, D. R., D. R. McNulty, R. K. Wayne, B. vonHoldt, y D. W. Smith. 2013. Adaptative value of morphological, behavioural and life-history traits in reproductive female wolves. Journal of Animal Ecology 82(1): 222-234.

Tanner, J. B., L. Smale, y K. E. Holekamp. 2007. Ontogenetic Variation in the Play Behavior of Spotted Hyenas. (Crocuta crocuta). Journal of Developmental Process 2: 5-30.

Theuerkauf, J., W. Jedrzejewski, K. Schmidt, H. Okarma, I. Ruczynski, S. Sniezko, y R. Gula. 2003. Daily Patterns and Duration of Wolf activity in the Bialowieza Forrest, Poland. Journal of Mammalogy 84(1): 243-253.

Thompson, K. 1998. Self assessment in juvenile play. Pp 183-204 en: Animal Play: Evolutionary, Comparative and Ecological Perspectives. M. Bekoff y J. Byers (Eds). Cambridge University Press. USA. 274 pp.

Timbergen, N. 1963. On aims and Methods of Ethology. Zeitschrift fur Tierpsychologie 20: 410-433.

Tsunoda, H., R. Gula, J. Theuerkauff, S. Rouys, S. Radler, B. Pirga, J. Eggermann, y B. Brzezowska. 2009. How does parental role influence the activity and movements of breeding wolves? Journal of Ethology 27: 185-189.

USFWS. 1982. Mexican wolf recovery Plan. USFWS, Albuquerque, New Mexico, 115 pp.

USFWS. 2015. Mexican Wolf Recovery Program. Progress Report \# 18. 60 pp.

Vázquez González, C. B. 2008. Algunos aspectos conductuales de las crías de lobo mexicano (Canis lupus baileyi) en cautiverio. Tesis de Licenciatura en Biología. Instituto Politécnico Nacional. México. 100 pp.

Villa, B. 1960. Combate contra lobos y coyotes en el Norte de México. Anales del Instituto de Biología. UNAM. 31: 469-499.

Wagener, T. K. 1998. The Ontogeny of the Red Wolf (Canis rufus) Social Behavior: Implications for Sociality and Taxonomic Status. Thesis for the Master in Science Degree. The University of Tennessee, Knoxville. 82 pp.

Ward, C., E. B. Bauer, y B: B. Smuts. 2008. Partner preferences and asymmetries in social play among domestic dog, Canis lupus familiaris littermates. Animal Behaviour 76: 1187-1199.

Wayne, R. K., y C. Vilá. 2003. Molecular Genetic Studies of Wolves. Pp 218-238 en: Wolves. Behavior, Ecology and Conservation. L. D. Mech y L. Boitani (Eds.). University of Chicago Press. USA. 448 pp. 
Wielebnowski, N. 1998. Contribution of Behavioral Studies to Captive Management and Breeding of Rare and Endangered Mammals. Pp 130-162 en: Behavioral Ecology and Conservation Biology. T. Caro (Ed). Oxford University Press. USA. 582 pp.

Woolpy, J. H. 1968. The Social Organization of Wolves. Natural History 77(5): 46-55.

Woolpy, J. H, y B. E. Ginsburg. 1967. A study of temperament in a wild social species. American Zoologist 7(2): 357-363.

Yachmennikova, A. A. 2012. Agonistic Behavior Interconnections in Hidden Patterns in Wolf Pups Groups During the Juvenile Hierarchy Stabilizing Period. Pp 109-132 en: Wolves: Biology, Behavior and Conservation. A. P. Maia and H. F. Crussi (Eds). Nova Science Publishers. Hauppauge, New York. 221 pp.

Yachmennikova, A. A, y D. Poyarkov. 2011. A New Approach to Study Organization of Wolves' Activity (Canis lupus) in Time Sequences. Biology Bulletin 38(2): 156-164.

Young, S. P., and E. A. Goldman. 1944. The Wolves of North America. The American Wildlife Institute, Washington, D. C., 636 pp.

Zamora, D. F. 2011. Análisis de la Viabilidad Poblacional del Lobo Mexicano (Canis lupus baileyi) en la Sierra Madre Occidental. Tesis de Licenciatura en Biología. Universidad Autónoma de Querétaro. 71 pp.

Zimen, E. 1975. Social Dynamics of the Wolf Pack. Pp. 336-362 in The Wild Canis: Their Systematics, Behavioral Ecology and Evolution (M. W. Fox, ed). Van Nostrand Reinhold, New York, 508 pp.

Zimen, E. 1976. On the regulation of pack size in Wolves. Zeitschrift für

Tierpsychologie 40: 300-341.

Zimen, E. 1981. The Wolf A Species in Danger. Delacorte Press, New York, 373 pp.

Zimen, E. 1982. A Wolf Pack Sociogram. Pp. 282-322, en Wolves of the World (F. H. Harrington, and P. C. Paquet, eds.). Noyes Publications, USA, 474 pp.

Zimen, E. 1987. Ontogeny of approach and flight behavior towards humans in wolves, poodles and wolf-poodles hybrids. Pp 275-292 en: Man and Wolf. Advances, Issues, and Problems in Captive Wolf Research ( $\mathrm{H}$. Frank. Ed). Dr. Junk Publishers. The Netherlands. 439 pp. 


\begin{abstract}
ANEXO I.
ETOGRAMA.

DESCRIPCIÓN DE LAS CONDUCTAS ENLISTADAS EN LOS ETOGRAMAS.
\end{abstract}

Conductas que ya han sido descritas en otros estudios

Conductas Tempranas

Se refiere a aquéllas conductas que se observaron durante las primeras semanas de vida.

Huddling. Puede ser definido como una agrupación estrecha y activa de animales, que están involucrados en una termorregulación social, para conservar el calor (Gilbert et al, 2010). Se registra cuando los cachorros, durante los primeros días después del nacimiento, cuando la madre los deja solos, se agrupan de manera compacta, tratando incluso de quedar unos sobre otros, quedándose dormidos poco después.

Mamar. Ver conductas de alimentación.

Mordisquear pezones de la madre. Ver conductas de alimentación. 
Conductas de alimentación

Incluyen todas aquellas conductas que están involucradas en obtener, manipular e ingerir alimento (McFarland, 1987). En esta categoría se incluyen además, aquellos comportamientos en los que los lobos juveniles proporcionan a su vez alimento a los cachorros nacidos el siguiente año:

Mamar. Acto de succionar la leche que producen las glándulas mamarias, sujetando el pezón con los labios y la lengua. Las crías acostumbran empujar con los miembros anteriores el tejido que rodea al pezón. Pueden alimentarse en diferentes posiciones: echados con la región ventral hacia abajo o de costado, perpendicularmente al cuerpo de la madre, que también se encuentra echada; en los otros casos la madre está parada y las crías levantadas sobre los miembros posteriores y los anteriores apoyados en el vientre de la madre, parados sobre las cuatro patas, levantando la cabeza hacia el vientre de la madre; o sentados levantando la cabeza hacia el vientre materno.

Mordisquear los pezones maternos. Es bastante similar a la anterior, sin embargo, se distingue porque los cachorros sujetan y sueltan el pezón alternada y repetidamente y la succión es muy escasa.

Solicitud de alimento general. Comprende patrones de conducta mediante los cuales los animales jóvenes inducen a sus padres a alimentarlos (Immelmann y Beer, 1989). En este caso, no se toma en cuenta el tipo de alimento solicitado. 
Solicitud de carne. Es cuando una o varias crías (o juveniles) se acercan a alguno de los miembros de la manada en busca de alimento, que en este caso el animal proveedor lleva un trozo de carne cruda en el hocico que entrega a las crías (o juveniles).

Solicitud de regurgitación. Los cachorros o juveniles se aproximan precipitadamente a un lobo juvenil o adulto (en el caso de los juveniles, sólo solicitan a un adulto), lo rodean, le lamen repetidamente el hocico, pudiendo además saltarle hacia el rostro, golpearle suavemente con las manos, empujarle el hocico o mover la cola, hasta que expulse el contenido del estómago.

Dar carne. Se registra cuando un lobo juvenil o adulto, de manera espontánea lleva un trozo de carne a donde está la madre con los cachorros pequeños del año siguiente, o cuando a solicitud de éstos les entrega el trozo que tiene en el hocico.

Regurgitar. Es una manera de alimentar principalmente a animales jóvenes y cachorros mediante la expulsión del estómago de alimento parcialmente digerido, en mamíferos es usado exclusivamente por cánidos (Malm, 1995). En este trabajo, se observa cuando después de que se les ha proporcionado el alimento y éste ha sido consumido por los animales, alguno de ellos (adulto o juvenil) devuelve al menos una parte frente a los cachorros para que lo consuman, puede ser de manera espontánea o por solicitación de los lobeznos, lamiendo, empujando, manoteando la cabeza o el hocico del proveedor (Mech, 1970). 
Disputa por alimento. Se observa cuando un animal jalonea o arrebata un trozo de carne o pieza de pollo con otro, de la misma o diferente edad, generalmente esta acción va acompañada de gruñidos.

$\underline{\text { Conductas Filiativas o Amistosas }}$

Son aquellas interacciones que desarrollan los lobos que demuestran nexos amistosos entre ellos (Servín, 1991).

Olfateo/ contacto hocico-piel. Un cachorro, juvenil o adulto se acerca para olfatear y tocar con el hocico, o alguna de las dos conductas, cualquier parte de la cabeza o cuerpo de otra cría, juvenil o adulto. Las orejas se observan hacia el frente, y en ocasiones mueve la cola.

Toque de hocicos. Dos lobos, de la misma o diferente edad, se acercan y se tocan los hocicos, en ocasiones mueven la cola.

Lamer. Un animal lame el hocico, cara, cuello, costado o patas de otro individuo del grupo; las orejas hacia el frente y a veces mueven la cola.

Parado sobre el compañero. Una cría se acerca a otra y se coloca sobre otra encuentra echada, Después, pueden exhibir juego con contacto corporal.

Contacto cabeza-cabeza. Uno o varios animales frotan las cabezas, contra la de otro individuo. 
Olfateo de periné. Un lobezno se acerca por detrás a otro miembro de la manada y le olfatea la región anal, si es mucho más pequeño que el receptor, puede levantarse sobre los miembros posteriores y apoyarse con los anteriores sobre el cuerpo del otro individuo. También se observa principalmente cuando la madre olfatea la región anal de los cachorros cuando son pequeños, pero en general, puede presentarse entre dos animales de cualquier edad,

Olfateo de genitales. Una cría se acerca a un miembro de la manada que está parado o echado y le olfatea el área genital; esta conducta también puede observarse en juveniles o adultos en el mismo contexto, o como parte del cortejo durante la temporada reproductiva (Fox, 1972b, Schenkel, 1947).

Lamer genitales. Esta conducta se puede presentar en diferentes contextos (Fox, 1972b):

- Cuando una cría se aproxima a otra que generalmente está echado, éste último levanta el rostro y lame los genitales del primero, que suele quedarse quieto por un momento y después se retira sin que nada más ocurra. Este mismo patrón motor puede ser exhibido entre juveniles o adultos.

- Cuando una madre se involucra en la continua actividad de lamer los genitales de las crías y consumir la orina expelida por dicha estimulación durante las primeras semanas de vida de los lobeznos.

- Cuando se presenta entre una pareja de lobos adultos como parte del cortejo (Packard, 2003). 
La lamida de genitales es un comportamiento complejo en los lobos, que es indicativo de un lazo social estrecho (filial o sexual) entre conspecíficos.

Lamer periné. Se observa cuando la madre lame la zona perineal de la cría durante las primeras semanas de vida, con el fin de estimularla para que defeque, ya que a una edad temprana no son capaces de hacerlo por sí mismas, la loba también consume las heces (Fox, 1972b, Mech, 1970).

Conductas de juego

Son todas aquellas actividades motoras que en apariencia no tienen un propósito definido, en las cuales, los patrones motores de otros contextos se pueden usar frecuentemente en formas modificadas y alteradas en secuencia temporal (Bekoff y Byers, 1981).

Juego con objetos. Los cachorros y juveniles pueden manipular diversos objetos que tengan a su alcance, llevarlos en el hocico, mordisquearlos, jalarlos, arrancarlos, romperlos, restregarse en ellos, aventarlos. En el caso particular del agua, pueden meter la cara al chorro, tratar de mordisquearlo o tirar agua del bebedero con los miembros anteriores. También se presenta cuando una cría mordisquea la oreja, cara, pata o cola de un juvenil o adulto sin que éste le corresponda en el juego o la agreda, generalmente permanece tolerante. 
Juego solitario. Una cría o juvenil corre, realiza la postura de solicitud de juego pero no la dirige a ningún congénere, mueve la cola, efectúa algunos saltos y giros, que puede combinar jugando con algún objeto que se encuentre en su camino. Aunque esté cerca de otras crías, juveniles o adultos, no interactúa con ellos.

Solicitud de juego. Un lobezno, juvenil o adulto se presenta frente a otro individuo, inclina hacia el suelo la mitad anterior del cuerpo, manteniendo levantado el tren posterior, mueve la cola, que está levantada, y da pequeños saltos hacia adelante o laterales.

Juego persecutorio. Uno o más cachorros, juveniles o adultos persiguen amistosamente a otro lobo; al alcanzarlo, pueden darle pequeños empujones y reanudar la persecución, así como invertir los papeles de perseguidor y perseguido, y al mismo tiempo desplegar con juego con contacto corporal.

Juego con contacto corporal. Consiste en combates ritualizados amistosos, en los cuales un lobo de cualquier edad interactúa con otra cría, juvenil o adulto, tratando de empujarse, derribarse, mordisquearse el hocico, cuello, lomo, pecho o patas, pueden rodar en el suelo. Ocasionalmente se escuchan algunos gruñidos. Es bastante común que se encuentren uno frente al otro, ambos con los hocicos abiertos, moviendo la cabeza, tratando simultáneamente de mordisquear el hocico del contrario. También acostumbran levantar uno de los miembros anteriores hacia el rostro del otro, generalmente sin que haya contacto entre ellos ("pawing"). 


\section{$\underline{\text { Conductas Sumisas }}$}

Son aquéllas que neutralizan o desvían la agresión de los congéneres, son ritualizadas y estereotipadas (Heymer, 1982; Servín, 1991).

Sumisión activa.- El cachorro lame o toca repetidamente el hocico de un juvenil o adulto (o un juvenil a un adulto) puede dirigir las orejas hacia atrás, mover la cola o colocarla entre las patas traseras, ladear la cabeza, agachar el tren posterior, o levantar la mano. Es similar a la solicitud de alimento, sin embargo se va a distinguir porque se registra, por un lado, en momentos diferentes a los de alimentación, particularmente cuando se reúnen las crías con la madre y los demás miembros de la manada después de un manejo de sujeción física o química, también cuando en aquéllos grupos que son encerrados diariamente para hacer el aseo del encierro, al momento de salir nuevamente al exhibidor, los cachorros acostumbran exhibir conductas sumisas. También se considera aún cuando sea la hora de comer, pero que el lobo adulto no lleva carne en el hocico, generalmente cuando la cría solicita alimento la interacción es un poco más larga. La sumisión suele presentarse igualmente, cuando existen interacciones agresivas entre otros lobos del grupo o después de una sesión de aullidos. Bajo circunstancias extraordinarias también se ha registrado por parte de un adulto hacia un animal de menor edad. 
Sumisión pasiva. La cría o juvenil rueda sobre el lomo, con las patas hacia arriba; permaneciendo momentáneamente en esa posición, frente a individuos mayores que éstos.

Sumisión de grupo. Los lobeznos o juveniles se reúnen alrededor de un adulto, lamiendo o tocándole repetidamente el hocico y moviendo la cola; pueden también ladear la cabeza, agachar el tren posterior, dirigir las orejas hacia atrás, o levantar la mano tratando de tocarle el hocico. El receptor se mantiene en el centro, con la cola levantada, las orejas y el cuerpo erectos. Al igual que la sumisión activa, se puede confundir con solicitud de alimento, por lo que se seguirán los mismos criterios que para dicho caso.

\section{Conductas Antagónicas o Agonísticas}

Son aquéllas que involucran un conflicto de agresión y su respuesta defensiva (Barrows, 2000); aunque en un sentido más amplio incluyen también aquellos comportamientos de apaciguamiento y huída (McFarland, 1987); sin embargo, en este estudio, siguiendo a Servín, (1991) y Zimen (1982), las conductas sumisas se consideraron por separado. En el caso de los lobos se pueden dividir en agresiones: sin contacto corporal, con contacto corporal, con intento de mordida, con mordida, y defensiva (Servín, 1991; Zimen, 1982).

Agresión sin contacto corporal 
Amenaza ofensiva. Un lobo muestra los caninos, y gruñe frente a otro, o efectúa una de ambas conductas, las orejas las dirigen hacia el frente o a los lados, y la cola en posición normal o levantada. En ocasiones, se pueden acompañar por un chillido o ladrido.

Amenaza subordinada. El lobo despliega una postura semejante a la de solicitud de juego, con el tren anterior flexionado y el posterior levantado, sin embargo, muestra los caninos y puede golpear el suelo con los miembros anteriores, así como tratar de morder al contrario. Se presenta cuando un animal de menor jerarquía amenaza a uno de mayor posición.

Ataque. Un animal que se encuentra a cierta distancia de otro, repentinamente se lanza hacia éste, pero se detiene antes de tocarlo. Dicha distancia puede o no ser corta.

Perseguir. Uno o varios individuos corren detrás de algún miembro de la manada y lo agraden al alcanzarlo. En el caso de animales muy jóvenes generalmente se inicia por imitación de un adulto.

Rodear. Varios individuos se colocan alrededor de otro, acorralándolo, y despliegan otras conductas agresivas, generalmente llevan la cola levantada.

Acoso. Se observa cuando un animal es agredido insistente y repetidamente por otro individuo. 
Agresión con contacto corporal

Imposición parado. Un lobo se acerca a otro y se para junto o frente a éste con la cola levantada, los miembros rígidos, y las orejas erectas.

Imposición parado sobre el contrario. Un animal se coloca encima otro que se encuentra en el suelo, generalmente sobre su costado, el primero con la cola levantada, las orejas dirigidas al frente y los miembros rígidos.

Manos o Mentón sobre lomo del contrario. Un lobo se acerca perpendicularmente a otro y coloca los miembros anteriores o el mentón sobre el lomo de éste, las orejas están erectas y puede llevar la cola levantada.

Mantener en suelo con el cuerpo. Un individuo se encuentra parado sobre otro que está en el suelo, y recarga el peso de su cuerpo contra éste, impidiendo que se levante.

Mantener en suelo con el hocico. Se registra cuando un lobo, generalmente un adulto, sujeta el hocico de otro individuo, y lo presiona contra el suelo impidiéndole levantarse, manteniéndolo así por algunos segundos.

Imposición por empujones. Un lobo se acerca paralelamente a otro individuo del grupo, y lo golpea con el costado, una o varias veces en rápida secuencia, generalmente lleva la cola levantada y las orejas erectas. La interacción puede darse entre dos animales que están a corta distancia uno del otro o en ocasiones 
el lobo agresor puede aproximarse desde alguna distancia, y dar un salto lateral para golpear el costado del receptor.

Agresión con intento de mordida

Coger hocico. Un lobo que está cerca de otro, mediante un rápido movimiento, sujeta brevemente con su hocico el del contrario, que generalmente se agacha un poco. Puede ser precedida de una amenaza ofensiva. Se observa entre dos animales de la misma edad, o de un mayor a otro menor.

Lanzarse y morder. Uno o varios lobos que se encuentran cerca de un miembro de la manada, se lanzan hacia delante para morder generalmente la región sacra, cara u hocico, y enseguida retroceder más o menos a la posición original; en ocasiones no alcanzan realmente a tocarlo, pero en otras sí pueden llegar a dar una mordida, aunque no severa, más bien un pellizco. La cola suele estar levantada y las orejas dirigidas al frente.

Levantarse y morder. Dos lobos que se encuentran uno frente al otro, en un rápido movimiento, se levantan casi simultáneamente apoyándose en los miembros posteriores, golpeando suave y rápidamente al contrario con los miembros anteriores, ambos se gruñen ruidosamente con los hocicos abiertos, que se pueden tocar, pero no se muerden. Cuando la agresión es de gran intensidad esta conducta puede preceder una mordida. 
Agresión con mordida

Mordida. Se presenta cuando un lobo encaja sus dientes cualquier parte del cuerpo de su oponente, mordiéndolo con fuerza; los sitios más comunes suelen ser la región sacra, los miembros posteriores o anteriores, cuello y rostro.

Defensivas

Amenaza defensiva. El lobo, muestra los caninos y gruñe a otra cría, juvenil o adulto, las orejas pueden estar dirigidas hacia los lados o atrás, la cola en posición normal, pegada al cuerpo o metida entre las patas traseras, puede tener el pelo del lomo erizado, emitir chillidos o lanzar un golpe rápido con la mano hacia el contrario. En ocasiones, en vez de gruñir, realizan resoplidos, en los que exhalan con fuerza por la nariz. En muchas ocasiones se presenta con relación al alimento, cuando un animal que ya tiene posesión de un pedazo de carne, lo defiende de otros compañeros que pretendan quitársela.

Chasquido. Un lobo que es amenazado por otro individuo de la manada, lanza hacia éste una mordida, sin llegar a tocarlo, escuchándose tan sólo el sonido del golpe de las piezas dentales al cerrar rápidamente el hocico cerca del receptor. Pueden colocar las orejas hacia el frente o a los lados.

Mantener distancia. Un individuo evita estar cerca de algún miembro de la manada, retirándose o manteniéndose lejos de éste. 
Huir. Un animal se aleja corriendo rápidamente de otro que lo persigue, y que al alcanzarlo, lo agrede; el que huye generalmente lleva la cola pegada al cuerpo, metida entre las patas, y las orejas dirigidas hacia atrás.

Defensa en círculo. Dos lobos se colocan paralelamente uno al otro, pero en sentidos opuestos, se desplazan con una trayectoria circular, siguiendo y vigilándose el uno al otro; volteando hacia atrás, generalmente ambos llevan la cola levantada, y pueden emitir amenazas.

Lanzar y morder defensivo. Ocurre cuando un animal lanza pequeños mordiscos, uno tras otro hacia el rostro o cuello del otro, al hacerlo, puede también dar pequeños saltos hacia el frente. Las orejas suelen estar dirigidas hacia atrás y la cola no está levantada. Se exhibe en respuesta a una agresión (Servín, 1991, Zimen, 1982).

Mordida defensiva. El lobo lanza una mordida hacia el rostro de un juvenil o adulto que se le aproxima, pudiendo apenas rozarlo o llegar a ocasionarle una herida, que no suele ser de consideración. Las orejas se pueden dirigir hacia atrás.

\section{$\underline{\text { Conductas Pseudoexuales }}$}

Son aquéllos patrones motores de las conductas sexuales, pero que no están en un contexto sexual, es decir no tienen propósito reproductivo. 
Monta-no sexual. Una cría apoya la mitad anterior del cuerpo paralelamente sobre el lomo de otra, y la sujeta con los miembros anteriores.

Movimientos pélvicos-no sexual. Una cría que está montando a otra mueve la cadera hacia delante y atrás de manera repetitiva. También puede realizar los movimientos sin monta previa, sólo parada sobre el otro cachorro que está echado.

Conductas sexuales

Son todas aquellas conductas que se exhiben con el fin de fertilizar un huevo por los espermatozoides (McFarland, 1987).

Presentación de genitales. La hembra se para delante del macho y desplaza la cola lateralmente, dejando expuesta la zona genital para que pueda ser inspeccionada por el macho.

Monta. El macho se acerca a la hembra, perpendicular a ésta, le coloca una mano sobre el lomo, se le sube por detrás y la sujeta con los miembros anteriores, también puede acercarse directamente desde atrás; en algunas ocasiones puede montarla también por la cabeza. 
Movimientos pélvicos. Una vez que el macho monta a la hembra, realiza movimientos de la pelvis alternados hacia adelante y atrás, con los que introduce el pene en la vagina de la loba.

Cópula. Se refiere al acoplamiento sexual del macho y la hembra, durante el cual el macho introduce el órgano copulatorio en la vagina de la hembra (Immelmann y Beer, 1989). En seguida de la intromisión, la porción posterior del pene, el bulbo del glande se inflama rápidamente dentro de la vagina debido a la acumulación de sangre, y es mantenido así por la constricción de los músculos de la vagina, resultando el candado característico de Canidae. El macho suele permanecer montado por alrededor de un minuto, después de lo cual se baja de la hembra poniendo sus miembros anteriores en el piso, a un lado de ésta, luego se da vuelta pasando uno de los miembros posteriores por sobre el lomo de ella, quedando en una posición un tanto más cómoda, con sus rostros dirigidos en sentidos opuestos; los animales suelen quedarse quietos o caminar lentamente (.Busch, 2007, Fuller y Fox, 1975, Mech y Boitani, 2003, Scott y Fuller, 1965).

\section{Conductas de marcaje}

En mamíferos se refiere a la aplicación del olor de un animal a su medioambiente (Peters y Mech, 1975), se piensa que está relacionado con el mantenimiento del territorio, el estatus social de los individuos dentro del grupo y la condición reproductiva, (Atisko, 1976, Peter y Mech, 1975). Se puede hacer de diferentes maneras, con orina, heces, o rascado. En este estudio sólo se ha tomado en 
cuenta el marcaje con orina, y sólo ha sido registrado cuando los animales juveniles empiezan a exhibirlo, el de los adultos no fue tomado en cuenta debido a que este trabajo se enfoca en la ontogenia de la conducta.

Marcar. Es cuando un individuo deposita una pequeña cantidad de orina, para delimitar su territorio o su propiedad sobre algo, levanta un poco una de las patas posteriores mientras orina, en ocasiones puede rascar el suelo con los miembros anteriores y posteriores (Harrington, 1981, Mech, 2006).

\section{Conductas que no han sido previamente descritas en ningún estudio:}

Buscar, trotar, correr por lámina. Se refiere a cuando animales que están en exhibidores adjuntos, separados por una división de malla o lámina, al menos uno de ellos busca o sigue, caminando o corriendo, a otro individuo que se encuentra en el otro exhibidor, ya sea que lo pueda ver o no. Se considera como una agresión sin contacto corporal, porque sin importar la intensidad de la conducta, la barrera que los separa impide dicho contacto.

Saltar por lámina. Se presenta en las mismas condiciones que en la conducta anterior, ocurre cuando un animal empieza a saltar para tratar de sobrepasar la altura de la división, generalmente una lámina, para observar al individuo que se encuentra del otro lado de dicha división, no se llega a dar contacto entre ellos. 
Golpear lámina. En condiciones como las mencionadas en la conducta anterior, uno animal golpea la división, generalmente de lámina, que lo separa de otro, lo que generalmente produce un fuerte sonido, a manera de intimidación, puede ser uno ó más golpes, más o menos fuertes, dependiendo de la intensidad de la conducta. Se considera como una agresión mayor que las conductas anteriores, y también es sin contacto corporal.

Seguir previo a cortejo. Se observa antes de que se presente el celo. Un animal sigue a otro del sexo opuesto a una distancia de pocos metros, pero de manera consistente, no suele haber contacto entre ellos.

Solicitud amistosa. Ocurre cuando un animal se para de frente, o a un lado de otro, mueve activamente la cola y generalmente vocaliza, puede continuarse con contactos hocico piel, solicitud de juego o alguna otra conducta amistosa. Se presume que este comportamiento está relacionado con la búsqueda de aceptación de un individuo ante otro. La cola suele estar levantada cuando la mueve.

Reunión. Se observa cuando varios animales se juntan, mueven la cola, hay contactos de cabezas y de hocicos, pero a diferencia de la sumisión de grupo, no existe un animal central ante el cual los demás se muestren sumisos. Este comportamiento puede ir seguido por algunas conductas agresivas. 


\section{ANEXO II.}

\section{ANTECEDENTES ETAPAS DE DESARROLLO Y SISTEMA NERVIOSO}

\section{Etapas de desarrollo}

Scott y Fuller (1965) observaron que los patrones conductuales básicos en lobos y perros eran muy similares, y de ahí surgió la pregunta de en qué momento durante su desarrollo empezaban a surgir las diferencias entre ellos, así como entre las diferentes razas de éstos últimos, por lo que realizaron un extenso trabajo en el cual podían registrar la interacción entre los factores hereditarios y ambientales moldeando el comportamiento durante el crecimiento de 5 razas de perros y algunas cruzas entre éstas. Al llevar a cabo el análisis de sus datos se percataron de que en algunos momentos el comportamiento de los cachorros podía cambiar rápidamente, y que el desarrollo caía en periodos o etapas distintivas de manera natural.

Estas fueron designados como etapa Neonatal, de Transición, Socialización, y Juvenil. Posteriormente, Fentress (1967), Pulliainen (1967), Woolpy y Ginsburg (1967), consideraron que estas etapas se ajustaban también al desarrollo conductual de los lobos, y a partir de la obra de Mech (1970), "The Wolf, Ecology and Behavior of an Endangered Species" se extendió la conveniencia de utilizar estas etapas para describir el desarrollo conductual de los lobos, especialmente la de socialización (Klinghammer y Goodman, 1987, Packard, 2003, Peters, 1980, Wagener, 1998, Zimen, 1981). 
Etapa neonatal

Al nacer los cachorros, la madre tiene que retirarles las membranas fetales que los cubren y cortar el cordón umbilical, antes de lo cual presentan muy poco movimiento espontáneo, sin embargo, con la estimulación producida por la lengua de la madre al descubrirlo y limpiarlo, se produce una respuesta masiva, empieza a respirar regularmente, a retorcerse, se endereza, empieza a arrastrarse hasta encontrar el pezón de la madre y alimentarse, los músculos de los miembros están flácidos; exhiben algunas vocalizaciones, principalmente de tipo et-epimilético (Mech, 1970, Scott y Fuller, 1965).

Son ciegos, sordos, anósmicos, no pueden regular su temperatura; no pueden orinar ni defecar por sí solos, la madre al lamer la zona ano genital, produce el reflejo de eliminación; son poco más que una serie de reflejos simples; presentan tigmotaxis y termotaxis positivas (Fox, 1964b, Maxwell y Thorne, 1987, Packard, 2003).

Etapa de transición

Comprende aproximadamente de los 15 a los 21 días. Es un periodo de grandes cambios que suceden rápidamente, los más notables hacia el final del mismo, inicia cuando los lobeznos abren los ojos, sin embargo la visión es muy pobre, empiezan a arrastrarse hacia adelante y hacia atrás, poco a poco, se van despegando el cuerpo del suelo, se apoyan en las 4 patas y comienzan a caminar 
con cierta torpeza y a mover la cola, alrededor del día 15 inicia la erupción de la dentición de leche; cuando se les deja solos forman una pila estrecha (huddling), aunque van mejorando el control de su temperatura continúan alimentándose de la leche materna, pueden mordisquear algunos objetos, ciertos patrones motores neonatales van disminuyendo o desaparecen. Hacia el final, los canales auditivos se abren y empiezan a registrarse las primeras respuestas de sobresalto, además, suelen empezar a explorar la cámara de la madriguera en la que se encuentran, logrando cada vez mayores desplazamientos, se observan los primeros gruñidos y juegos (Fox, 1964b, Markwell y Thorne, 1987, Mech, 1970, Navarrete, 2004, Packard, 2003, Pal, 1998, Scott, 1958, Scott y Fuller, 1965).

Etapa de socialización

Se considera que inicia cuando los cachorros comienzan a salir de la madriguera, donde suele vérseles jugar, esto ocurre alrededor de las 3 semanas de vida; (Mech, 1970, Murie, 1944, Packard, 2003, Zimen, 1981).

Durante esta etapa hay una gran cantidad de acontecimientos, de manera abreviada se puede decir que el sistema sensorial y locomotor prácticamente alcanzan el nivel del adulto, se lleva a cabo la transición del tipo de alimentación de líquida a sólida, la dentición de leche está completa; hay un rápido desarrollo de patrones conductuales, y se considera que es cuando establecen relaciones sociales con los miembros de su manada y lazos con el lugar en el que nacen, el 
juego social tiene prioridad y está estrechamente ligado con el desarrollo de dichas relaciones (Mech, 1970, Packard, 2003, Zimen, 1981).

Esta es una etapa de un rápido desarrollo de patrones conductuales, en contraste con la etapa de transición, en la cual los cambios son principalmente en las capacidades sensoriales y motoras (Fentress, 1967, Scott y Fuller, 1965, Zimen, 1981).

El final de la etapa parece estar determinado por lo que haya ocurrido en ella, y por lo tanto, está sujeto a modificación (Markwell, 1987).

Se pueden observar algunos patrones conductuales básicos que son relevantes para la formación de relaciones sociales, entre las 3 y 5 semanas el cachorro tendrá respuesta de aproximación y contacto con cualquier nuevo individuo, después disminuye y se desarrolla una respuesta de temor; la cría sólo puede hacer contacto con extraños por un corto periodo de tiempo. El mecanismo adaptativo se lleva a cabo de manera que a una edad temprana pueda socializar con individuos de su especie, y pueda evitar a los depredadores, (Scott y Fuller, 1965, Zimen, 1981).

Etapa juvenil

Ha sido la menos estudiada, se caracteriza por ser una etapa de perfeccionamiento y refinamiento de las habilidades, es cuando los animales 
pueden dispersarse, aprenden a cazar con los adultos, y definen su posición jerárquica en el grupo (Mech, 1970, Packard, 2003, Scott y Fuller, 1965).

\section{Sistema nervioso}

El comportamiento es un fenómeno complejo que implica la interacción entre un organismo y su medio ambiente, no obstante, para ello el animal debe ser capaz de tener conocimiento de su entorno, por medio de un equipo sensorial adecuado, la información sensorial debe entonces ser procesada y analizada por las estructuras nerviosas, por último, la respuesta dependerá de las habilidades motoras que pueda expresar (Loubiere, 2010). Por lo tanto, la expresión de un comportamiento sólo es posible si las capacidades subyacentes están lo suficientemente desarrolladas, de tal modo que cualquier comportamiento expresado dependerá del desarrollo del sistema nervioso (Dehasse, 1994, Fox, 1966).

En el desarrollo del sistema nervioso se pueden encontrar 4 fases en la maduración celular: 1.) Proliferación neuronal 2) Crecimiento y diferenciación de las neuronas 3) Sinaptogénesis 4) Mielinización. Se ha encontrado que ésta última no depende de los estímulos que recibe el individuo, sin embargo, no ocurre lo mismo con la sinaptogénesis, ya que se ha observado que aquellas neuronas que son mayormente estimuladas presentan una mayor densidad y complejidad dendrítica, puesto que sólo las conexiones que se utilizan son las que sobreviven (Guarner, 1996). 
Al nacer, todas las partes del encéfalo están formadas, pero en una proporción diferente a la del adulto, la corteza motora está desarrollada, pero sólo los nervios craneales que sirven para la alimentación, la sensibilidad del rostro y la parte no acústica del nervio auditivo están mielinizados. El cerebro cambia poco durante los primeros 15 días de vida, sin embargo, ocurren cambios espectaculares entre el día 16 y 28, un rápido crecimiento, la diferenciación de las neuronas y la mielinización de los axones son los principales fenómenos observados. La composición química del encéfalo también cambia rápidamente, hay un incremento en la síntesis de aminoácidos, lípidos y DNA (Fox, 1966, Loubiere, 2010).

La organización histológica de la corteza cerebelosa del neonato se encuentra incompletamente diferenciada, es similar la del adulto a partir de los 45 días, pero la mielinización es un proceso más gradual, se completa a las 10 semanas (Phemister y Young, 1968). En tanto, la mielinización subcortical cerebral alcanza su máximo nivel a las 4 semanas y la mielinización neocortical a las 6 semanas, después es más lenta y gradual, puesto que se completa a los 9 meses (Fox, 1964b, 1966, Loubiere, 2010).

La mielinización de la médula espinal también es gradual, ocurre primero en la región cervical y en las raíces motoras. Los haces corticoespinales, encargados de asegurar una buena coordinación motora son los últimos en mielinizarse, iniciando a las 6 semanas y alcanzando la capacidad del adulto entre 6 meses y un año. Por tanto, se puede concluir que el cerebro del cachorro es estructuralmente como el 
del adulto a las 6 semanas, pero la maduración, dada por la mielinización se presenta posteriormente y de manera gradual (Fuller y Fox, 1969, Loubiere, 2010).

Hasta los 18 días, el EEG es monomórfico, los cachorros pasan bruscamente del estado de sueño al de vigilia sin transición, el patrón del adulto se empieza a observar a las 5 semanas y se alcanza alrededor de las 8 semanas. Al nacer, el sueño REM representa un de un 90 a $95 \%$ del tiempo total de sueño, el valor del adulto de alrededor de $20 \%$ se observa hasta después de un mes de vida (Fox, 1966, Loubiere, 2010, Markwell y Thorne, 1987, Scott, 1958, Scott y Fuller, 1965).

El recién nacido tiene una resistencia a la anoxia superior a la del adulto, pero que va disminuyendo hasta que se alcanza a los 28 días de edad. El cachorro es capaz de distinguir entre lo frío y lo caliente y de regular su temperatura a las 3 semanas de vida (Fuller y Fox, 1969, Loubiere, 2010, Scott y Fuller, 1965).

Organos de los sentidos

Visión. Comprende al globo ocular, el nervio óptico y el área del cerebro que interpreta la información sensorial. La mielinización de la corteza occipital inicia a las 6 semanas. Los ojos se abren entre los 10 y 16 días, pero la visión es muy limitada, puesto que la cámara anterior, el humor acuoso y el cristalino no son aun totalmente transparentes, y la retina se encuentra todavía en proceso de diferenciación, su actividad eléctrica es como la del adulto a los 28 días. El nervio óptico está mielinizado a los 21 días, en tanto que el patrón del potencial evocado 
se alcanza a los 35 días, que es cuando los cachorros son capaces de seguir un objeto en movimiento y percibir la profundidad (Loubiere, 2010, Parry, 1953, Scott y Fuller, 1965).

Audición. El cachorro es sordo al nacer, aunque el oído medio e interno están diferenciados, el canal auditivo se puede empezar a abrir a los 14 días, acompañados con las primeras reacciones al ruido, pero los potenciales evocados adultos se logran hasta los 35 días (Ehret, 1980, Fox, 1964a, Scott y Fuller, 1965).

Olfato. Al nacer los nervios y bulbos olfativos se encuentran pobremente mielinizados, este sentido empieza a ser funcional entre los 8 y 13 días (Loubiere, 2010, Scott y Fuller, 1965).

Gusto. Las papilas gustativas se forman a partir de los 47 días de gestación, el gusto ya está presente al nacer, y al parecer tan desarrollado como en el adulto, aunque se va enriqueciendo con la experiencia olfativa (Loubiere, 2010).

Tacto. Los cachorros tienen una sensibilidad táctil y nocioceptiva desde el nacimiento, Durante las primeras semanas la presencia de un gran número de reflejos es indicativa de la inmadurez del sistema nervioso, inicialmente se observa una predominancia flexora, que más adelante cambia a una dominancia extensora y posteriormente se estabiliza; con la edad, algunos de ellos desaparecen, mientras que otros se hacen más rápidos (Fox, 1964a, Loubiere, 2010, Markwell y Thorne, 1987, Scott, 1958). 
Aparato locomotor

El desarrollo de las habilidades motoras determina el tipo de respuesta que puede producir un organismo en un momento dado de su desarrollo, esta capacidad motora está en estrecha relación con el equilibrio y la propiocepción, que se encuentran presentes al nacimiento, la parte vestibular del nervio vestíbulo coclear está ya mielinizada al nacer, lo que permite el equilibrio, sin embargo, el tono muscular y coordinación no están bien desarrollados aún (Loubiere, 2010, Scott y Fuller, 1965).

Para desplazarse, los neonatos sólo son capaces de arrastrarse unos pocos metros, en los primeros 3-4 días se puede apreciar una predominancia flexora, seguida por una extensora, y finalmente se obtiene la normotonía alrededor de las 4 semanas. Este proceso se ve expresado en los cambios ocurridos en una serie de reflejos que están estrechamente relacionados con una progresión rostral del desarrollo del sistema nervioso (Fox, 1964a, 1966, Markwell y Thorne, 1987). Para entonces, los reflejos neonatales se han desvanecido (Fox, 1964), van apareciendo y perfeccionándose otros como la colocación visual, la colocación por contacto de miembros anteriores, posteriores, mentón y cola, que ocurre entre las 3 y 9 semanas (Czarkowska, 1983)

Los músculos de la cara son funcionales al nacer, aunque las respuestas son más lentas. La mielinización de la médula espinal inicia en la región cervical, por lo que inicialmente el cachorro sólo se puede apoyar en los miembros anteriores, 
aproximadamente a los 10 días ya puede enderezar su cabeza con el tórax, no es sino hasta el día 15 en que puede levantar del suelo el tren posterior, y hasta los 21 días, con el fortalecimiento del los músculos del tronco, que es capaz de exhibir una posición cuadrúpeda y empezar a caminar, aunque al principio con una marcha atáxica, que va mejorando hasta que a los 42 días adquiere un nivel cercano al del adulto. Los últimos axones en mielinizarse son los del tracto corticoespinal implicados en el ajuste de la marcha, el fortalecimiento de los músculos es igualmente importante (Fox, 1966, Gorska, 1974, Loubiere, 2010)

Por otro lado, diversos estudios han llevado a considerar el desarrollo del sistema nervioso como un proceso global e integral, al encontrar que la maduración de una capacidad sensorial o motora está relacionada tanto con el desarrollo de otras áreas de este sistema como con el medio ambiente externo (Loubiere, 2010). 


\section{ANEXO III.}

\section{ANTECEDENTES HUDDLING.}

Huddling puede definirse como una agregación estrecha y activa de animales, que permite a los individuos involucrados disminuir la pérdida de calor; es usado por muchas aves y mamíferos durante condiciones climáticas difíciles, es especialmente importante en animales que enfrentan esta pérdida de calor por una relación superficie/volumen alta (Gilbert, 2007, 2010). Las crías de los mamíferos altriciales nacen con muy poco aislamiento son incapaces de regular su temperatura como en este caso; es efectivo en animales multíparos y en los que nacen en un nido (Fuller y Fox, 1969). A pesar de que ya se habían hecho algunos estudios para probar la eficiencia de este comportamiento, no fue sino hasta hace poco que Gilbert $(2007,2010)$ hace una cuantificación más precisa y analiza las implicaciones de esta estrategia conductual.

Huddling permite a los individuos maximizar el ahorro de energía mediante:

(1) disminuir la superficie corporal expuesta al frío

(2) reduce la pérdida de calor al calentar la temperatura ambiente alrededor del grupo, y

(3) eventualmente disminuir su temperatura por medio de procesos fisiológicos. Huddling produce un ahorro substancial de energía y se estima que reduce el gasto de energía entre un 6 y 53\%, estas variaciones dependen del número de individuos y la especie en involucrados, la temperatura ambiente a la que están 
expuestos y la densidad de las agrupaciones. Se ha observado que los ejemplares involucrados tienen una mayor supervivencia, un menor consumo de alimento, menor pérdida de masa corporal, una mayor tasa de crecimiento, menor pérdida de agua y/o temperatura corporal más constante, junto con una reducción significativa en la tasa metabólica.

De acuerdo con Canals (2011) huddling es adaptativo, auto-organizable, no costoso, y por tanto tiene una mayor probabilidad de evolucionar por selección natural; su estructura aparece de las interacciones locales de los elementos que lo componen, sin autoridad central ni elemento externo que lo imponga.

Conforme a lo descrito anteriormente, durante las primeras dos semanas de vida que corresponden a esta etapa, los lobeznos no tienen la capacidad de regular su temperatura, por lo que la exhibición de la conducta de huddling es por demás apropiada para ayudarlos a evitar la pérdida de calor cuando la madre los deja solos, especialmente aquéllos que se encuentran en las latitudes más al Norte. 


\section{ANEXO IV.}

\section{ANTECEDENTES CONDUCTAS DE JUEGO.}

Posiblemente las primeras referencias sobre el estudio del juego como comportamiento animal datan de 1898, con la publicación de la obra "The play of animals" (Pellegrini, 2006), en la cual expresa que el juego es un fenómeno general común a los humanos y a los animales más evolucionados, y que es una preparación importante para la vida adulta posterior. A partir de entonces se han publicado numerosos trabajos sobre el tema, sin embargo, a lo largo de más de 100 años no todos los investigadores han estado de acuerdo en su definición (Packard, 2003).

Caro (1988), y Martin y Caro (1985), mencionan que el juego es una característica predominante de los animales en desarrollo, especialmente aves y mamíferos. Por otro lado, Peters (1980) señala que el juego es una de las formas más comunes de interacción entre las crías de lobos, Fedderson-Petersen (1991) y Yachmennikova y Poyarkov (2011) reportan que los lobos jóvenes se caracterizan porque durante su primer año de vida o un poco más, por exhibir pronunciadas actividades de juego y que las conductas de juego son la actividad principal dentro de los patrones sociales de los cachorros de lobo.

Como ya se había mencionado anteriormente, los perros y lobos presentan un desarrollo muy similar, especialmente en las primeras etapas del mismo; Scott y Fuller (1965) señalan que el juego en perros aparece al principio de la etapa de 
socialización. Fox (1970) y Bekoff (1974) también reportan el inicio del registro del juego en lobos, coyotes y perros a esta misma edad. Young y Goldman (1944) y Mech (1970) observan a los lobeznos jugando en la entrada de la madriguera a esta edad.

A pesar de la dificultad en definir juego (Bekoff y Byers, 1998, Mc Leod, 1996), diversos autores coinciden en que el juego en animales (Burghardt, 2010) y en cánidos (Bekoff, 1974, Packard, 2003, Zimen, 1981) se puede caracterizar como sigue:

- Comprende acciones observadas también en otros contextos

- La secuencia normal de patrones es alterada, a diferencia del comportamiento "serio", los actos individuales de un comportamiento aparecen en combinaciones infinitamente variables

- Algunos patrones conductuales pueden repetirse y expresarse de manera exagerada

- Se aprecia un intercambio de roles

- Ocurre cuando hay un ambiente relajado (no hay impulsos de otros campos como hambre, fatiga, huída)

- No se presenta la fase consumatoria como en los comportamientos serios 
- Cada periodo de juego típicamente es precedido por una señal metacomunicativa que indica "lo que sigue es juego" (Bateson, 1985). Estas señales se pueden apreciar también durante el periodo de juego

- Es una actividad que parece placentera

$\underline{\text { Juego con objetos }}$

Fagen (1981) lo define como "Interacciones entretenidas con un objeto inanimado" y Hall (1998) dice que "es la implicación de objetos inanimados de diversos tipos en las actividades de juego de los animales", concuerdan que es una actividad bulliciosa y que parecen disfrutar.

\section{Funciones del juego}

A pesar de haberse llevado a cabo numerosos estudios sobre el juego, existe aun discrepancia entre los diferentes autores en cuanto a su función (Bekoff, 1972, 1974,AM, 1989, 1998; Burghardt, 2010, Byers, 1998; Byers y Walker, 1995, Caro, 1988, Cordoni, 2009, Held y Spinka, 2011, Maier, 1998, Packard, 2003, Pal, 2010, Pellegrini et al, 2007, Pellis e Iwaniuk, 2000, Pellis y Pellis, 1998, Tanner et al, 2007, Thompson, 1998; Ward et al, 2008, Zimen, 1982). 
Algunos de los puntos en discusión se refieren a si:

- Los beneficios del juego son a corto o largo plazo

- Si es una actividad costosa y si lo es, entonces debe tener un valor adaptativo

- Sirve como entrenamiento físico

- Permite una plasticidad conductual sobre la que puede actuar la selección natural

- Ayuda a los animales a enfrentar ambientes inestables

- Ayuda a la formación y mantenimiento de relaciones sociales, tanto amistosas como jerárquicas

- Contribuye al conocimiento del oponente

- Permite conocer las consecuencias de los actos y eventualmente aprender a modularlos de acuerdo a las circunstancias

- Contribuye al bienestar de los animales 


\section{ANEXO V.}

\section{ANTECEDENTES CONDUCTAS AGONISTAS.}

El término comportamiento agonista es utilizado para el conjunto de comportamientos agresivos, defensivos y de sumisión expresados por individuos involucrados en disputas sobre el acceso a recursos concretos como alimento, pareja; o el expresado por los individuos para el desarrollo y mantenimiento de las relaciones sociales que limitan el movimiento social o la expresión conductual individual (Jenks, 2011, McFarland, 1987).

Para que un grupo social sea funcional, debe tener una cierta estabilidad que depende del tipo y fortaleza de las relaciones que se desarrollen entre sus miembros. Las relaciones de dominancia-subordinación son generadas por medio de interacciones agonísticas, determinan los patrones de comunicación entre los miembros del grupo, y pueden ser modificadas por factores demográficos y ecológicos (Jenks, 2011).

Las relaciones de dominancia-subordinación han sido utilizadas para analizar la estructura social de los lobos (Fentrss et al., Rabb, 1967, Schotté y Ginsburg, 1987, Zimen, 1981).

Históricamente han existido diferentes percepciones sobre la estructura social de los lobos. Inicialmente se consideró una jerarquía linear simple que se modificó 
hacia el concepto de los jerarquías lineales paralelas, una para machos y otra para hembras (Mech, 1970, Schenkel, 1947, Zimen, 1975, 82), en las que los animales de más alto rango son designados como macho y hembra "alfa" y los de menor posición como lobos "omega"; Zimen (1982) incluso considera que la jerarquía está relacionada con el grupo de edad de los individuos; sin embargo, los mismos autores se percataron de que las relaciones entre los lobos eran más complejas. Posteriormente, Mech (1999) considera que la rigidez de las relaciones sociales previamente descritas es debida al efecto de los grupos artificiales formados en cautiverio, y que las manadas observadas por él en vida silvestre eran principalmente grupos familiares con un bajo grado de agresión, y que las relaciones de dominancia se formaban de manera natural por la diferencia de edad entre padres e hijos, y que además, cada grupo de edad desempeñaba un papel particular durante el ciclo anual.

Packard (2003) señala que en las manadas existen comportamientos que promueven la cohesión de la manada pero también otros que tienen que ver con la competencia por recursos y conflictos en el grupo. Feddersen-Petersen (1991) menciona que un balance dinámico entre ambos grupos de conductas son las bases para la creación y mantenimiento de una jerarquía social. Además, dice que el comportamiento agresivo es importante para el establecimiento de las jerarquías, aunque no debe considerarse sin la respuesta que evoca en el receptor. 